Review

\title{
Transfer RNA Modification Enzymes from Thermophiles and Their Modified Nucleosides in tRNA
}

\author{
Hiroyuki Hori *(D), Takuya Kawamura, Takako Awai, Anna Ochi, Ryota Yamagami, \\ Chie Tomikawa and Akira Hirata \\ Department of Materials Science and Biotechnology, Graduate School of Science and Engineering, \\ Ehime University, Bunkyo 3, Matsuyama, Ehime 790-8577, Japan; t.kwmr.0115@gmail.com (T.K.); \\ takak0v0@gmail.com (T.A.); annaoti009@yahoo.co.jp (A.O.); w844038k@yahoo.co.jp (R.Y.); \\ tomikawa.chie.mm@ehime-u.ac.jp (C.T.); hirata.akira.mg@ehime-u.ac.jp (A.H.) \\ * Correspondence: hori.hiroyuki.my@ehime-u.ac.jp; Tel.: +81-89-927-8548
}

Received: 12 September 2018; Accepted: 17 October 2018; Published: 20 October 2018

\begin{abstract}
To date, numerous modified nucleosides in tRNA as well as tRNA modification enzymes have been identified not only in thermophiles but also in mesophiles. Because most modified nucleosides in tRNA from thermophiles are common to those in tRNA from mesophiles, they are considered to work essentially in steps of protein synthesis at high temperatures. At high temperatures, the structure of unmodified tRNA will be disrupted. Therefore, thermophiles must possess strategies to stabilize tRNA structures. To this end, several thermophile-specific modified nucleosides in tRNA have been identified. Other factors such as RNA-binding proteins and polyamines contribute to the stability of tRNA at high temperatures. Thermus thermophilus, which is an extreme-thermophilic eubacterium, can adapt its protein synthesis system in response to temperature changes via the network of modified nucleosides in tRNA and tRNA modification enzymes. Notably, tRNA modification enzymes from thermophiles are very stable. Therefore, they have been utilized for biochemical and structural studies. In the future, thermostable tRNA modification enzymes may be useful as biotechnology tools and may be utilized for medical science.
\end{abstract}

Keywords: archaea; methylation; pseudouridine; RNA modification; tRNA methyltransferase; tRNA modification

\section{Introduction}

Transfer RNA is an adaptor molecule required for the conversion of genetic information encoded by nucleic acids into amino acid sequences of proteins [1,2]. Figure $1 \mathrm{~A}$ shows typically conserved nucleosides in a tRNA molecule, which is represented as a cloverleaf structure (herein, the nucleotide positions in tRNA are numbered, according to Sprinzl et al. [3]). These conserved nucleotides are important for tRNA folding and for stabilization of the L-shaped tRNA structure (Figure 1B) [4-6]. In addition to the standard nucleosides, numerous modified nucleosides in tRNA (for structures, see the MODOMICS and tRNAmodviz databases: http:/ / modomics.genesilico.pl/; http:/ / genesilico. pl/trnamodviz [7]) have been discovered in both thermophilic and mesophilic tRNAs [7,8] (see Supplementary Table S1 for abbreviations of modified nucleosides). 
A

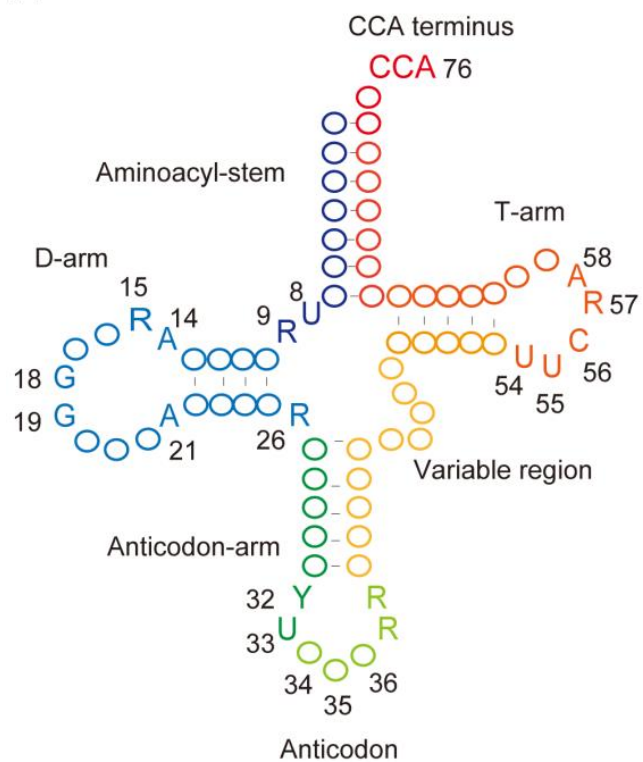

B

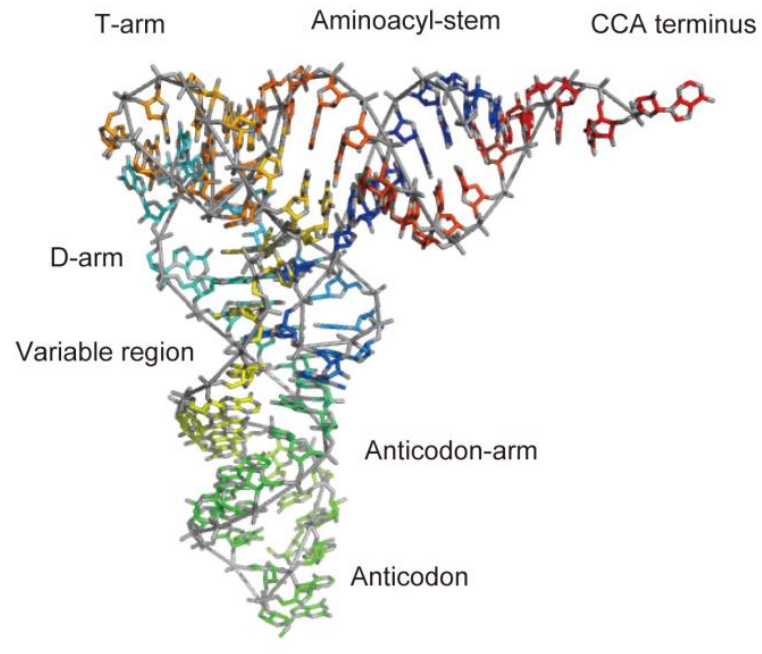

Figure 1. The structure of tRNA. (A) Representation of secondary structure of tRNA in a cloverleaf structure. This figure shows tRNA with a short variable region. Conserved nucleosides are shown with position numbers. Abbreviations: R, purine. Y, pyrimidine. (B) The L-shaped structure of Saccharomyces cerevisiae tRNA ${ }^{\text {Phe }}$. The colors of nucleosides correspond to those in (A).

A comprehensive review of the modified nucleosides in tRNA from thermophiles and their positions, distribution, predicted (or confirmed) tRNA modification enzymes and structural effects (Table 1) [9-264], which suggests that the majority of modified nucleosides in tRNA from thermophiles are common to those in tRNA from mesophiles. The functions of modified nucleosides in tRNAs have been gradually elucidated by biochemical and structural studies, physicochemical measurements, and analyses of gene disruption strains. The modified nucleosides primarily function in protein synthesis (e.g., stabilization of tRNA structure [88,265-267], correct folding of tRNA [88,265-267], reinforcement, restriction, and/or alteration of codon-anticodon interaction [108,109,114-117,120,124,268-270], recognition by aminoacyl-tRNA synthetases $[109,116,117,271]$, recognition by translation factors [272], and prevention of the frameshift error $[122,123,157,158]$ among others). In short, living organisms cannot synthesize proteins correctly or efficiently without modifications in tRNA.

For some organisms, modifications in tRNA have not been confirmed, but the tRNA modification enzymes have been studied. For example, although no tRNA sequences from Thermotoga maritima have been reported, the properties of several tRNA modification enzymes of this hyper-thermophilic eubacterium have been documented and, thus, the nucleoside modifications are predicted. Although many of the functions and biosynthesis pathways of modified nucleosides in tRNA from thermophiles have not yet been investigated, most of them are considered to be basically common to those from mesophiles. However, thermophiles live in extreme environments (e.g., high temperature, anaerobic conditions, extreme $\mathrm{pH}$, and high pressure). Therefore, it is possible that tRNA modifications observed in thermophiles may have novel functions. Furthermore, in some cases, the biosynthesis pathways of some modifications may differ between thermophiles and mesophiles. Moreover, in eukaryotes, tRNA modifications are related to higher biological processes such as cellular transport of tRNA [273-278], RNA quality control [274,279-281], infection [282-286], and the immune response [287-290]. As yet, modified nucleosides in tRNA from thermophilic eukaryotes have not been investigated, but it is possible that a relationship between modified nucleosides in tRNA and these biological phenomena may also be discovered in thermophilic eukaryotes.

In this review, we focus on the modified nucleosides and tRNA modification enzymes from thermophiles including the difficulties in sequencing the rigid and stable tRNAs from thermophiles. 
Since the tRNA modifications in moderate thermophiles are essentially similar to those in mesophiles, we describe them separately from extreme-thermophiles and hyper-thermophiles. We focus on the strategies for tRNA stabilization of extreme hyperthermophiles. Furthemrore, we describe the potential effects of these modifications during oxidative and other environmental stresses at high temperatures. Lastly, we describe biotechnological and therapeutic uses for tRNA modification enzymes. To avoid overlap with previous publications, we intentionally refer to representative articles and reviews of modified nucleosides in tRNA and tRNA modification enzymes from mesophiles (main text and Table 1) to aid understanding by the readers. For example, tRNA modifications in archaea including mesophiles have been extensively covered [48,87,291-294] and pseudouridine modifications and methylated nucleosides in tRNA are reviewed elsewhere [87,203,295,296]. Furthermore, the stability of nucleic acids at high temperatures has been reviewed [297]. Other useful publications are pointed out in the appropriate sections throughout the review. 
Table 1. Modified nucleosides in tRNA from thermophiles.

\begin{tabular}{|c|c|c|c|c|}
\hline $\begin{array}{l}\text { Modified Nucleoside } \\
\text { and Position }\end{array}$ & Distrib. & Modification Enzyme & Predicted Functions and Additional Information & References \\
\hline $\mathrm{Am}_{6}$ & A & Unknown & $\begin{array}{l}\text { Stabilization of aminoacyl-stem } \\
\text { Enzymatic activity for Am } 6 \text { formation has been detected in the cell extract } \\
\text { of Pyrococcus furiosus }\end{array}$ & [9] \\
\hline $\mathrm{m}^{2} \mathrm{G}_{6}$ & $\mathrm{~B} / \mathrm{A}$ & $\operatorname{TrmN} / \operatorname{Trm} 14$ & Stabilization of aminoacyl-stem & {$[10-15]$} \\
\hline $\mathrm{U}_{8}$ & A & CDAT8 & $\begin{array}{c}\text { Increasing G-C content in tRNA genes } \\
\text { In Methanopyrus kandleri, } \mathrm{U}_{8} \text { in several tRNA is produced from } \mathrm{C}_{8} \text { by the } \\
\text { deamination [16] } \\
\text { In Methanopyrus kandleri, numerous nucleosides in RNA may be } \\
\text { 2-O-methylated (see main text) [17] }\end{array}$ & {$[16,17]$} \\
\hline$s^{4} U_{8}$ & $\mathrm{~B} / \mathrm{A}$ & ThiI + IscS/ThiI & $\begin{array}{l}\text { UV resistance in E. coli and Salmonella typhimurium (see main text) } \\
\text { Stabilization of D-arm structure in E. coli (see main text) }\end{array}$ & {$[10,11,18-35]$} \\
\hline$s^{4} U_{8}$ and $s^{4} U_{9}$ & A & ThiI $+\alpha ?$ & $\begin{array}{c}\text { UV resistance } \\
\text { Stabilization of D-arm structure (see main text) } \\
\text { Sulfur-containing modifications in tRNA are reviewed in Reference [35]. }\end{array}$ & [36] \\
\hline $\mathrm{m}^{1} \mathrm{~A}_{9}$ & A & Archaeal Trm10 & $\begin{array}{l}\text { Stabilization of the D-arm structure } \\
\text { Prevention of formation of a Watson-Crick base pair } \\
\text { Correct folding of the D-arm region }\end{array}$ & {$[37,38]$} \\
\hline $\mathrm{m}^{1} \mathrm{G}_{9}$ and $\mathrm{m}^{1} \mathrm{~A}_{9}$ & A & archaeal Trm10 & $\begin{array}{c}\text { Stabilization of D-arm structure } \\
\text { Prevention of formation of a Watson-Crick base pair } \\
\text { Correct folding of D-arm region } \\
\text { Thermococcus kodakarensis Trm10 forms } \mathrm{m}^{1} \mathrm{G}_{9} \text { and } \mathrm{m}^{1} \mathrm{~A}_{9} \text {, whereas } \\
\text { Sulfolobus acidocaldarius Trm } 10 \text { forms only } \mathrm{m}^{1} \mathrm{~A}_{9}\end{array}$ & {$[37,39]$} \\
\hline ( $\mathrm{m}^{2} \mathrm{G}_{10}$ and) $\mathrm{m}^{2}{ }_{2} \mathrm{G}_{10}$ & A & $\begin{array}{l}\text { archaeal Trm11 (Trm- } \mathrm{G}_{10} \\
\text { Trm- }{ }^{2}{ }_{2} \mathrm{G}_{10} \text { enzyme) }\end{array}$ & $\begin{array}{l}\text { Prevention of formation of a Watson-Crick base pair } \\
\text { Correct folding of tRNA in Pyroccocus furiosus } \\
\text { Correct folding of the D-arm region }\end{array}$ & {$[40-43]$} \\
\hline$\Psi_{13}$ & $\mathrm{~B} / \mathrm{A}$ & TruD/TruD or archaeal Pus7 & $\begin{array}{l}\text { Stabilization of D-stem structure } \\
\text { Archaeal Pus7 generally catalyzes formation of } \Psi 35 \text { in tRNA }{ }^{\text {Tyr }} \text {, but } \\
\text { Sulfolobus solfaraticus Pus7 has weak } \Psi 13 \text { formation activity [46] }\end{array}$ & {$[23,44-46]$} \\
\hline $\mathrm{G}^{+} 13$ & A & ArcTGT + ArcS? & $\begin{array}{c}\text { Stabilization of the D-arm structure } \\
\text { Thermoplasma acidophilum tRNA } \text { tRu exceptionally possesses a G }^{+} 13 \\
\text { modification and T. acidophilum ArcTGT acts on positions } 13 \text { and } 15 \\
\text { in this tRNA [47] }\end{array}$ & {$[36,47]$} \\
\hline
\end{tabular}


Table 1. Cont

\begin{tabular}{|c|c|c|c|c|}
\hline $\begin{array}{l}\text { Modified Nucleoside } \\
\text { and Position }\end{array}$ & Distrib. & Modification Enzyme & Predicted Functions and Additional Information & References \\
\hline $\mathrm{G}^{+}{ }_{15}$ & A & $\begin{array}{c}\text { ArcTGT }+\underset{\text { protein }}{\text { ArcS or QueF-like }} \\
\text { proting }\end{array}$ & $\begin{array}{c}\text { Stabilization of interaction between the D-arm and the variable region } \\
\text { Several archaea possess a split-type ArcTGT [60,61] } \\
\text { Several species in Crenarchaeota possess a QueF-like protein } \\
\text { instead of ArcS [60,62,63] } \\
\mathrm{G}^{+} \text {is not found in nucleosides from a Stetteria hydrogenophila } \\
\text { tRNA mixture [56] }\end{array}$ & {$[25,36,47-63]$} \\
\hline $\mathrm{D}_{17}$ & B & Dus family protein? & $\begin{array}{l}\text { Maintenance of D-loop flexibility } \\
\mathrm{D}_{17} \text { and } \mathrm{D}_{20} \text { modifications have been reported in } \\
\text { Geobacillus stearothermophilus tRNA. However, } \mathrm{D}_{17} \text { and } \mathrm{D}_{20} \text { are formed by } \\
\text { DusB and DusA, respectively, in Escherichia coli }[65,66] \text { and the } \\
\text { G. stearothermophilus genome possesses only one } d u s \text {-like gene. This is also } \\
\text { observed in Bacillus subtilis, which is a mesophilic eubacterium. }\end{array}$ & {$[18,19,64-66]$} \\
\hline $\mathrm{Gm}_{18}$ & B & TrmH & $\begin{array}{l}\text { Stabilization of the D-arm and the T-arm interaction. } \\
\text { TrmH from thermophiles possess relative broad substrate tRNA } \\
\text { specificities as compared with TrmH from E. coli. The substrate tRNA } \\
\text { specificities of TrmH enzymes differ among thermophiles. TrmH from } \\
\text { Thermus thermophilus can methylate all tRNA species. }\end{array}$ & {$[10,11,20,21,23,24,30,67-81]$} \\
\hline $\mathrm{D}_{20}$ & B & Dus family protein & $\begin{array}{c}\text { Stabilization of local structure of D-loop in E. coli? } \\
\text { In A. aeolicus, the nucleosides at positions } 20 \text { and 20a in tRNA Cys } \\
\text { are } \mathrm{D}_{20} \text { and } \mathrm{U}_{20} \text {, respectively. Therefore, Dus from A. aeolicus } \\
\text { may act only on } \mathrm{U}_{20} \text { in tRNA. }\end{array}$ & {$[24,33,65,66,82]$} \\
\hline $\mathrm{D}_{20}$ and $\mathrm{D}_{20 \mathrm{a}}$ & B & DusA & $\begin{array}{l}\text { Stabilization of local structure of the D-loop } \\
\text { The melting temperature of a tRNA mixture from the E. coli dusA gene } \\
\text { disruptant strain is lower than that from the wild-type strain [33]. } \\
\text { Therefore, } \mathrm{D}_{20} \text { and } \mathrm{D}_{20 \text { a }} \text { modifications may contribute to stabilize local } \\
\text { structure of the D-loop. } \\
\text { Thermus thermophilus Dus was recently confirmed as a member of the } \\
\text { DusA family }[65,66,84,85] \text {. }\end{array}$ & {$[21-23,33,65-67,83-85]$} \\
\hline $\mathrm{m}^{1} \mathrm{~A}_{22}$ & B & $\operatorname{TrmK}$ & Prevention of formation of a Watson-Crick base pair & {$[18,20,86]$} \\
\hline$\Psi_{22}$ & $\mathrm{~A}$ & Unknown & The $\Psi_{13}-\Psi_{22}$ base pair may stabilize D-arm structure [88] & {$[87,88]$} \\
\hline
\end{tabular}


Table 1. Cont.

\begin{tabular}{|c|c|c|c|c|}
\hline $\begin{array}{l}\text { Modified Nucleoside } \\
\text { and Position }\end{array}$ & Distrib. & Modification Enzyme & Predicted Functions and Additional Information & References \\
\hline $\mathrm{m}^{2} \mathrm{G}_{26}$ and $\mathrm{m}^{2}{ }_{2} \mathrm{G}_{26}$ & A & Trm1 & $\begin{array}{l}\text { Stabilization of three-dimensional core structure } \\
\text { Correct folding of tRNA } \\
\text { Recently, it has been reported that } \mathrm{m}^{2}{ }_{2} \mathrm{G}_{26} \text { modification is required for } \\
\text { correct folding of precursor tRNA } \mathrm{A}^{\text {Ser }} \text { from Schizosaccharomyces pombe [94]. } \\
\text { Therefore, a similar phenomenon may take place in thermophiles. }\end{array}$ & {$[9,25,44,89-94]$} \\
\hline $\begin{array}{c}\mathrm{m}^{2} \mathrm{G}_{26}, \mathrm{~m}^{2}{ }_{2} \mathrm{G}_{26} \\
\mathrm{~m}^{2} \mathrm{G}_{27} \text { and } \mathrm{m}^{2}{ }_{2} \mathrm{G}_{27}\end{array}$ & $\mathrm{~B}$ & Trm1 & $\begin{array}{l}\text { Stabilization of three-dimensional core structure in A. aeolicus. } \\
\text { In the case of } \mathrm{m}^{2} \mathrm{G}_{27} \text { and } \mathrm{m}^{2}{ }_{2} \mathrm{G}_{27} \text {, stabilization of aminoacyl-stem }\end{array}$ & {$[24,95]$} \\
\hline $\mathrm{m}_{2}^{2} \mathrm{Gm}_{26}$ & A & Trm1 + unknown MT & $\begin{array}{l}\text { Stabilization of three-dimensional core structure } \\
\text { The presence of } \mathrm{m}_{2}^{2} \mathrm{Gm} \text { has been confirmed in nucleosides of a tRNA } \\
\text { mixture from several thermophilic archaea [56,97-100]. } \\
\text { Although the nucleoside at position } 26 \text { in } S \text {. acidocaldarius tRNA }{ }_{i}^{\text {Met }} \text { was } \\
\text { originally reported as an unidentified } \mathrm{G} \text { modification [44], it was recently } \\
\text { described as } \mathrm{m}_{2}^{2} \mathrm{Gm}[96] \text {. } \\
\text { The MT for 2'-O-methylation is unknown. }\end{array}$ & {$[44,96]$} \\
\hline $\mathrm{Cm}_{32}$ & A & archaeal TrmJ & Stabilization of anticodon-loop & [96] \\
\hline $\mathrm{Cm}_{32}$ and $\mathrm{Nm}_{32}$ & B & TrmJ & $\begin{array}{c}\text { Stabilization of anticodon-loop } \\
\text { TrmJ from E. coli does not recognize the base at position } 32[96,102] . \\
\mathrm{Um}_{32} \text { and } \mathrm{Am}_{32} \text { have not been reported in tRNAs from } \\
\text { thermophilic eubacteria. }\end{array}$ & {$[96,101,102]$} \\
\hline $\mathrm{I}_{34}$ & B & TadA & $\begin{array}{l}\text { Alteration of codon-anticodon interaction } \\
\text { A-to-I editing in tRNA is reviewed in Reference [107] }\end{array}$ & [103-107] \\
\hline$k^{2} C_{34}$ & B & Tils & $\begin{array}{l}\text { Alteration of codon-anticodon interaction (E. coli and B. subtilis) } \\
\text { Change of recognition by aminoacyl-tRNA synthetase } \\
(E . \text { coli and B. subtilis) }\end{array}$ & [108-113] \\
\hline $\operatorname{agm}^{2} C_{34}$ & A & TiaS & $\begin{array}{c}\text { Alteration of codon-anticodon interaction } \\
\text { (Arhaeoglobus fulgidus and Haloarcula marismourtui) } \\
\text { Change of recognition by aminoacyl-tRNA synthetase } \\
\text { (Arhaeoglobus fulgidus and Haloarcula marismourtui) } \\
\text { Decoding of AUA codons by } \mathrm{k}^{2} \mathrm{C}_{34} \text { and agm }{ }^{2} \mathrm{C}_{34} \text { modifications is } \\
\text { reviewed in References }[114,115] \text {. }\end{array}$ & [114-120] \\
\hline
\end{tabular}


Table 1. Cont.

\begin{tabular}{|c|c|c|c|c|}
\hline $\begin{array}{l}\text { Modified Nucleoside } \\
\text { and Position }\end{array}$ & Distrib. & Modification Enzyme & Predicted Functions and Additional Information & References \\
\hline $\mathrm{xm}^{5} \mathrm{U}_{34}$ derivatives & $\mathrm{B} / \mathrm{A}$ & $\begin{array}{l}\mathrm{MnmE}+\mathrm{MnmG}+\mathrm{MnmC} \\
\quad \text { (for } \mathrm{mnm}^{5} \mathrm{U}_{34} \text { in } \\
\text { eubacteria)/Elp3? + } \alpha \\
\text { (for } \mathrm{cm}^{5} \mathrm{U}_{34} \text { in archaea) } \\
\text { IscS + TusA + TusBCD + TusE } \\
+ \text { mnmA (for 2-thiolation in } \\
\text { E. coli) or YrvO + mnmA (for } \\
\text { 2-thiolation in B. subtilis) } \\
\text { SAMP2 + UbaA + NcsA (for } \\
\text { 2-thiolation in M. maripuludis) }\end{array}$ & 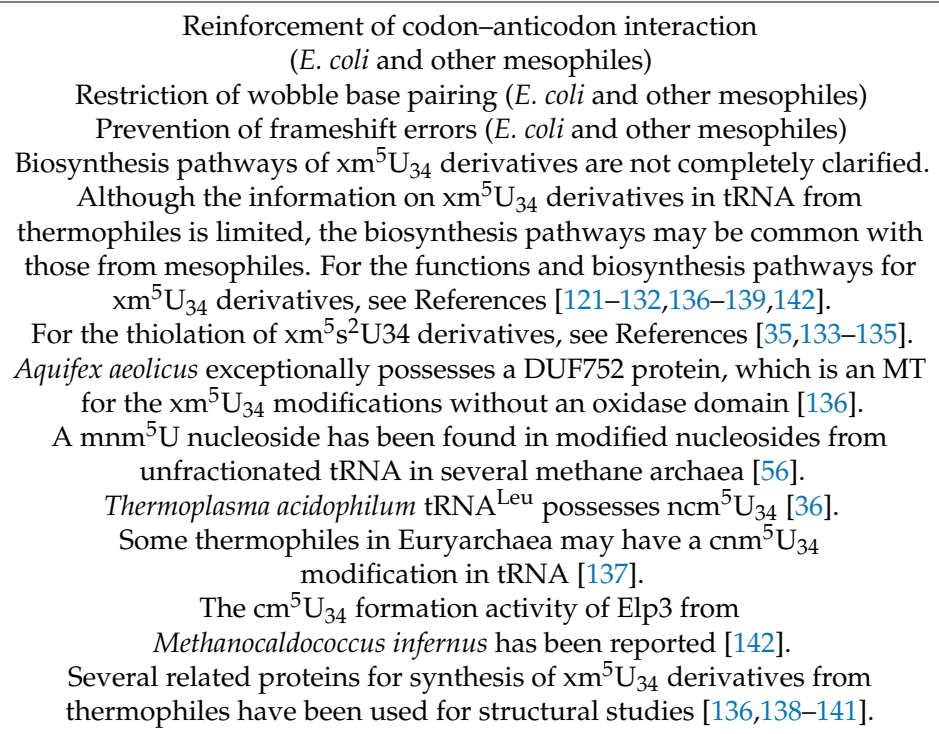 & {$[34-36,56,121-142]$} \\
\hline $\begin{array}{c}\mathrm{Cm}_{34} \text { and } \\
\mathrm{cmnm}^{5} \mathrm{Um}_{34}\end{array}$ & B & $\operatorname{TrmL}$ & Reinforcement of codon-anticodon interaction (E. coli) & {$[18,143,144]$} \\
\hline $\mathrm{Gm}_{34}$ & B & Unknown & Reinforcement of codon-anticodon interaction (G. stearothermophilus) & [19] \\
\hline $\mathrm{Q}_{34}$ derivatives & B & Tgt + QueA + QueG & $\begin{array}{c}\text { Reinforcement of codon-anticodon interaction (E. coli) } \\
\text { Prevention of frame-shift error (E. coli) } \\
\text { Biosynthesis pathways and functions of Q derivatives are reviewed in } \\
\text { References [152,153]. } \\
\text { A crystal structure of QueA from T. maritima has been reported [151]. }\end{array}$ & {$[20,122,145-153]$} \\
\hline $\begin{array}{l}\mathrm{Cm}_{34} \text { and } \mathrm{Um}_{39} \\
\quad\left(\text { or } \mathrm{Cm}_{39}\right)\end{array}$ & A & $\begin{array}{l}\text { L7Ae + Nop5 + archaeal } \\
\text { fibrillarin + Box C / D guide } \\
\text { RNA (intron) }\end{array}$ & $\begin{array}{c}\text { Reinforcement of codon-anticodon interaction } \\
\text { Reinforcement of anticodon-arm } \\
\text { In several archaea, an intron in precursor tRNA } \\
\text { Box C/D guide RNA. }\end{array}$ & {$[9,154,155]$} \\
\hline$\Psi 35$ & A & $\begin{array}{l}\text { aPus7 and H/ACA guide } \\
\text { RNA system }\end{array}$ & Reinforcement of codon-anticodon interaction & [46] \\
\hline
\end{tabular}


Table 1. Cont.

\begin{tabular}{|c|c|c|c|c|}
\hline $\begin{array}{l}\text { Modified Nucleoside } \\
\text { and Position }\end{array}$ & Distrib. & Modification Enzyme & Predicted Functions and Additional Information & References \\
\hline $\mathrm{m}^{1} \mathrm{G}_{37}$ & $\mathrm{~B} / \mathrm{A}$ & TrmD/Trm5 & $\begin{array}{l}\text { Prevention of frame-shift error (E. coli and other mesophiles) } \\
\text { Recognition by aminoacyl-tRNA synthetase (Saccharomyces cerevisiae) }\end{array}$ & {$[36,156-171]$} \\
\hline wyosine $_{37}$ derivatives & A & $\operatorname{Trm} 5+$ Taw $1+$ Taw2 + Taw3 & $\begin{array}{c}\text { Reinforcement of codon-anticodon interaction } \\
\text { Prevention of the frame-shift error } \\
\text { In several archaea, } \mathrm{m}^{1} \mathrm{G}_{37} \text { in tRNA } \mathrm{Rh}^{\text {Phe }} \text { is further modified to } \\
\text { wyosine derivatives. } \\
\text { For the biogenesis pathway of wyosine derivatives, } \\
\text { see References [181-183]. }\end{array}$ & [172-183] \\
\hline $\mathrm{t}^{6} \mathrm{~A}_{37}$ derivatives & $\mathrm{B} / \mathrm{A}$ & $\begin{array}{l}\text { TsaB, TsaC (TsaC2), TsaD and } \\
\text { TsaE/KEOPS complex: Kae1, } \\
\text { Bud32, Cgi121 and } \\
\text { Pcc1 + Sua } 5\end{array}$ & $\begin{array}{c}\text { Reinforcement of codon-anticodon interaction } \\
\text { Prevention of frame-shift error } \\
\text { Recognition by aminoacyl-tRNA synthetases } \\
\text { The biogenesis pathway for } \mathrm{t}^{6} \mathrm{~A} \text { derivatives is reviewed in Reference [191] }\end{array}$ & {$[68,184-191]$} \\
\hline $\mathrm{i}^{6} \mathrm{~A}_{37}$ derivatives & B & $\mathrm{MiaA}+\mathrm{MiaB}$ & $\begin{array}{c}\text { Prevention of frame-shift error } \\
\text { Reinforcement of codon-anticodon interaction } \\
\text { Recognition by aminoacyl-tRNA synthetases } \\
\mathrm{i}^{6} \text { A derivatives are reviewed in Reference [197] }\end{array}$ & {$[10,11,18-20,24,192-197]$} \\
\hline$m^{6} A_{37}$ & B & YfiC (TrmG?) & & {$[64,198]$} \\
\hline$\Psi_{38}, \Psi_{39}$ and $\Psi_{40}$ & $\mathrm{~B} / \mathrm{A}$ & TruA/Pus3 & $\begin{array}{l}\text { Prevention of frame-shift error }(E . \text { coli }) \\
\text { Reinforcement of anticodon-arm }\end{array}$ & {$[10,11,18-20,23,87,199-203]$} \\
\hline $\mathrm{m}^{7} \mathrm{G}_{46}$ & B & $\operatorname{TrmB}$ & $\begin{array}{c}\text { Stabilization of three-dimensional core } \\
\text { In the case of } T \text {. thermophilus, } \mathrm{m}^{7} \mathrm{G}_{46} \text { modification functions a key factor in } \\
\text { a network between modified nucleosides in tRNA and tRNA modification } \\
\text { enzymes (see main text) [11] }\end{array}$ & {$[10,11,19,67,204-208]$} \\
\hline $\mathrm{m}^{5} \mathrm{C}_{48}$ and $\mathrm{m}^{5} \mathrm{C}_{49}$ & A & archaeal Trm 4 & Stabilization of three-dimensional core & {$[9,209,210]$} \\
\hline $\mathrm{m}^{7} \mathrm{G}_{49}$ & A & Unknown & & [36] \\
\hline $\mathrm{m}^{5} \mathrm{C}_{51}$ & A & Unknown & Stabilization of T-arm structure & [209] \\
\hline $\mathrm{m}^{5} \mathrm{C}_{52}$ & A & Unknown & Stabilization of T-arm structure & [209] \\
\hline$\Psi_{54}$ and $\Psi_{55}$ & A & Pus10 & Stabilization of D-arm and T-arm interaction & [211-214] \\
\hline $\mathrm{m}^{1} \Psi_{54}$ & A & Pus10 + TrmY & Stabilization of D-arm and T-arm interaction & [215-217] \\
\hline
\end{tabular}


Table 1. Cont.

\begin{tabular}{|c|c|c|c|c|}
\hline $\begin{array}{l}\text { Modified Nucleoside } \\
\text { and Position }\end{array}$ & Distrib. & Modification Enzyme & Predicted Functions and Additional Information & References \\
\hline $\mathrm{m}^{5} \mathrm{U}_{54}+\mathrm{m}^{5} \mathrm{~s}^{2} \mathrm{U}_{54}$ & $\mathrm{~B} / \mathrm{A}$ & $\begin{array}{l}\text { TrmFO }+ \text { TtuA }+ \text { TtuB }+ \text { TtuC } \\
+ \text { TtuD }+ \text { IscS } / \text { TrmA }+ \text { TtuA? } \\
+ \text { TtuB? }+\alpha\end{array}$ & $\begin{array}{l}\text { Stabilization of D-arm and T-arm interaction (see main text) } \\
\text { 2-Thiolation of } \mathrm{m}^{5} \mathrm{~s}^{2} \mathrm{U}_{54} \text { in tRNA is reviewed in Reference [239] }\end{array}$ & $\begin{array}{c}{[10,11,21-24,67,97,98,134,218-} \\
239]\end{array}$ \\
\hline $\mathrm{Um}_{54}$ & $\mathrm{~A}$ & Unknown & Stabilization of D-arm and T-arm interaction & [44] \\
\hline$\Psi_{55}$ & $\mathrm{~B} / \mathrm{A}$ & $\begin{array}{l}\text { TruB/Pus } 10 \text { or archaeal } \\
\text { Cbf5 }+\alpha\end{array}$ & $\begin{array}{c}\text { Stabilization of D-arm and T-arm interaction } \\
\text { In the case of } T \text {. thermophilus, } \Psi_{55} \text { is required for low-temperature } \\
\text { adaptation (see main text) [248]. }\end{array}$ & $\begin{array}{c}{[10,11,18-20,23,25,36,44,64,67,} \\
211-214,240-248]\end{array}$ \\
\hline $\mathrm{Cm}_{56}$ & A & $\operatorname{Trm} 56$ & Stabilization of D-arm and T-arm interaction & {$[9,25,36,44,48,89,249-251]$} \\
\hline $\mathrm{m}^{2} \mathrm{G}_{57}$ & A & Unknown & & {$[44,252]$} \\
\hline $\mathrm{m}^{1} \mathrm{I}_{57}$ & A & $\begin{array}{l}\text { archaeal TrmI + unknown } \\
\text { deaminase }\end{array}$ & Stabilization of T-arm structure & {$[44,253,254]$} \\
\hline $\mathrm{m}^{1} \mathrm{~A}_{57}$ and $\mathrm{m}^{1} \mathrm{~A}_{58}$ & A & archaeal TrmI & Stabilization of T-arm structure & {$[44,255-258]$} \\
\hline $\mathrm{m}^{1} \mathrm{~A}_{58}$ & B & TrmI & Stabilization of T-arm structure & {$[11,23,67,204,259-264]$} \\
\hline
\end{tabular}

This table shows the nucleosides that are modified in tRNA from thermophiles. Most modifications are common to those in tRNA from mesophiles. Several modifications include Q derivatives have not been confirmed in $\mathrm{RNA}$ from T. maritima, the drivatives). In some cases, only modification enzymes from thermophiles have been reported. For example, although for tRNA modifications and tRNA modification enzymes are mainly those for thermophiles. While there are many references for mesophiles, only representative references are cited. Where available, reviews of a modification and related proteins have been cited. Since modified nucleosides in tRNA from thermophilic eukaryotes have not been reported, modified nucleosides in eukaryotic tRNA have not been included here. The following modified nucleosides have been found in unfractionated tRNA from thermophiles. However, their positions and modified tRNA species are unknown: $\mathrm{ac}^{6} \mathrm{~A}, \mathrm{hn}^{6} \mathrm{~A}, \mathrm{~ms}^{2} \mathrm{hn}^{6} \mathrm{~A}$, methyl-hn ${ }^{6} \mathrm{~A}, \mathrm{~m}^{2}, 7 \mathrm{Gm}, \mathrm{s}^{2} \mathrm{Um}$, and $\mathrm{ac}^{4} \mathrm{Cm}[56,97-100]$. Abbreviations are as follows: A, archaea, B, eubacteria, and MT, methyltransferase. The "?" mark indicates the potential function speculated from the structure of the modified nucleosides. 


\section{Sequencing of tRNA from Thermophiles}

The sequence of tRNA provides the most basic information of tRNA. However, as shown in Figure 2, which displays nucleotide sequences of tRNAs from thermophilic eubacteria $[10,11,18-24,64,67]$ and archaea $[25,36,44,252]$, the sequences of only 14 tRNA species have been reported from thermophiles. In addition, in the case of Aquifex aeolicus tRNA ${ }^{\text {Cys }}$, the sequence has been only partially determined [24].

In general, sequencing of tRNA from thermophiles is difficult for the following reasons. First, purification of specific tRNA from thermophiles is not easy. Currently, tRNA is purified by the solid DNA probe method [298-300]. In this method, the solid-phase complementary DNA probe is placed in a column and hybridized with the target tRNA and then the target tRNA is eluted from the column. Since the structures of tRNA from thermophiles are very rigid, denaturing the tRNA to allow hybridization is difficult. This problem has been solved by incorporating tetraalkyl-ammonium salt in the hybridization buffer [301]. This salt destabilizes the secondary and tertiary structures of tRNA and promotes formation of the RNA-DNA hetero-duplex. This alteration enabled us to purify A. aeolicus tRNA ${ }^{\text {Cys }}$ [24], Thermus thermophilus tRNA ${ }^{\text {Phe }}$ [11], tRNA $^{\text {Met }}{ }_{f} 1$ [248] and tRNA ${ }^{\text {Thr }}$ [263,302], Thermoplasma acidophilum initiator tRNA ${ }^{\text {Met }}$ [89], elongator tRNA ${ }^{\text {Met }}$ [89], and tRNA ${ }^{\text {Leu }}$ [36]. Even with the use of tetraalkyl-ammonium salt, however, the solid DNA probe method is not versatile. For example, because the difference between T. thermophilus tRNA ${ }_{\mathrm{Met}} 1$ and $\mathrm{tRNA}^{\mathrm{Met}}{ }_{\mathrm{f}} 2$ is only one G-C base pair in the T-stem (Figure 2H) [21], purification of tRNA ${ }_{\mathrm{f}}^{\mathrm{Met}} 1$ required its separation from tRNA $_{\mathrm{fet}} 2$ by BD-cellulose column chromatography before the solid DNA probe method could be applied [248].

Second, since the structure of tRNA from thermophiles is rigid, limited cleavage by formamide $[303,304]$ is difficult. Therefore, it is difficult to apply the classical technique used for RNA sequencing to tRNA from thermophiles. Liquid-chromatography/mass-spectrometry (LC/MS) has been found to be the most reliable method to overcome this problem [305,306]. In general, LC/MS requires prior cleavage of tRNA by RNases. However, because the G-C content in the stem regions of tRNA from thermophiles is very high (Figure 2), RNA fragments with the same sequences are often generated by RNase cleavage. Therefore, use of multiple RNases and/or preparation of gene disruptant strains are required to overcome this problem.

Furthermore, given that it is not possible to distinguish uridine and pseudouridine by MS, cyanoethylation of tRNA is generally required to detect this nucleoside [307]. In the sequencing of T. acidophilum $\mathrm{tRNA}^{\mathrm{Leu}}$ [36], we used a combination of the cyanoethylation and classical formamide method for detection of $\Psi_{54}$ because the efficiency of cyanoethylation of $\Psi_{54}$ was low. Thus, specific techniques are required even if an LC/MS system is available.

Third, to determine the modified nucleoside precisely, preparation of a standard compound is often required. For example, it was necessary to prepare the standard $n \mathrm{~cm}^{5} \mathrm{U}$ nucleoside from the Saccharomyces cerevisiae trm9 gene disruptant strain [308] to determine the anticodon modification of T. acidophilum RRNA $^{\text {Leu }}$ [36]. In some cases, synthesis of a standard compound by organic chemistry may be required. Lastly, preparing cultures of thermophiles is not so easy for general biochemical researchers (e.g., under anaerobic conditions at high temperatures).

To overcome these problems, the cooperation of researchers in different fields is required. At present, the solid DNA probe method with tetraalkyl-ammonium coupled with LC/MS is the main method for sequencing tRNA from thermophiles. Therefore, it is anticipated that a large numbers of sequences of tRNA from thermophiles will be reported by using this approach in the future. 


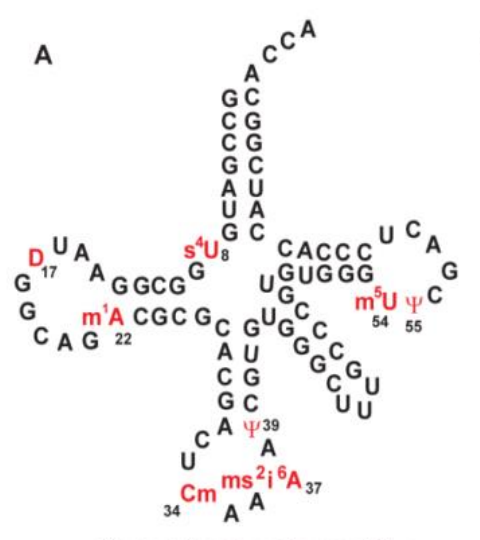

Geobacillus stearothermophilus tRNA ${ }^{\text {Leu }}$

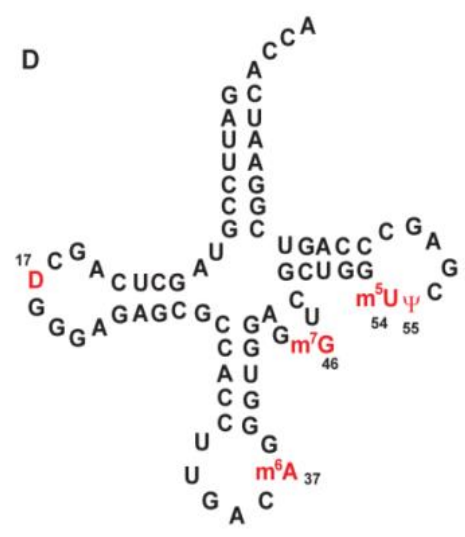

Geobacillus stearothermophilus tRNA ${ }^{\text {Val }}$

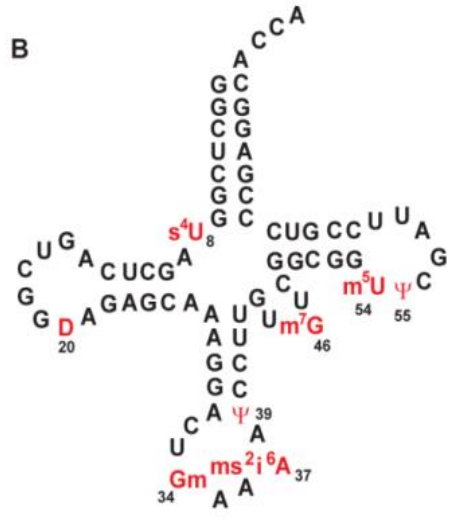

Geobacillus stearothermophilus tRNA ${ }^{\text {Phe }}$

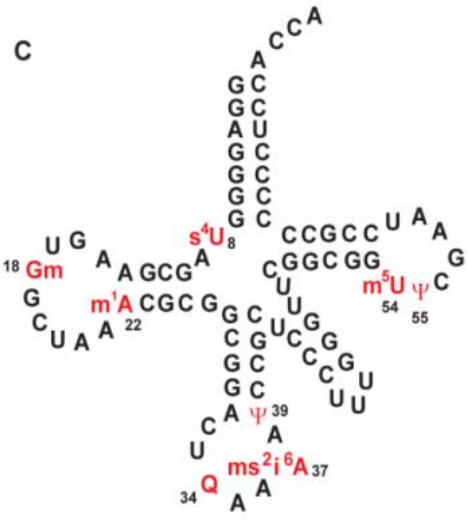

Geobacillus stearothermophilus tRNA $^{\text {Tyr }}$

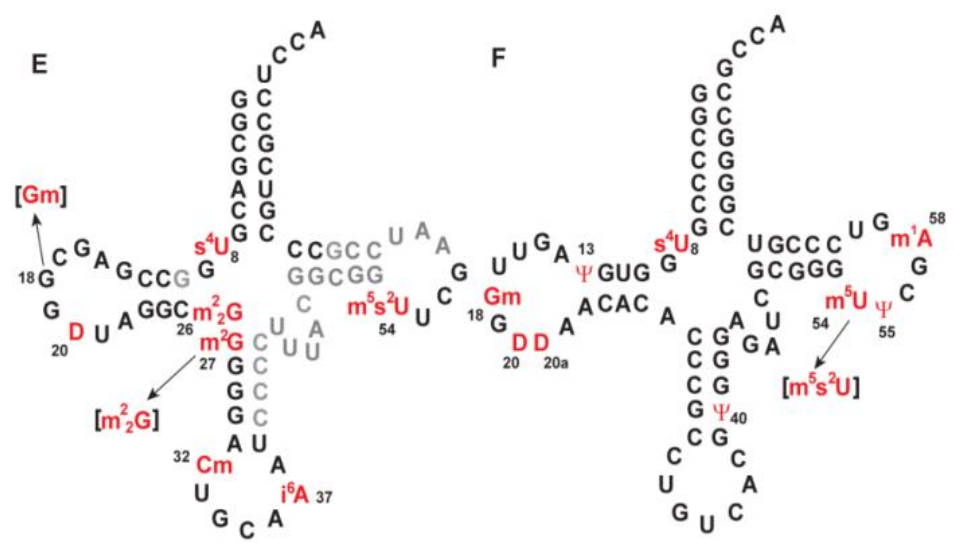

Aquifex aeolicus tRNA ${ }^{\text {Cys }}$
Thermus thermophilus tRNA ${ }^{\text {Asp }}$

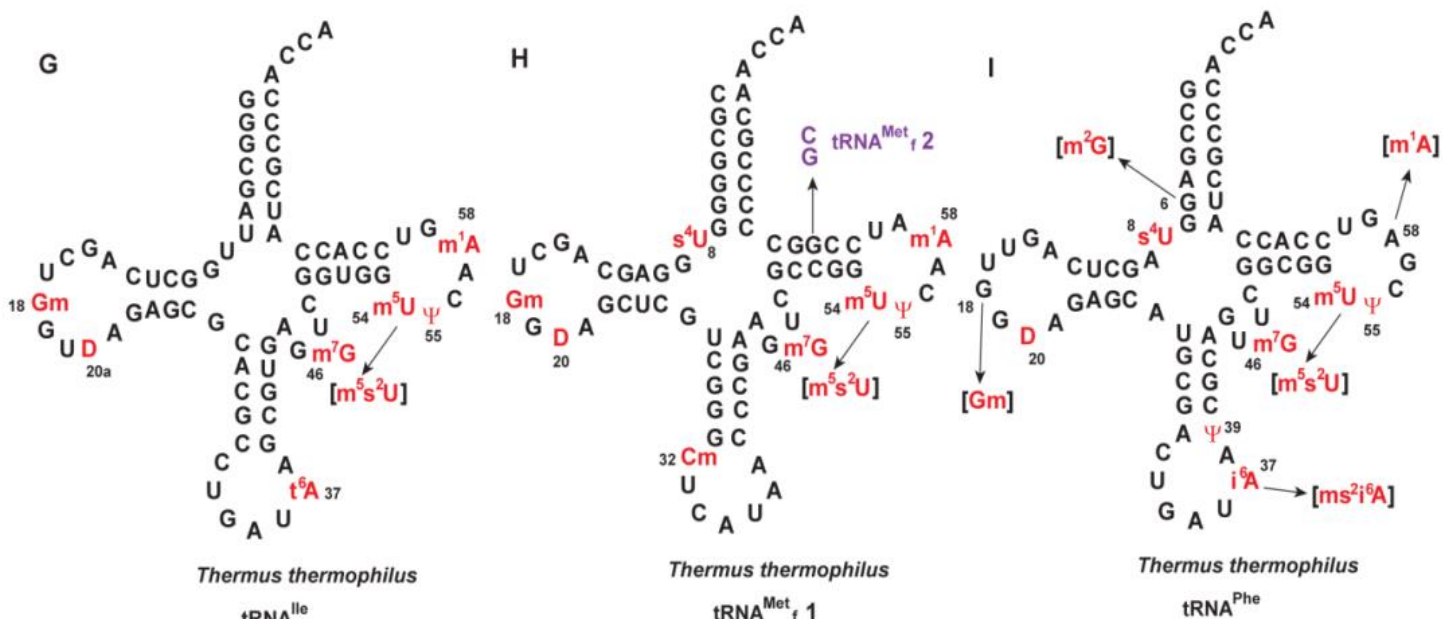

Figure 2. Cont. 
$\mathbf{J}$

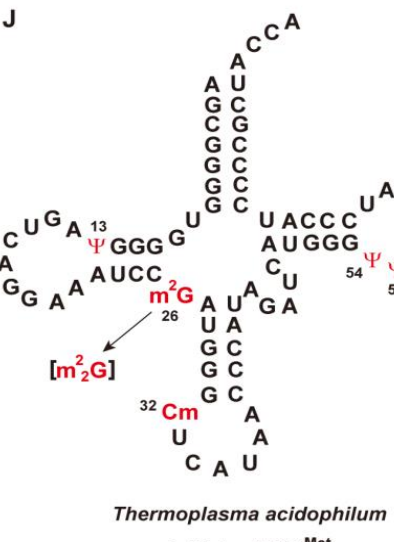

initiator tRNA ${ }^{\text {Met }}$
K

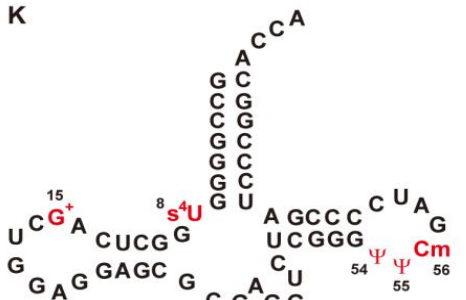

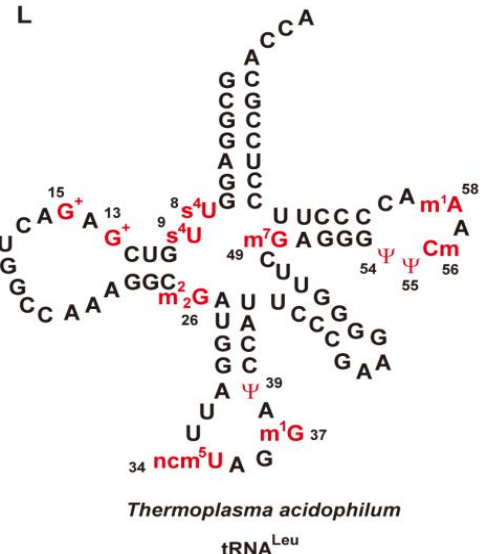

M

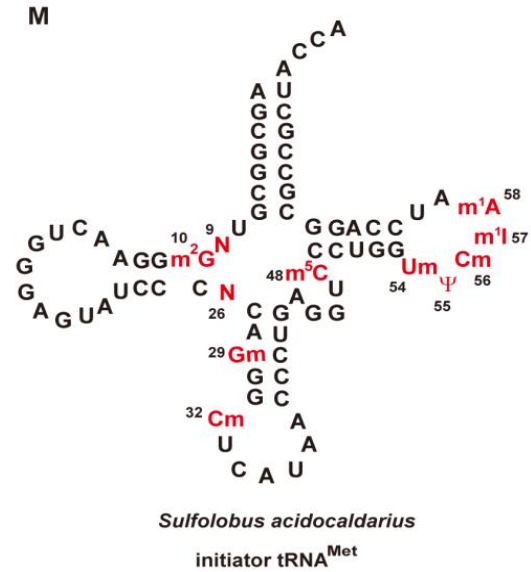

Figure 2. Sequences of tRNA from thermophiles. The modified nucleosides are indicated in red with their positions. Parentheses indicate that a portion of the modified nucleoside is further modified to its derivative. Abbreviations of modified nucleosides are given in Supplementary Table S1. (A) Geobacillus stearothermophilus tRNA ${ }^{\text {Leu }}$. (B) G. stearothermophilus tRNA ${ }^{\text {Phe }}$. (C) G. stearothermophilus tRNA $^{\text {Tyr }}$. (D) G. stearothermophilus tRNA ${ }^{\text {Val }}$. (E) Aquifex aeolicus tRNACys. (F) Thermus thermophilus tRNA $^{\text {Asp. }}$. (G) T. thermophilus tRNA ${ }^{\text {Ile }}$. (H) T. thermophilus tRNA ${ }_{\mathrm{f}}{ }_{\mathrm{f}} 1$. (I) T. thermophilus tRNA ${ }^{\text {Phe }}$. (J) Thermoplasma acidophilum initiator tRNA ${ }^{\mathrm{Met}}$. (K) T. acidophilum elongator tRNA ${ }^{\mathrm{Met}}$. (L) T. acidophilum tRNA $^{\text {Leu. }}$. (M) Sulfolobus acidocaldarius initiator tRNA ${ }^{\text {Met }}$ In A. aeolicus tRNACys (E) the nucleotides shown in gray could not be determined and cyanoethylated $t R N A^{C y s}$ was not analyzed. Therefore, this tRNA may possess additional modifications (e.g., $\Psi_{39}, \Psi_{55}$ and $\mathrm{m}^{1} \mathrm{~A} 58$ ). Thermus thermophilus possesses two tRNA ${ }_{\mathrm{f}}^{\text {Met }}$ species. The difference of $\mathrm{tRNA}^{\mathrm{Met}}{ }_{\mathrm{f}} 2$ is single G-C base pair, which is indicated in purple in $(\mathrm{H})$. In S. acidocaldarius initiator tRNA ${ }^{\mathrm{Met}}(\mathrm{M})$, the nucleosides at positions 9 and 26 may be $\mathrm{m}^{1} \mathrm{~A}_{9}$ and $\mathrm{m}_{2}^{2} \mathrm{Gm}_{26}$, respectively.

\section{Modified Nucleosides in tRNA from Moderate Thermophiles Are Common to Those from Mesophiles}

Seven tRNA sequences from moderate thermophiles (Geobacillus stearothermophilus and T. acidophilum), which live at below $75{ }^{\circ} \mathrm{C}$, have been reported (Figure 2). Furthermore, the modified nucleosides in unfractionated tRNA from moderate thermophiles (Methanobacterium thermoaggregans, Methanobacterium thermoautotrophicum, and Methanococcus thermolithotrophicus) were analyzed [97,99]. These studies have shown that the modified nucleosides in tRNA from moderate thermophiles are typically common to those in tRNA from mesophiles. In summarizing the information on tRNA modifications and tRNA modification enzymes by thermophilic species [8-330] (Table 2), we have separately considered moderate thermophiles, extreme-thermophiles, and hyper-thermophiles. However, there are some differences between moderate thermophiles and mesophiles. For 
example, the degree of 2'-O-methylation in tRNA from G. stearothermophilus is increased at high temperatures [309]. Furthermore, several modifications $\left(\mathrm{Gm}_{18}\right.$, D modifications, and $\left.\mathrm{Gm}_{34}\right)$ in tRNA from G. stearothermophilus cannot be explained by the enzymatic activities of the already-known tRNA modification enzymes, which is described in Table 2. Moreover, T. acidophilum possesses several distinct tRNA modifications such as $\mathrm{G}^{+}{ }_{13}$ and $\mathrm{m}^{7} \mathrm{G}_{49}$ (Table 2) [36]. Although these differences are present, thermophile-specific modified nucleosides have not been found in tRNA from moderate thermophiles, which suggests that living organisms can survive at $75{ }^{\circ} \mathrm{C}$ via the tRNA modifications in mesophiles. 
Table 2. Thermophiles: their tRNA modifications and tRNA modification enzymes.

\begin{tabular}{|c|c|c|c|}
\hline Species & Predicted Enzyme & Distinct tRNA Modifications and General Information & References \\
\hline \multicolumn{4}{|l|}{ Moderate Thermophiles } \\
\hline \multicolumn{4}{|l|}{ Eubacteria } \\
\hline \multirow[t]{6}{*}{$\begin{array}{l}\text { Geobacillus stearothermophilus } \\
\text { (Bacillus stearothermophilus) } 30-75{ }^{\circ} \mathrm{C}\end{array}$} & & $\begin{array}{l}\text { Sequences of tRNA }{ }^{\mathrm{Leu}}[18], \mathrm{tRNA}^{\mathrm{Phe}}[19], \mathrm{tRNA}^{\mathrm{Tyr}}[20] \text {, and tRNA } \mathrm{Val}^{2}[64] \\
\text { have been reported (Figure 2). The majority of modifications in tRNA are } \\
\text { similar to those in B. subtilis. With increasing culture temperature, the extent } \\
\text { of 2'-O-methylation in the tRNA mixture increases [309]. }\end{array}$ & \\
\hline & $\mathrm{Gm}_{18}(\mathrm{TrmH}$ ) & $\begin{array}{l}\text { Although } \operatorname{trmH} \text { is not encoded in the B. subtilis genome, a trmH-like gene is } \\
\text { encoded in the G. stearothermophilus genome. Gm } 18 \text { has been found in } \\
\text { tRNA }{ }^{\text {Tyr }} \text { but not in tRNA }{ }^{\text {Leu. }} \text {. This modification pattern suggests that the } \\
\text { substrate tRNA specificity of G. stearothermophilus TrmH may be different } \\
\text { from that of other known TrmH enzymes. }\end{array}$ & [20] \\
\hline & $\begin{array}{l}D_{17}, D_{20} \text { and } D_{20 a} \\
\text { (Dus family protein?) }\end{array}$ & $\begin{array}{l}\text { In G. stearothermophilus tRNA, } \mathrm{D}_{17}, \mathrm{D}_{20} \text {, and } \mathrm{D}_{20 \mathrm{a}} \text { modifications have been } \\
\text { reported. In E. coli, three Dus family proteins known as DusA, DusB, and } \\
\text { DusC, produce } \mathrm{D}_{20} \text { and } \mathrm{D}_{20 \mathrm{a}}, \mathrm{D}_{17} \text {, and } \mathrm{D}_{16} \text {, respectively }[65,66] \text {. In the } \\
\text { G. stearothermophilus genome, however, only one gene is annotated as a } \\
\text { dus-like gene. Therefore, D modifications in } G \text {. stearothermophilus cannot be } \\
\text { explained by the tRNA substrate specificity of the known Dus proteins. }\end{array}$ & {$[17,19,64]$} \\
\hline & $\mathrm{m}^{1} \mathrm{~A}_{22}(\operatorname{TrmK} ?)$ & $\begin{array}{l}\text { The } \mathrm{m}^{1} \mathrm{~A}_{22} \text { modification has been found in tRNA } \\
\text { B. subtilis and and Mycoplasma capricolum }[310,311] \text {. G. stearothermophilus tRNA }{ }^{\text {Seu }} \text { from } \\
\text { and tRNA } \mathrm{Tyr} \text { possess } \mathrm{m}^{1} \mathrm{~A}_{22}[18,20] \text {. The presence of a trmK-like gene in the } \\
\text { genome of G. stearothermophilus has been reported [86]. }\end{array}$ & {$[20,86]$} \\
\hline & $\mathrm{Gm}_{34}$ (unknown MT) & $\begin{array}{l}\text { G. stearothermophilus tRNA }{ }^{\text {Phe }} \text { possesses } \mathrm{Gm}_{34} \text { (Figure 2B) [19]. In contrast, the } \\
\text { nucleoside at position } 34 \text { in E. coli } \text { tRNA }^{\text {Phe }} \text { is unmodified G. Given that } E \text {. coli } \\
\text { TrmL acts only on tRNA }{ }^{\text {Leu }} \text { isoacceptors [143], the } 2^{\prime}-O \text {-methylation of } \mathrm{G}_{34} \text { in } \\
\text { tRNA }{ }^{\text {Phe }} \text { from G. stearothermophilus is cannot be simply explained by the } \\
\text { activity of known TrmL. }\end{array}$ & [19] \\
\hline & $\mathrm{m}^{6} \mathrm{~A}_{37}$ (YfiC; TrmG?) & & [198] \\
\hline \multicolumn{4}{|l|}{ Archaea } \\
\hline $\begin{array}{l}\text { Methanobacterium thermoaggregans } \\
\text { Optimum growth temperature } 60^{\circ} \mathrm{C}\end{array}$ & & Sequences of tRNA ${ }^{\text {Asn }}$ and tRNA Gly have been reported [8]. & \\
\hline $\begin{array}{l}\text { Methanobacterium } \\
\text { thermoautotrophicum } 45-75^{\circ} \mathrm{C}\end{array}$ & & $\begin{array}{l}\text { The modified nucleosides in unfractionated tRNA are essentially common to } \\
\text { those in tRNA from mesophilic methane archaea [97]. }\end{array}$ & \\
\hline
\end{tabular}


Table 2. Cont.

\begin{tabular}{|c|c|c|c|}
\hline Species & Predicted Enzyme & Distinct tRNA Modifications and General Information & References \\
\hline $\begin{array}{l}\text { Methanococcus thermolithotrophicus } \\
17-62{ }^{\circ} \mathrm{C}\end{array}$ & & $\begin{array}{l}\text { The modified nucleosides in unfractionated tRNA are essentially common to } \\
\text { those in tRNA from mesophilic methane archaea [99]. }\end{array}$ & \\
\hline \multirow[t]{8}{*}{$\begin{array}{l}\text { Thermoplasma acidophilum } \\
\text { Optimum growth temperature } \\
55-60^{\circ} \mathrm{C}\end{array}$} & & $\begin{array}{l}\text { Sequences of tRNA }{ }^{\mathrm{Met}_{\mathrm{i}}}[44,252], \mathrm{tRNA} \mathrm{Met}_{\mathrm{M}}[25] \text {, and tRNA }{ }^{\mathrm{Leu}}[36] \text { have been } \\
\text { reported. Several recombinant tRNA modification enzymes have been used } \\
\text { for biochemical studies. }\end{array}$ & \\
\hline & $s^{4} U_{8}$ and $s^{4} U_{9}($ ThiI $?+\alpha)$ & $\begin{array}{l}\text { The } \mathrm{s}^{4} \mathrm{U}_{9} \text { modification has been found in } \mathrm{tRNA}^{\mathrm{Leu}}[36] \text {. The sulfur donor for } \\
\qquad \mathrm{s}^{4} \mathrm{U} \text { formation is unknown [35]. }\end{array}$ & [36] \\
\hline & $\begin{array}{c}\mathrm{G}^{+} 13 \text { and } \mathrm{G}^{+} 15 \\
\text { (ArcTGT }+ \text { ArcS?) }\end{array}$ & $\begin{array}{l}\text { The } \mathrm{G}^{+} 13 \text { modification has been found only in tRNA }{ }^{\text {Leu }} \text { from T. acidophilum } \\
\text { [36]. ArcTGT from T. acidophilum acts on both G13 and G15 in tRNA }{ }^{\text {Leu }}[47] .\end{array}$ & {$[36,47]$} \\
\hline & $\mathrm{m}^{2}{ }_{2} \mathrm{G}_{26}(\operatorname{Trm} 1)$ & & [89] \\
\hline & $\mathrm{ncm}^{5} \mathrm{U}_{34}(\mathrm{Elp} 3 ?)$ & & [36] \\
\hline & $\mathrm{m}^{1} \mathrm{G}_{37}(\operatorname{Trm} 5)$ & & [89] \\
\hline & $\mathrm{m}^{7} \mathrm{G}_{49}$ (unknown MT) & & [36] \\
\hline & $\mathrm{Cm}_{56}(\operatorname{Trm} 56)$ & $\begin{array}{c}\text { The presence of unusual trm56-like gene in the T. acidophilum genome has } \\
\text { been reported in a bioinformatics study [250]. The Trm56 enzymatic activity } \\
\text { has been confirmed via the recombinant protein [89]. T. acidophilum Trm56 } \\
\text { exceptionally possesses a long C-terminal region in the SPOUT } \\
\text { tRNA MT [312]. }\end{array}$ & {$[89,250,312]$} \\
\hline \multicolumn{4}{|l|}{$\begin{array}{l}\text { Extreme-thermophiles and } \\
\text { Hyper-thermophiles }\end{array}$} \\
\hline \multicolumn{4}{|l|}{ Eubacteria } \\
\hline \multirow[t]{5}{*}{$\begin{array}{l}\text { Aquifex aeolicus } \\
\text { Optimum growth temperature } \\
85-94^{\circ} \mathrm{C}\end{array}$} & & $\begin{array}{l}\text { The partial sequence of tRNA }{ }^{\text {Cys }} \text { has been reported [24] (Figure 2E). Several } \\
\text { tRNA MT activities have been detected in the A. aeolicus cell extract using an } \\
\text { E. coli tRNA mixture [24]. The tRNA modification enzymes listed below were } \\
\text { characterized via recombinant proteins. }\end{array}$ & \\
\hline & $\mathrm{Gm}_{18}(\mathrm{TrmH})$ & & {$[74,77]$} \\
\hline & $\mathrm{D}_{20}($ Dus $)$ & $\begin{array}{c}\mathrm{D}_{20} \text { exists in tRNA }{ }^{\text {Cys }} \text {. However, the nucleoside at position 20a is unmodified } \\
\mathrm{U} \text { [24]. Therefore, A. aeolicus Dus may act only on } \mathrm{U}_{20} \text {. }\end{array}$ & {$[24,82]$} \\
\hline & $\begin{array}{l}\mathrm{m}^{2} \mathrm{G}_{26}, \mathrm{~m}^{2}{ }_{2} \mathrm{G}_{26}, \mathrm{~m}^{2} \mathrm{G}_{27} \text { and } \\
\mathrm{m}^{2}{ }_{2} \mathrm{G}_{27} \text { (Trm1) }\end{array}$ & Aquifex aeolicus exceptionally possesses $\operatorname{Trm} 1$ in eubacteria [24]. & {$[24,95]$} \\
\hline & $\mathrm{I}_{34}(\operatorname{TadA})$ & & {$[104,105]$} \\
\hline
\end{tabular}


Table 2. Cont.

\begin{tabular}{|c|c|c|c|}
\hline Species & Predicted Enzyme & Distinct tRNA Modifications and General Information & References \\
\hline & $\mathrm{mnm}^{5} \mathrm{U}_{34}(\mathrm{MnmC} 2)$ & $\begin{array}{l}\text { MnmC catalyzes the final methylation step of } \mathrm{mnm}^{5} \mathrm{U} \text { synthesis. } \\
\text { Aquifex aeolicus MnmC2 comprises only an MT domain. }\end{array}$ & [136] \\
\hline & $\begin{array}{l}\text { (MnmD; previously } \\
\text { called GidA) }\end{array}$ & & {$[140,141]$} \\
\hline & $\mathrm{k}^{2} \mathrm{C}_{34}$ (TilS) & & [111-113] \\
\hline & $\mathrm{m}^{1} \mathrm{G}_{37}(\operatorname{TrmD})$ & $\begin{array}{l}\text { The dimer structure of A. aeolicus TrmD is stabilized by inter-subunit disulfide } \\
\text { bonds [165]. }\end{array}$ & {$[160,162,165]$} \\
\hline & $\mathrm{m}^{7} \mathrm{G}_{46}(\mathrm{TrmB})$ & $\begin{array}{l}\text { TrmB proteins from thermophiles (A. aeolicus and T. thermophilus) possess a } \\
\text { long C-terminal region. }\end{array}$ & [206-208] \\
\hline & $\mathrm{m}^{5} \mathrm{U}_{54}$ and $\mathrm{m}^{5} \mathrm{~s}^{2} \mathrm{U}_{54}(\mathrm{TrmFO})$ & $\begin{array}{l}\text { The presence of trmFO gene in A. aeolicus genome was initially described in } \\
\text { Reference [221]. }\end{array}$ & {$[24,221]$} \\
\hline & $\mathrm{m}^{1} \mathrm{~A}_{58}(\operatorname{TrmI})$ & & {$[257,262]$} \\
\hline \multirow[t]{10}{*}{ Thermotoga maritima $80-90^{\circ} \mathrm{C}$} & & $\begin{array}{l}\text { Sequences of tRNA from T. maritima have not been reported. Recombinant } \\
\text { proteins have been used for biochemical and structural studies. }\end{array}$ & \\
\hline & $h n^{6} \mathrm{~A}(?)$ & $\begin{array}{l}\mathrm{hn}^{6} \mathrm{~A} \text { was first identified in modified nucleosides from unfractionated tRNA } \\
\text { from T. maritima [313]. Because } \mathrm{hn}^{6} \mathrm{~A} \text { was subsequently found in modified } \\
\text { nucleosides from psychrophilic archaea [56], it is not a thermophile-specific } \\
\text { modification. Thermotoga maritima and Thermodesulfobacterium commune } \\
\text { exceptionally possess } \mathrm{hn}^{6} \mathrm{~A} \text { in eubacteria. The modification position in } \mathrm{tRNA} \text {, } \\
\text { modified tRNA species, and biosynthesis pathway of } \mathrm{hn}^{6} \mathrm{~A} \text { are unknown. }\end{array}$ & {$[56,313]$} \\
\hline & $\mathrm{s}^{4} \mathrm{U}_{8}$ (ThiI + IscS) & & {$[31,32]$} \\
\hline & $\mathrm{oQ}_{34}(\mathrm{QueA})$ & & [151] \\
\hline & $\mathrm{mnm}^{5} \mathrm{U}_{34}(\operatorname{TrmE})$ & & {$[138,139]$} \\
\hline & $\begin{array}{l}\mathrm{t}^{6} \mathrm{~A}_{37} \text { (TsaB, TsaC/TsaC2, TsaD } \\
\text { and TsaE) }\end{array}$ & & [190] \\
\hline & $\mathrm{ms}^{2} \mathrm{i}^{6} \mathrm{~A}_{37}(\mathrm{MiaB})$ & & [194-196] \\
\hline & $\mathrm{m}^{1} \mathrm{G}_{37}(\operatorname{TrmD})$ & & [171] \\
\hline & $\begin{array}{l}\mathrm{m}^{5} \mathrm{U}_{54} \text { and } \mathrm{m}^{5} \mathrm{~s}^{2} \mathrm{U}_{54} \\
(\mathrm{TrmFO} \text { and TtuA) }\end{array}$ & $\begin{array}{l}\text { The } \mathrm{m}^{5} \mathrm{~s}^{2} \mathrm{U} \text { nucleoside has been found in unfractionated tRNA } \\
\text { from T. maritima [97]. }\end{array}$ & {$[97,134,221,222]$} \\
\hline & $\Psi_{55}(\operatorname{TruD})$ & & [244-247] \\
\hline
\end{tabular}


Table 2. Cont

\begin{tabular}{ccc}
\hline Species & Predicted Enzyme & Distinct tRNA Modifications and General Information \\
\hline & $\mathrm{m}^{1} \mathrm{~A}_{58}(\operatorname{TrmI})$ & References \\
\hline
\end{tabular}

Thermodesulfobacterium commune unfractionated tRNA from T. commune. The ms $\quad \mathrm{hn}^{6} \mathrm{~A}$ and $\mathrm{ms}^{2} \mathrm{hn}^{6} \mathrm{~A}($ ?) $\quad$ A modification may be

Optimum growth temperature $70^{\circ} \mathrm{C} \quad \mathrm{hn}^{6} \mathrm{~A}$ and $\mathrm{ms}^{2} \mathrm{hn}^{6} \mathrm{~A}(?) \quad \begin{aligned} & \text { derived from } \mathrm{hn} \\ & \mathrm{ms}^{2} \mathrm{hn}\end{aligned}$ $m s^{2} h n^{6} \mathrm{~A}$ in tRNA. The modification position in tRNA, modified tRNA
species, and biogenesis pathway of $\mathrm{hn}^{6} \mathrm{~A}$ and $\mathrm{ms}^{2} \mathrm{hn}^{6} \mathrm{~A}$ are unknown.

Thermus flavus

Optimum growth temperature $70{ }^{\circ} \mathrm{C}$

Thermus thermophiles $50-83{ }^{\circ} \mathrm{C}$
Partial purification of tRNA $\mathrm{m}^{1} \mathrm{~A} 58 \mathrm{MT}$ has been reported: the activity of tRNA $m^{7} \mathrm{G}_{46}$ MT has also been described [204].

Sequences of tRNA ${ }^{\text {Met }}$ f1 [21], tRNA ${ }^{\text {Met }}$ f2 [21], tRNA ${ }^{\text {Ile }} 1$ [67], tRNA Asp [23], and tRNA ${ }^{\text {Phe }}[10,11]$ have been reported (Figure 2). Partial sequences of

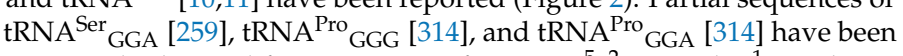

determined. The modification extent of $\mathrm{Gm}_{18}, \mathrm{~m}^{5} \mathrm{~s}^{2} \mathrm{U}_{54}$ and $\mathrm{m}^{1} \mathrm{~A}_{58}$ changes

with the culture temperature. At high temperatures $\left(>75^{\circ} \mathrm{C}\right), \mathrm{m}^{7} \mathrm{G}_{46}$ [11],

$\mathrm{m}^{5} \mathrm{~s}^{2} \mathrm{U}_{5}$ [230], and $\mathrm{m}^{1} \mathrm{~A}{ }^{2}$ [260] modification are essential for survival. At

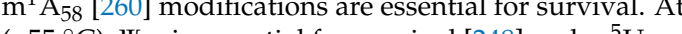

low temperatures $\left(<55^{\circ} \mathrm{C}\right), \Psi_{55}$ is essential for survival [248] and $\mathrm{m}^{5} \mathrm{U}_{54}$

supports this effect [225] (see the main text). Recombinant proteins have been used for biochemical and structural studies.

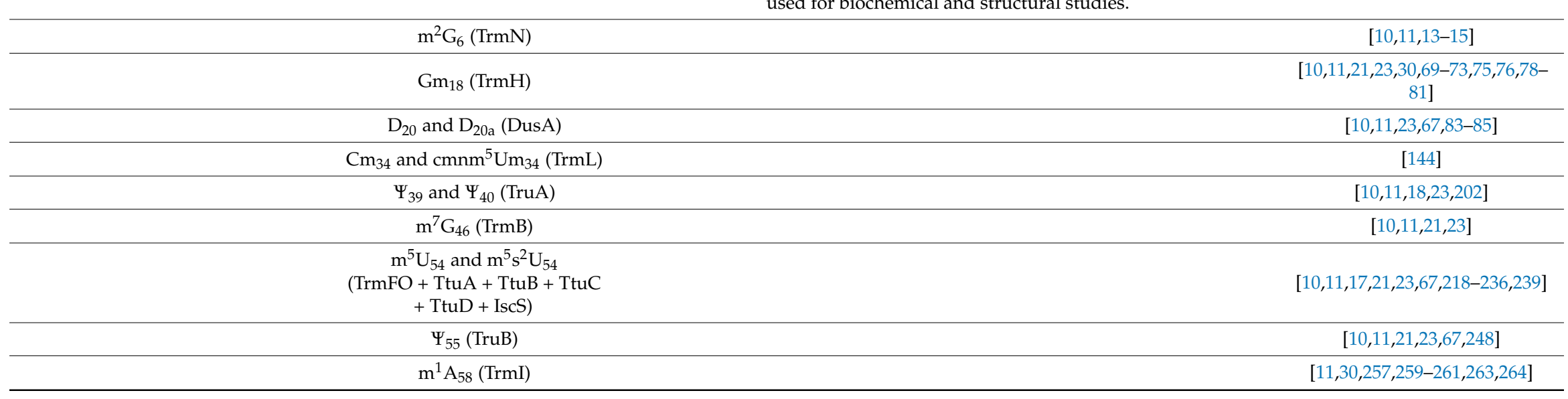


Table 2. Cont.

\begin{tabular}{|c|c|c|c|}
\hline Species & Predicted Enzyme & Distinct tRNA Modifications and General Information & References \\
\hline \multicolumn{4}{|l|}{ Archaea } \\
\hline Aerophyrum pernix $80-100{ }^{\circ} \mathrm{C}$ & $\begin{array}{l}\Psi_{13} \text { and } \Psi_{15} \text { (archaeal Pus7 and } \\
\text { H/ACA guide RNA system) }\end{array}$ & $\begin{array}{l}\text { A guide RNA for } \Psi \text { formation has been predicted based } \\
\text { on genome sequencing. }\end{array}$ & [46] \\
\hline \multirow[t]{2}{*}{ Archaeoglobus fulgidus $60-95^{\circ} \mathrm{C}$} & & $\begin{array}{l}\text { Modified nucleosides in unfractionated tRNA from A. fulgidus } \\
\text { have been reported [97]. }\end{array}$ & \\
\hline & $\operatorname{agm}^{2} \mathrm{C}_{34}$ (TiaS) & & {$[116,118,119,315]$} \\
\hline $\begin{array}{l}\text { Methanocaldcoccus igneus } \\
\text { (Methanococcus igneus; } \\
\text { Methanotorris igneus) } 45-91^{\circ} \mathrm{C}\end{array}$ & & $\begin{array}{c}\text { Modified nucleosides in unfractionated tRNA from M. igneus } \\
\text { have been reported }[56,99] .\end{array}$ & \\
\hline Methanocaldococcus infernus $55-92^{\circ} \mathrm{C}$ & $\mathrm{cm}^{5} \mathrm{U}_{34}(\mathrm{Elp} 3)$ & & [142] \\
\hline $\begin{array}{c}\text { Methanocaldcoccus jannashii } \\
\text { (Methanococcus janaschii) } 48-94{ }^{\circ} \mathrm{C}\end{array}$ & & $\begin{array}{l}\text { Although sequences of tRNA are unknown, the recombinant proteins listed } \\
\text { below have been used for biochemical and structural studies. }\end{array}$ & \\
\hline & $\mathrm{m}^{2} \mathrm{G}_{6}(\operatorname{Trm} 14)$ & & [12] \\
\hline & $\mathrm{G}^{+}{ }_{15}(\mathrm{ArcTGT}+\mathrm{ArcS})$ & & {$[51,59]$} \\
\hline & $\begin{array}{l}\mathrm{Cm}_{34} \text { and } \mathrm{Um}_{39} \\
\text { (L7Ae, Nop5, aFib, Box C/D } \\
\text { guide RNA system) }\end{array}$ & & [316] \\
\hline & $\mathrm{m}^{1} \mathrm{G}_{37}(\mathrm{Trm} 5)$ & & {$[159,161,163,164,166-170]$} \\
\hline & imG2 $37(\operatorname{Trm} 5 b+$ Taw1) & & {$[173,179]$} \\
\hline & $\mathrm{yW}-86_{37}(\mathrm{Taw} 2)$ & & [174] \\
\hline & $\begin{array}{l}\mathrm{m}^{5} \mathrm{C}_{48} \text { and } \mathrm{m}^{5} \mathrm{C}_{49} \\
\text { (archaeal Trm4) }\end{array}$ & & [210] \\
\hline & $\Psi_{54}$ and $\Psi_{55}($ Pus10) & & [211-214] \\
\hline & $\mathrm{m}^{1} \Psi_{54}(\mathrm{Pus} 10+\operatorname{Trm} Y)$ & & [215-217] \\
\hline & $\Psi_{55}$ (archaeal Cbf5) & & [240] \\
\hline $\begin{array}{l}\text { Methanopyrus kandleri } 84-110^{\circ} \mathrm{C} \\
\left.\quad \text { (Strain 116: up to } 122^{\circ} \mathrm{C}\right)\end{array}$ & & $\begin{array}{l}\text { Many unique modified nucleosides have been found in unfractionated } \\
\text { tRNA [100]. tRNAs likely contain many 2'-O-methylated nucleosides derived } \\
\text { from the C/D box guide RNA system [17]. }\end{array}$ & \\
\hline
\end{tabular}


Table 2. Cont.

\begin{tabular}{|c|c|c|c|}
\hline Species & Predicted Enzyme & Distinct tRNA Modifications and General Information & References \\
\hline & $\mathrm{ac}^{6} \mathrm{~A}(?)$ & $\begin{array}{l}\text { The ac }{ }^{6} \mathrm{~A} \text { nucleoside has been purified from the modified nucleosides in } \\
\text { unfractionated tRNA and its structure determined. The modification site, } \\
\text { modified tRNA species, and biosynthesis pathway are unknown. }\end{array}$ & {$[100]$} \\
\hline & $\mathrm{U}_{8}$ (CDAT8) & & [16] \\
\hline Methanothermus fervidus $80-97^{\circ} \mathrm{C}$ & & Only tRNA genes were reported in an early study [317]. & \\
\hline Nanoarchaeum equitans $70-98^{\circ} \mathrm{C}$ & & $\begin{array}{l}\text { A unique tRNA processing system has been found [318,319]. The processing } \\
\text { of small RNAs in N. equitans is reviewed in Reference [320]. }\end{array}$ & \\
\hline & $\mathrm{m}^{1} \mathrm{G}_{37}$ and $\mathrm{imG}_{37}(\operatorname{Trm} 5 \mathrm{a})$ & & [176] \\
\hline & $\mathrm{m}^{5} \mathrm{U}_{54}$ (TrmA-like protein) & & [237] \\
\hline $\begin{array}{l}\text { Pyrobaculum aerophilum } \\
\text { Optimum growth temperature } \\
100^{\circ} \mathrm{C}\end{array}$ & $\begin{array}{l}\mathrm{Cm}_{56} \text { (L7Ae, Nop5, aFib, Box } \\
\text { C/D guide RNA system) }\end{array}$ & $\begin{array}{l}\mathrm{Cm}_{56} \text { in } \mathrm{tRNA} \text { is generally produced by } \mathrm{Trm} 56 \text {. However, this modification in } \\
\text { P. aerophilum is synthesized by the } \mathrm{C} / \mathrm{D} \text { box guide RNA system. }\end{array}$ & [249] \\
\hline Pyrobaculum calidifontis $90-95^{\circ} \mathrm{C}$ & $\begin{array}{l}\mathrm{G}^{+}{ }_{15}(\text { ArcTGT }+ \text { QueF-like } \\
\text { protein) }\end{array}$ & $\begin{array}{l}\text { Eubacterial } \mathrm{QueF} \text { catalyzes the conversion from } \mathrm{pre}_{0} \text { to } \mathrm{preQ}_{1} \text {. } \\
\text { In P. caldifontis, however, QueF-like protein catalyzes the conversion from } \\
\text { preQ } \\
\text { at position } 15 \text { in tRNA to } \mathrm{G}^{+}{ }_{15} \text {. }\end{array}$ & {$[60,62,63]$} \\
\hline $\begin{array}{l}\text { Pyrobaculum islandicum } \\
\text { Optimum growth temperature } \\
100^{\circ} \mathrm{C}\end{array}$ & & $\begin{array}{l}\text { Modified nucleosides in unfractionated tRNA from } P \text {. islandicum have been } \\
\text { reported [97]. }\end{array}$ & \\
\hline \multirow[t]{6}{*}{$\begin{array}{l}\text { Pyrococcus abyssi } \\
\text { Optimum growth temperature } 96^{\circ} \mathrm{C}\end{array}$} & & $\begin{array}{l}\text { No tRNA sequence has been determined. However, the tRNA modification } \\
\text { enzymes listed below have been characterized. }\end{array}$ & \\
\hline & $\begin{array}{c}\mathrm{m}^{2} \mathrm{G}_{10} \text { and } \mathrm{m}^{2}{ }_{2} \mathrm{G}_{10} \text { (archaeal } \\
\text { Trm11, Trm-G10 enzyme, } \\
\text { Trm-m22G10 enzyme) }\end{array}$ & & {$[40,41]$} \\
\hline & $\begin{array}{l}\Psi_{13} \text { and } \Psi_{35} \text { (archaeal Pus7 and } \\
\text { H/ACA guide RNA system) }\end{array}$ & & [46] \\
\hline & $\begin{array}{l}\mathrm{Cm}_{34} \text { and } \mathrm{Um}_{39} \text { (L7Ae, Nop5, } \\
\text { aFib, and C/D box guide } \\
\text { RNA system) }\end{array}$ & $\begin{array}{c}\mathrm{Cm}_{34} \text { and } \mathrm{Um}_{39} \text { in } \mathrm{tRNA}{ }^{\mathrm{Trp}} \text { are formed by the } \mathrm{C} / \mathrm{D} \text { box guide RNA system in } \\
\text { which the intron functions as a guide RNA. }\end{array}$ & {$[154,155]$} \\
\hline & $\mathrm{m}^{1} \mathrm{G}_{37}(\operatorname{Trm} 5 \mathrm{~b})$ & & [180] \\
\hline & $\mathrm{m}^{1} \mathrm{G}_{37}$ and $\mathrm{imG} 2_{37}(\operatorname{Trm} 5 \mathrm{a})$ & & {$[176,177,179]$} \\
\hline
\end{tabular}


Table 2. Cont.

\begin{tabular}{|c|c|c|c|}
\hline Species & Predicted Enzyme & Distinct tRNA Modifications and General Information & References \\
\hline & imG-14 37 (Taw1) & & {$[173,175]$} \\
\hline & $\mathrm{t}^{6} \mathrm{~A} 37$ (Kae1) & & [185] \\
\hline & (KEOPS complex) & & [184] \\
\hline & (Sua5 + KEOPS complex) & & {$[187,189]$} \\
\hline & $\begin{array}{l}\mathrm{m}^{5} \mathrm{C}_{48} \text { and } \mathrm{m}^{5} \mathrm{C}_{49} \text { (archaeal } \\
\text { Trm4 + archaese) }\end{array}$ & & [209] \\
\hline & $\begin{array}{l}\mathrm{m}^{5} \mathrm{U}_{54} \text { (TrmA-like protein, } \\
\text { PAB0719) }\end{array}$ & & {$[237,238]$} \\
\hline & $\Psi_{55}($ Cbf5 + Nop10) & & [241] \\
\hline & $\mathrm{Cm}_{56}(\operatorname{Trm} 56)$ & & [249] \\
\hline & $\begin{array}{l}\mathrm{m}^{1} \mathrm{~A}_{57} \text { and } \mathrm{m}^{1} \mathrm{~A}_{58} \\
\text { (archaeal TrmI) }\end{array}$ & & [255-258] \\
\hline $\begin{array}{c}\text { Pyrococcus furiosus } \\
\text { Optimum growth temperature } \\
100^{\circ} \mathrm{C}\end{array}$ & \multicolumn{3}{|c|}{$\begin{array}{c}\text { Modified nucleosides in unfractionated tRNA from } P \text {. furiosus have been } \\
\text { reported [98]. Activity of several tRNA modification enzymes has been } \\
\text { detected in the cell extract of } P \text {. furious [9]. }\end{array}$} \\
\hline \multicolumn{3}{|c|}{$\mathrm{m}^{2} \mathrm{G}_{6}(\operatorname{Trm} 14)$} & {$[13,15]$} \\
\hline \multicolumn{3}{|c|}{$\begin{array}{c}\mathrm{m}^{2} \mathrm{G}_{10} \text { and } \mathrm{m}_{2}^{2} \mathrm{G}_{10} \text { (archaeal } \\
\text { Trm11, Trm-G10 enzyme, } \\
\text { Trm-m22G10 enzyme) }\end{array}$} & [42] \\
\hline \multicolumn{3}{|c|}{$\mathrm{G}^{+}{ }_{15}(\mathrm{ArcTGT})$} & [57] \\
\hline \multicolumn{3}{|c|}{$\mathrm{m}^{2} \mathrm{G}_{26}$ and $\mathrm{m}_{2}^{2} \mathrm{G}_{26}(\mathrm{Trm} 1)$} & {$[91,92]$} \\
\hline \multicolumn{3}{|c|}{$\mathrm{t}^{6} \mathrm{~A} 37$ (KEOPS complex) } & [188] \\
\hline \multicolumn{3}{|c|}{$\Psi_{54}$ and $\Psi_{55}($ Pus10) } & {$[212,214]$} \\
\hline \multicolumn{3}{|c|}{$\Psi_{55}($ Cbf5 + Nop10 + Gar1) } & [242] \\
\hline Pyrococcus horikoshii $80-102^{\circ} \mathrm{C}$ & \multicolumn{3}{|c|}{$\begin{array}{c}\text { The crystal structure of Nop5 in the C/D box guide RNA system from } \\
\text { P. horikoshii has been solved [321]. }\end{array}$} \\
\hline & $\mathrm{G}^{+}{ }_{15}(\mathrm{ArcTGT})$ & & {$[50,52-55,89]$} \\
\hline & $\mathrm{m}^{2} \mathrm{G}_{26}$ and $\mathrm{m}_{2}^{2} \mathrm{G}_{26}(\operatorname{Trm} 1)$ & & {$[89,93]$} \\
\hline
\end{tabular}


Table 2. Cont.

\begin{tabular}{|c|c|c|c|}
\hline Species & Predicted Enzyme & Distinct tRNA Modifications and General Information & References \\
\hline & yW-86 37 (Taw2) & & [174] \\
\hline & $\mathrm{m}^{5} \mathrm{~s}^{2} \mathrm{U}_{54}(\mathrm{TtuA})$ & & [233] \\
\hline & $\mathrm{Cm}_{56}(\operatorname{Trm} 56)$ & & [251] \\
\hline $\begin{array}{l}\text { Pyrodictium occultum } \\
\text { Optimum growth temperature } \\
105^{\circ} \mathrm{C}\end{array}$ & & $\begin{array}{l}\text { Modified nucleosides in unfractionated tRNA have been analyzed and many } \\
\text { 2'-O-methylated nucleosides found [97,98]. mimG was originally found } \\
\text { among the modified nucleosides in tRNAs from P. occultum, } \\
\text { Sulfolobus solfaraticus, and Thermoproteus neutrophilus [322]. } \\
\text { Although the melting temperature of P. occultum } \text { tRNA }^{\text {Met }} \text { i transcript is only } \\
80^{\circ} \mathrm{C} \text { and that of native tRNA }{ }^{\text {Met }} i_{i} \text { is more than } 100{ }^{\circ} \mathrm{C} \text { (see main text) [323]. }\end{array}$ & \\
\hline $\begin{array}{c}\text { Pyrolobus fumarii } \\
\text { This archaeon can survive at } 113^{\circ} \mathrm{C} \text {. }\end{array}$ & & Modified nucleosides in unfractionated tRNA have been analyzed [324]. & \\
\hline $\begin{array}{c}\text { Stetteria hydrogenophila } \\
\text { Optimum growth temperature } 95{ }^{\circ} \mathrm{C}\end{array}$ & & $\begin{array}{l}\text { Modified nucleosides in unfractionated tRNA have been analyzed and } \\
\text { methyl-hn }{ }^{6} \mathrm{~A}, \mathrm{~ms}^{2} \mathrm{hn}^{6} \mathrm{~A} \text {, and } \mathrm{m}^{2,7} \mathrm{Gm} \text { identified [56]. }\end{array}$ & \\
\hline \multirow[t]{4}{*}{$\begin{array}{l}\text { Sulfolobus acidocaldarius } \\
\text { Optimum growth temperature } \\
75-80^{\circ} \mathrm{C}\end{array}$} & & $\begin{array}{l}\text { Sequence of tRNA } \text { Met } \text { has been reported [44]. The } \mathrm{m}^{1} \mathrm{I}_{57} \text { modification was } \\
\text { originally found in tRNAs from S. acidocaldarius and Haloferax volcanii [253]. } \\
\mathrm{G}^{+} \text {was first isolated from the nucleosides in S. acidocaldarius tRNAs and its } \\
\text { structure determined [49]. The structures of wyosine derivatives (imG-14 and } \\
\text { imG2) have been determined by using the nucleosides from S. acidocaldarius } \\
\text { tRNAs [325]. }\end{array}$ & \\
\hline & $\mathrm{m}^{1} \mathrm{~A}_{9}($ archaeal Trm10) & & {$[37,38]$} \\
\hline & $\begin{array}{l}\Psi_{13} \text { and } \Psi_{35} \text { (archaeal Pus7 and } \\
\text { H/ACA guide RNA system) }\end{array}$ & & [46] \\
\hline & $\mathrm{Cm}_{32}$ (archaeal TrmJ) & & [96] \\
\hline \multirow[t]{3}{*}{ Sulfolobus solfaraticus $55-90^{\circ} \mathrm{C}$} & & $\begin{array}{l}\text { mimG was originally found among the modified nucleosides in tRNAs from } \\
\text { P. occultum, S. solfaraticus, and Thermoproteus neutrophilus [322]. The structure } \\
\text { of box C/D RNP from S. solfaraticus has been reported [326]. }\end{array}$ & \\
\hline & $\operatorname{agm}^{2} \mathrm{C}(\mathrm{TiaS})$ & $\begin{array}{l}\text { The identification of } \operatorname{agm}^{2} C_{34} \text { in Haloarcula marismortui } \mathrm{tRNA}^{\text {Ile }} 2 \text { and the } \\
\text { presence of } \operatorname{agm}^{2} \mathrm{C} \text { in } S \text {. solfaraticus tRNA have been reported. }\end{array}$ & [117] \\
\hline & $\begin{array}{l}\Psi_{13} \text { and } \Psi_{35} \text { (archaeal Pus7 and } \\
\text { H/ACA guide RNA system) }\end{array}$ & $\begin{array}{c}\text { Generally, } \Psi_{35} \text { in tRNA }{ }^{\text {Tyr }} \text { is synthesized by archaeal Pus7. However, Pus7 } \\
\text { from } S . \text { solfaraticus possesses weak } \Psi_{13} \text { formation activity but not } \Psi_{35} \\
\text { formation activity. In } S \text {. solfaraticus and A. pernix, a guide RNA for } \Psi_{35} \\
\text { formation exists. }\end{array}$ & [46] \\
\hline
\end{tabular}


Table 2. Cont.

\begin{tabular}{|c|c|c|c|}
\hline Species & Predicted Enzyme & Distinct tRNA Modifications and General Information & References \\
\hline & $\begin{array}{l}\mathrm{imG} 2_{37} \text { (Trm5a; SSO2439 } \\
\text { protein) }\end{array}$ & $\begin{array}{c}\text { Trm5a (SSO2439 protein) does not possess } \mathrm{m}^{1} \mathrm{G}_{37} \text { formation activity and is } \\
\text { used only for imG2 formation. }\end{array}$ & [178] \\
\hline & $\operatorname{mimG}_{37}$ (Taw3) & & [180] \\
\hline \multirow[t]{2}{*}{$\begin{array}{l}\text { Sulfolobus tokodaii } \\
\text { This archaeon can survive at } 87^{\circ} \mathrm{C} \text {. }\end{array}$} & $\begin{array}{l}\Psi_{13} \text { and } \Psi_{35} \text { (archaeal Pus7 and } \\
\text { H/ACA guide RNA system) }\end{array}$ & & [46] \\
\hline & $t^{6} A_{37}$ (Sua5) & & [327-329] \\
\hline $\begin{array}{l}\text { Thermococuus celer } \\
\text { This archaeon can survive at } 85^{\circ} \mathrm{C} \text {. }\end{array}$ & & $\begin{array}{l}\text { Although tRNA genes were analyzed in an early study [330], there is no } \\
\text { information on tRNA modifications. }\end{array}$ & \\
\hline \multirow[t]{4}{*}{$\begin{array}{l}\text { Thermococcus kodakarensis } \\
\text { (Thermococcus kodakaraensis; } \\
\text { Pyrococcus kodakarensis) } 65-100{ }^{\circ} \mathrm{C}\end{array}$} & $\begin{array}{l}\mathrm{m}^{1} \mathrm{~A}_{9} \text { and } \mathrm{m}^{1} \mathrm{G}_{9} \\
\text { (archaeal Trm10) }\end{array}$ & & {$[37,39]$} \\
\hline & $\begin{array}{c}\mathrm{m}^{2} \mathrm{G}_{10} \text { and } \mathrm{m}_{2}{ }_{2} \mathrm{G}_{10} \text { (archaeal } \\
\text { Trm11, Trm-G10 enzyme, } \\
\text { Trm-m22G10 enzyme) }\end{array}$ & & [43] \\
\hline & $\mathrm{G}^{+}{ }_{15}(\mathrm{ArcTGT})$ & & [47] \\
\hline & $\mathrm{m}^{5} \mathrm{U}_{54}$ (TrmA-like protein) & & [237] \\
\hline $\begin{array}{l}\text { Thermoproteus neutrophilus } \\
\text { Optimum growth temperature } 85{ }^{\circ} \mathrm{C}\end{array}$ & & $\begin{array}{l}\text { Modified nucleosides in unfractionated tRNA have been analyzed [97]. } \\
\text { mimG was originally found among the modified nucleosides in tRNAs from } \\
\text { P. occultum, S. solfaraticus, and T. neutrophilus [322]. }\end{array}$ & \\
\hline
\end{tabular}




\section{Strategies of tRNA Stabilization by Modified Nucleosides in Extreme-Thermophiles and Hyper-Thermophiles}

In general, the G-C content in the stem regions of tRNA from thermophiles is very high (Figure 2). However, the stability of tRNA from thermophiles cannot be explained only by the increase in G-C content in the stem region. For example, although the melting temperature of T. thermophilus tRNA ${ }^{\text {Phe }}$ transcript is $76^{\circ} \mathrm{C}$, that of the native tRNA ${ }^{\text {Phe }}$ is $84.5^{\circ} \mathrm{C}$ [11]. Thus, modified nucleosides are essentially required for stabilization of tRNA at high temperatures. Modified nucleosides in tRNA from thermophiles have been studied mainly from the view point of tRNA stabilization. So far, only a few modified nucleosides specific to thermophiles have been found (Figure 3). These thermophile-specific modified nucleosides seem to stabilize the tRNA structures at high temperatures. As described below, extreme-thermophiles and hyper-thermophiles possess two strategies of tRNA stabilization by modified nucleosides. One is based on thermophile-specific modification such as $\mathrm{m}^{5} \mathrm{~s}^{2} \mathrm{U}_{54}$ (Figure $3 \mathrm{~A}$ ) and the other is based on 2'-O-methylations at multiple positions in tRNA (Figure 3B-E). Recently, the unknown modified nucleoside at position 26 in Sulfolobus acidocaldarius tRNA ${ }^{\text {Met }}$ (Figure 2M) was described as $\mathrm{m}^{2}{ }_{2} \mathrm{Gm}$ [96]. On the whole, however, the modification site(s), modified tRNA species, and biosynthesis pathways of most thermophile-specific modified nucleosides are unknown. Moreover, these nucleosides may have additional functions at high temperatures beyond their structural effect.

A

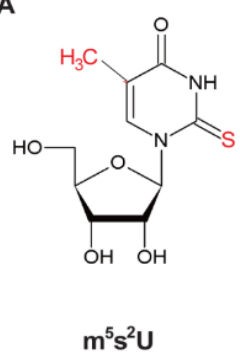

B<smiles>CO[C@H]1[C@@H](O)[C@@H](CO)O[C@H]1n1cc(C)c(N)nc1=O</smiles>

C<smiles></smiles>

$m^{1} I m$

$E$

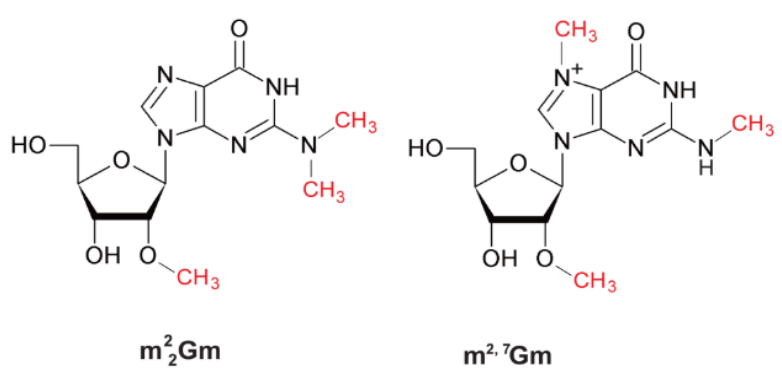

Figure 3. Thermophile-specific modified nucleosides in tRNA. Abbreviations of modified nucleosides are given in Supplementary Table S1. (A) $\mathrm{m}^{5} \mathrm{~s}^{2} \mathrm{U}$. (B) $\mathrm{m}^{5} \mathrm{Cm}$. (C) $\mathrm{m}^{1} \mathrm{Im}$. (D) $\mathrm{m}^{2}{ }_{2} \mathrm{Gm}$. (E) $\mathrm{m}^{2,7} \mathrm{Gm}$. The modifications are indicated in red.

\section{1. $m^{5} s^{2} U_{54}$ Is a Typical Thermophile-Specific Modified Nucleoside in tRNA}

The $\mathrm{m}^{5} \mathrm{~s}^{2} \mathrm{U}_{54}$ modification was originally found in tRNA from T. thermophilus [331]. Subsequently, this modified nucleoside was found in tRNA from A. aeolicus, T. maritima, Pyrococcus abyssi, Pyorococcus horikoshii, and T. kodakarensis (Table 2) but not from mesophiles. The $\mathrm{m}^{5} \mathrm{~s}^{2} \mathrm{U}_{54}$ modification forms a reverse Hoogsteen base-pair with $\mathrm{A}_{58}\left(\right.$ or $\left.\mathrm{m}^{1} \mathrm{~A}_{58}\right)$ in tRNA and stabilizes the tRNA structure by stacking with the $\mathrm{G}_{51}-\mathrm{C}_{61}$ base-pair [220]. Because the 2-thio-modification at position 54 increases the melting temperature of tRNA by more than $3{ }^{\circ} \mathrm{C}[22,218,220]$, the $\mathrm{m}^{5} \mathrm{~s}^{2} \mathrm{U}_{54}$ modification contributes to stabilization of the tRNA structure. The degree of $\mathrm{m}^{5} \mathrm{~s}^{2} \mathrm{U}_{54}$ modification increases with an increasing temperature $[22,67,220,229]$. At $80{ }^{\circ} \mathrm{C}$, the extent of $\mathrm{m}^{5} \mathrm{~s}^{2} \mathrm{U}_{54}$ modification in tRNA is 
almost $100 \%[22,67,220,229]$. The melting temperature of tRNA mixture is maintained above $85^{\circ} \mathrm{C}$ due to the presence of $\mathrm{m}^{5} \mathrm{~s}^{2} \mathrm{U}_{54}$ modification [229] and T. thermophilus can grow at 50 to $83^{\circ} \mathrm{C}$. Thus, living organisms can survive at $80^{\circ} \mathrm{C}$ due to the presence of $\mathrm{m}^{5} \mathrm{~s}^{2} \mathrm{U}_{54}$ modification in tRNA.

4.2. The Network Between Modified Nucleosides in tRNA and tRNA Modification Enzymes in T. thermophilus Adapts Protein Synthesis at Low and High Temperatures

Under natural conditions, the temperature of hot spring water fluctuates for several reasons including an influx of river water, snowfall, and an eruption of hot water. In accordance with these temperature changes, T. thermophilus can synthesize proteins efficiently at a wide range of temperatures (50 to $83^{\circ} \mathrm{C}$ ) by regulating the flexibility (rigidity) of its tRNA [220]. At high temperatures (above $75^{\circ} \mathrm{C}$ ), three modified nucleosides in tRNA, $\mathrm{m}^{5} \mathrm{~s}^{2} \mathrm{U}_{54}$ [230], $\mathrm{m}^{1} \mathrm{~A}_{58}$ [260], and $\mathrm{m}^{7} \mathrm{G}_{46}$ [11] are essential for survival of $T$. thermophilus. The $\mathrm{m}^{1} \mathrm{~A}_{58}$ modification is one of the positive determinants for the two-thiolation system of $\mathrm{m}^{5} \mathrm{~s}^{2} \mathrm{U}_{54}$. Thus, a T. thermophilus disruptant strain of the trmI gene encoding the tRNA $\mathrm{m}^{1} \mathrm{~A}_{58}$ methyltransferase cannot grow at $80{ }^{\circ} \mathrm{C}[229,260]$. The presence of $\mathrm{m}^{7} \mathrm{G}_{46}$ modification in tRNA increases the speed of tRNA modification enzymes such as TrmH for $\mathrm{Gm}_{18}, \operatorname{TrmD}$ for $\mathrm{m}^{1} \mathrm{G}_{37}$, and TrmI for $\mathrm{m}^{1} \mathrm{~A}_{58}$ [11]. The $\mathrm{m}^{1} \mathrm{~A}_{58}$ modification further increases the rate of sulfur-transfer to $\mathrm{m}^{5} \mathrm{U}_{54}$ by the 2-thiolation system and the introduced modified nucleosides coordinately stabilize the tRNA structure. Thus, the $\mathrm{m}^{7} \mathrm{G}_{46}$ modification produced by $\operatorname{TrmB}$ is a key factor in the network between modified nucleosides in tRNA and tRNA modification enzymes of $T$. thermophilus at high temperatures. In the trmB-gene disruptant starin, $\mathrm{tRNA}^{\text {Phe }}$ and tRNA ${ }^{\text {Ile }}$ were found to be degraded by a temperature shift from $70{ }^{\circ} \mathrm{C}$ to $80^{\circ} \mathrm{C}$ and heat-shock proteins were not synthesized efficiently [11].

At low temperatures (below $55^{\circ} \mathrm{C}$ ), in contrast, the $\Psi_{55}$ modification produced by TruB is essential for the survival of $T$. thermophilus [248]. The presence of $\Psi_{55}$ stabilizes both the local structure of the T-arm and the interaction of the T-arm with the D-arm in tRNA. The local rigidity in tRNA caused by $\Psi_{55}$ slows down the speeds of introducing modified nucleosides around $\Psi_{55}\left(\mathrm{Gm}_{18}, \mathrm{~m}^{5} \mathrm{~s}^{2} \mathrm{U}_{54}\right.$ and $\mathrm{m}^{1} \mathrm{~A}_{58}$ ), which maintains the flexibility of tRNA at low temperatures. The presence of $\mathrm{m}^{5} \mathrm{U}_{54}$ modification by TrmFO supports this effect of $\Psi_{55}$ [225].

It should be mentioned that $\mathrm{D}$ modifications are thought to bring flexibility to tRNA because $\mathrm{D}$ does not stack with other bases and brings about the $\mathrm{C} 2^{\prime}$-endo form of ribose [332]. However, a T. thermophilus disruptant strain of the $d u s A$ gene encoding tRNA $D_{20} / D_{20 a}$ synthase did not show growth retardation at $50,60,70$, or $80^{\circ} \mathrm{C}$, and abnormal modifications were not observed in tRNA from this strain [85]. Therefore, the function of $\mathrm{D}_{20}$ and $\mathrm{D}_{20 \mathrm{a}}$ modifications is unknown. Since DusA recognizes the interaction of T-arms and D-arms in tRNA [84], the stabilization of the L-shaped tRNA structure by other modified nucleosides is required for the efficient introduction of $D_{20}$ and $D_{20 a}$ at high temperatures [85]. Thus, $\mathrm{D}_{20}$ and $\mathrm{D}_{20 \mathrm{a}}$ are relatively late modifications in T. thermophilus tRNA.

Although the above network is a temperature adaptation system of T. thermophilus, it regulates the order in which modified nucleosides are introduced into tRNA. Similar networks have been found in mesophiles [333]. In Escherichia coli, for example, the 2'-O-methylation at position 34 by TrmL requires an $\mathrm{i}^{6} \mathrm{~A}_{37}$ modification [334]. However, the network in T. thermophilus is distinct because it regulates the structure of a three-dimensional core and many modifications in tRNA are related. One of the advantages of this system is that protein synthesis is not required. The response of the system is very rapid. It is possible that thermophilic archaea possess a similar network between modified nucleosides in tRNA and tRNA modification enzymes because some of them can also grow at a wide range of temperatures.

\subsection{Stabilization of tRNA Structure by 2'-O-Methylation}

Because 2'-O-methylation shifts the equilibrium of ribose puckering to the $\mathrm{C}^{\prime}$-endo form and enhances the hydrophobic interaction, this modification, when carried out at multiple positions, brings rigidity of tRNA. Furthermore, 2'-O-methylations prevents hydrolysis of phophodiester-bonds in tRNA at high temperatures. Therefore, $2^{\prime}-O$-methylations may prolong the half-lives of tRNA. Notably, there 
is a living organism in which tRNA is stabilized without $\mathrm{m}^{5} \mathrm{~s}^{2} \mathrm{U}_{54}$ modification. A hyper-thermophilic archaeon, Pyrodictium occultum can grow at $105^{\circ} \mathrm{C}$, and various $2^{\prime}-\mathrm{O}$-methylted nucleosides such as $\Psi \mathrm{m}, \mathrm{m}^{1} \mathrm{Im}$, and $\mathrm{m}^{2}{ }_{2} \mathrm{Gm}$ are present in its tRNA, but $\mathrm{s}^{2} \mathrm{U}$ and $\mathrm{m}^{5} \mathrm{~s}^{2} \mathrm{U}$ are not observed [97,98]. Notably, although the melting temperature of the P. occultum tRNA ${ }^{\text {Met }}$ transcript is $80^{\circ} \mathrm{C}$, that of the native tRNA ${ }^{\text {Met }}$ is more than $100{ }^{\circ} \mathrm{C}$ [323]. Thus, the melting temperature of P. occultum tRNA is increased by more than $20^{\circ} \mathrm{C}$ through a combination of numerous $2^{\prime}$-O-methylated nucleosides.

Methanopyrus kandleri can grow at more than $110^{\circ} \mathrm{C}$ and tRNAs from this archaeon contain many unique modifications such as $\mathrm{U}_{8}$ (the product of $\mathrm{C}_{8}$ to $\mathrm{U}_{8}$ editing) [16], ac ${ }^{6} \mathrm{~A}, \mathrm{~m}^{2,7} \mathrm{Gm}$, and methyl-hn ${ }^{6} \mathrm{~A}$ [100]. Furthermore, M. kandleri possesses 132 species of C/D-box guide RNAs [17], which suggests that RNAs are highly methylated by the L7Ae, Nop5, aFib, and C/D-box guide RNA system. In the case of M. kandleri, therefore, tRNA seems to be stabilized by unique modifications and 2'-O-methylations.

These observations suggest that living organisms can survive at more than $100{ }^{\circ} \mathrm{C}$ by a combination of 2'-O-methylations and other thermophile-specific tRNA modifications.

\subsection{Other tRNA Stabilization Factors}

RNA binding proteins, polyamines, magnesium ions, and potassium ions are all able to stabilize tRNA in thermophiles. For example, transfer RNA-binding protein 111 (Trbp111) is an RNA-binding protein that is observed only in A. aeolicus [335-337]. A. aeolicus can grow at $94{ }^{\circ} \mathrm{C}$ and modified nucleosides in tRNA of this hyperthermophilic eubacterium are not so different from those in tRNA from $T$. thermophilus, which grows at temperatures below $83^{\circ} \mathrm{C}$. Therefore, Trbp 111 may provide more than $10^{\circ} \mathrm{C}$ of tRNA stabilization in A. aeolicus. The docking model of Trbp 111 and tRNA suggests that Trbp111 stabilizes the three-dimensional core of tRNA [336]. Archease is another tRNA-binding protein that can change the methylation site of P. abyssi Trm4 [209]. Furthermore, archease promotes the ligation of tRNA exons during tRNA splicing $[338,339]$. Therefore, it has the potential to stabilize the tRNA structure at high temperatures.

Many tRNA-binding proteins and RNA chaperone proteins have been identified in eukaryotic cells $[340,341]$. Although these types of protein are unknown in thermophilic eukaryotes, some of them may stabilize the tRNA structure (or help correct folding of tRNA) at high temperatures. Recently, it was revealed that $E$. coli TruB (tRNA $\Psi_{55}$ synthase [243]) possesses an RNA chaperone activity [342,343]. In the case of $T$. thermophilus, although the $\Psi_{55}$ modification is required for survival at low temperatures (below $55^{\circ} \mathrm{C}$ ), the truB gene disruptant strain shows abnormal growth at $80^{\circ} \mathrm{C}$ [248]. Therefore, the RNA chaperone effect of TruB may also be expressed at high temperatures in T. thermophilus. Furthermore, these observations suggest that other tRNA modification enzymes have the potential to work as RNA chaperones.

In general, polyamines have the potential to interact with nucleic acids and phospholipids because they possess multiple positive charges and hydrophobic areas. There are several studies on the interaction between tRNA and polyamines [344-347]. Thermophiles produce unique polyamines including long and branched polyamines [348-351]. Therefore, polyamines probably contribute to stabilize the tRNA structure at high temperatures. Furthermore, in vitro studies have shown that thermophile-specific long and branched polyamines affect the activities of several tRNA modification enzymes [81,352]. For example, TrmH from T. thermophilus methylates tRNA transcript at $80^{\circ} \mathrm{C}$ only in the presence of long or branched polyamines [81]. Moreover, the long and branched polyamines are required for the maintenance of several tRNAs and the 70S ribosome and are essential for the survival of T. thermophilus at high temperatures [353].

Lastly, magnesium ions have been shown to be a tRNA stabilization factor $[6,88,354]$ and are very important when considering the structural effects of several modified nucleosides in tRNA [58,88,354-356]. However, the precise concentration of magnesium ions in thermophile cells is unknown. It may differ depending on the growth environments. Potassium ions also function as RNA stabilization factor [88]. Notably, the interacellular concentration of some hyperthermophilic archaea 
(M. fervidus and P. furiosus) is much higher (700-900 $\mathrm{mM}$ ) than that of mesophilic archaea [357]. In the case of Methanothermus sociabilis, the interacellular potassium concentration reaches $1060 \mathrm{mM}$ [357]. These high concentrations of potassium ions may have effects on the stability of tRNA and the activities of tRNA modification enzymes.

\section{5. tRNA Modifications and Environmental Stresses at High Temperatures}

Recent studies have revealed that the modifications in tRNA are stress-resistance and/or stress-response factors [102,358-361]. Furthermore, a high temperature itself can be a stress factor for living organisms because some modified nucleosides $\left(D\right.$ and $\left.m^{7} G\right)$ are liable at high temepratures [297].

\subsection{Oxidative Stress}

Many thermophiles can grow under aerobic conditions. For example, Aerophyrum pernix can grow at $100{ }^{\circ} \mathrm{C}$ under aerobic conditions. Under such conditions at high temperatures, living organisms seem to be exposed to heavy oxidative stress, which is a typical environmental stress. The amount of antioxidant enzymes such as superoxide-dismutase, catalase, and peroxidase in Thermus filiformis, which is an extreme-thermophilic eubacterium, increases at high temperatures [362].

Among tRNA modification enzymes, both Fe-S cluster proteins [34,130,134,142,150,173,196,236,363] for sulfur-transfer, reduction of base and/or radical S-adenosyl-1-methionine (SAM) reaction, and enzymes with catalytic cysteine residues [141,210,364-366], seem to be easily changed under oxidative stress. In some cases, the substrate (e.g., electron donors and folate derivatives $[126,221,227,367])$ may be unstable under aerobic conditions at high temperatures. Similarly, several modified nucleosides such as $\mathrm{D}$ and $\mathrm{s}^{4} \mathrm{U}$ may be labile under oxidative stress at high temperatures. Therefore, aerobic thermophiles need to protect their cellular components from oxidative stress and their tRNA modifications may respond to such stress as in mesophiles. Overall, however, the relationship between oxidative stress and tRNA modifications in thermopiles is unclear. In addition, tRNA modification systems in some thermophiles may utilize aerobic conditions at high temperatures. For example, A. aeolicus grows under microaerophilic conditions at high temperatures $\left(80-94^{\circ} \mathrm{C}\right)$ and the dimer structure of A. aeolicus TrmD is stabilized by inter-subunit disulfide bonds [165].

\subsection{Other Environmental Stresses}

Thermophiles often live in severe environments such as extreme $\mathrm{pH}$ and high pressure in addition to high temperatures. These environmental stresses may give rise to the diversity of tRNA modifications. At present, however, there are no data to support this viewpoint.

UV-stress is one such environmental stress and the $s^{4} U$ modification in tRNA is a known UV-stress-resistance factor for E. coli [368] and Salmonella typhimurium [27]. Thus, the $\mathrm{s}^{4} \mathrm{U}$ modification in tRNA is likely to work similarly to a UV-resistant factor in thermophiles. Interestingly, the genomes of Archaeoglobus fulgidus and Methanocaldococcus janaschii, which were isolated from the oil mines under the sea and deep sea, respectively, contain a thiI genes [369] (AF_RS04455 and MJ_RS04985, respectively) encoding tRNA $s^{4} U_{8}$ synthetase. Since sunlight does not reach the environments in which these thermophilic archaea live, the $\mathrm{s}^{4} \mathrm{U}$ modification and/or Thil may have an additional function (e.g., sulfur-metabolism) in these archaea. Furthermore, it was recently reported that the melting temperature of tRNA from an E. coli thiI-gene disruptant strain was decreased relative to the wild-type strain [33]. Therefore, the $s^{4} U_{8}$ modification may contribute to stabilize tRNA structure. Furthermore, UV-stress may have an effect on other tRNA modifications via the cross-linking of $s^{4} U$ in tRNA. For example, the methylation speed of T. thermophilus TrmH is decreased when the substrate tRNA is cross-linked [30].

Lastly, the availability of nutrient-factors may have an effect on tRNA modifications in thermophiles. To test this idea, the extent of modifications in tRNA from T. thermophilus cells cultured in a nutrient-poor condition was investigated [227]. Contrary to expectation, the extent of the modification of all methylated nucleosides analyzed was normal, which demonstrates that the limited nutrients 
were preferentially consumed in the tRNA modification systems [227]. Thus, the findings indicated the importance of tRNA modifications for the survival of T. thermophilus.

\section{Utilization of tRNA Modification Enzymes from Thermophiles}

Given that proteins from thermophiles are heat-resistant and very stable, numerous tRNA modification enzymes have been used in biochemical and structural studies (Tables 1 and 2). In particular, crystal structural studies of thermostable enzymes provided significant information on catalytic mechanisms and RNA-protein interactions. Studies on the crystal structures of tRNA modification enzymes from thermophiles are summarized in Supplementary Table S2. It is anticipated that thermostable proteins will continue to contribute structural studies in the future. Thermostable tRNA modification enzymes can be a tool for molecular and cell biology. For example, A. fulgidus TiaS with agmatine analogues has been used for site-specific RNA-labeling in mammalian cells [315]. In addition, thermostable tRNA modification enzymes may be used for healthcare. For example, $\mathrm{Gm}_{18}$ modification in tRNA does not stimulate the Toll-like receptor $7[287,288]$ and tRNA with $\mathrm{Gm}_{18}$ alleviates inflammation [288]. Since TrmH from T. thermophilus can methylate all tRNA species [72] and is very stable, it may be useful for preparing tRNAs with $\mathrm{Gm}_{18}$ modifications for tRNA therapy.

\section{Perspective}

Given that the temperature of ancient Earth was very high relative to that of present-day Earth, thermophiles may be remnants of ancient living organisms. Therefore, studies on tRNA modification enzymes and modified nucleosides in tRNA from thermophiles will contribute to the considerations of the evolutionary pathways of living organisms. Furthermore, such studies will continue to shed light on the variety and environmental adaptations of living organisms. Moreover, as outlined above, the thermostable enzymes may be useful as biotechnological and medical tools and may contribute toward the production of valuable materials.

Supplementary Materials: The following are available online at http:/ /www.mdpi.com/2076-2607/6/4/110/s1, Table S1: Abbreviations of modified nucleosides, Table S2: Crystal structural studies on tRNA modification enzymes from thermophiles.

Author Contributions: All authors determined the concept of this review and collected the information from the references. H.H. wrote the manuscript and all authors revised and approved the manuscript.

Funding: This work was supported by a Grant-in-Aid for Scientific Research (16H04763 to H.H.) from the Japan Society for the Promotion of Science (JSPS).

Acknowledgments: We dedicate this review to Kimitsuna Watanabe who died in 2016. He discovered the $\mathrm{m}^{5} \mathrm{~s}^{2} \mathrm{U}_{54}$ modification in tRNA and encouraged our studies. We thank previous collaborators.

Conflicts of Interest: The authors declare no conflict of interest.

\section{References}

1. Crick, F.H. On protein synthesis. Symp. Soc. Exp. Biol. 1958, 12, 138-163. [PubMed]

2. Grunberger, D.; Weinstein, I.B.; Jacobson, K.B. Codon recognition by enzymatically mischarged valine transfer ribonucleic acid. Science 1969, 166, 1635-1637. [CrossRef] [PubMed]

3. Sprinzl, M.; Horn, C.; Brown, M.; Ioudovitch, A.; Steinberg, S. Compilation of tRNA sequences and sequences of tRNA genes. Nucleic Acids Res. 1998, 26, 148-153. [CrossRef] [PubMed]

4. Robertus, J.D.; Ladner, J.E.; Finch, J.T.; Rhodes, D.; Brown, R.S.; Clark, B.F.C.; Klug, A. Structure of yeast phenylalanine tRNA at $3 \AA$ resolution. Nature 1974, 250, 546-551. [CrossRef] [PubMed]

5. Kim, S.H.; Suddath, F.L.; Quigley, G.J.; McPherson, A.; Sussan, J.L.; Wang, A.H.J.; Seeman, N.C.; Rich, A. Three-dimensional tertiary structure of yeast phenylalanine transfer RNA. Science 1974, 185, 435-440. [CrossRef] [PubMed]

6. Shi, H.; Moore, P.B. The crystal structure of yeast phenylalanine tRNA at 1.93 A resolution: A classic structure revisited. RNA 2000, 6, 1091-1105. [CrossRef] [PubMed] 
7. Boccaletto, P.; Machnicka, M.A.; Purta, E.; Piatkowski, P.; Baginski, B.; Wirecki, T.K.; de Crécy-Lagard, V.; Ross, R.; Limbach, P.A.; Kotter, A.; et al. MODOMICS: A database of RNA modification pathways. 2017 update. Nucleic Acids Res 2018, 46, D303-D307. [CrossRef] [PubMed]

8. Juhling, F.; Morl, M.; Hartmann, R.K.; Sprinzl, M.; Stadler, P.F.; Putz, J. tRNAdb 2009: Compilation of tRNA sequences and tRNA genes. Nucleic Acids Res. 2009, 37, D159-D162. [CrossRef] [PubMed]

9. Constantinesco, F.; Motorin, Y.; Grosjean, H. Transfer RNA modification enzymes from Pyrococcus furiosus: Detection of the enzymatic activities in vitro. Nucleic Acids Res. 1999, 27, 1308-1315. [CrossRef] [PubMed]

10. Grawunder, U.; Schön, A.; Sprintzl, M. Sequence and base modifications of two phenylalanine-tRNAs from Thermus thermophilus HB8. Nucleic Acids Res. 1992, 20, 137. [CrossRef] [PubMed]

11. Tomikawa, C.; Yokogawa, T.; Kanai, T.; Hori, H. $N^{7}$-Methylguanine at position $46\left(\mathrm{~m}^{7} \mathrm{G} 46\right)$ in tRNA from Thermus thermophilus is required for cell viability through a tRNA modification network. Nucleic Acids Res. 2010, 38, 942-957. [CrossRef] [PubMed]

12. Menezes, S.; Gaston, K.W.; Krivos, K.L.; Apolinario, E.E.; Reich, N.O.; Sowers, K.R.; Limbach, P.A.; Perona, J.J. Formation of $\mathrm{m}^{2} \mathrm{G} 6$ in Methanocaldococcus jannaschii tRNA catalyzed by the novel methyltransferase Trm14. Nucleic Acids Res. 2011, 39, 7641-7655. [CrossRef] [PubMed]

13. Fislage, M.; Roovers, M.; Münnich, S.; Droogmans, L.; Versées, W. Crystallization and preliminary X-ray crystallographic analysis of putative tRNA-modification enzymes from Pyrococcus furiosus and Thermus thermophilus. Acta Crystallogr. Sect. F Struct. Biol. Cryst. Commun. 2011, 67, 1432-1435. [CrossRef] [PubMed]

14. Roovers, M.; Oudjama, Y.; Fislage, M.; Bujnicki, J.M.; Versées, W.; Droogmans, L. The open reading frame TTC1157 of Thermus thermophilus HB27 encodes the methyltransferase forming $N^{2}$-methylguanosine at position 6 in tRNA. RNA 2012, 18, 815-824. [CrossRef] [PubMed]

15. Fislage, M.; Roovers, M.; Tuszynska, I.; Bujnicki, J.M.; Droogmans, L.; Versées, W. Crystal structures of the tRNA:m² G6 methyltransferase Trm14/TrmN from two domains of life. Nucleic Acids Res. 2012, 40, 5149-5161. [CrossRef] [PubMed]

16. Randau, L.; Stanley, B.J.; Kohlway, A.; Mechta, S.; Xiong, Y.; Söll, D. A cytidine deaminase edits C to U in transfer RNAs in Archaea. Science 2009, 324, 657-659. [CrossRef] [PubMed]

17. Su, A.A.; Tripp, V.; Randau, L. RNA-Seq analyses reveal the order of tRNA processing events and the maturation of C/D box and CRISPR RNAs in the hyperthermophile Methanopyrus kandleri. Nucleic Acids Res. 2013, 41, 6250-6258. [CrossRef] [PubMed]

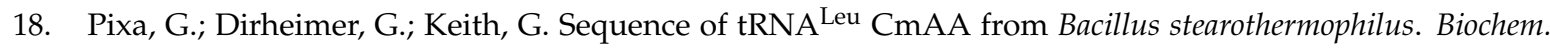
Biophys. Res. Commun. 1983, 112, 578-585. [CrossRef]

19. Keith, G.; Guerrier-Takada, C.; Grosjean, H.; Dirheimer, G. A revised sequence for Bacillus stearothermophilus phenylalanine tRNA. FEBS Lett. 1977, 84, 241-243. [CrossRef]

20. Brown, R.S.; Rubin, J.R.; Rhodes, D.; Guilley, H.; Simoncsits, A.; Brownlee, G.G. The nucleoside sequence of tyrosine tRNA from Bacillus stearothermophilus. Nucleic Acids Res. 1978, 5, 23-36. [CrossRef] [PubMed]

21. Watanabe, K.; Kuchino, Y.; Yamaizumi, Z.; Kato, M.; Oshima, T.; Nishimura, S. Nucleotide sequence of formylmethionine tRNA from an extreme thermophile, Thermus thermophilus HB8. J. Biochem. 1979, 86, 893-905. [CrossRef] [PubMed]

22. Watanabe, K.; Oshima, T.; Hansske, F.; Ohta, T. Separation and comparison of 2-thioribothymidine-containing transfer ribonucleic acid and the ribothymidine-containing counterpart from cells of Thermus thermophilus HB 8. Biochemistry 1983, 22, 98-102. [CrossRef] [PubMed]

23. Keith, G.; Yusupov, M.; Briand, C.; Moras, D.; Kern, D.; Brion, C. Sequence of tRNA ${ }^{\text {Asp }}$ from Thermus thermophilus HB8. Nucleic Acids Res. 1993, 21, 4399. [CrossRef] [PubMed]

24. Awai, T.; Kimura, S.; Tomikawa, C.; Ochi, A.; Ihsanawati, I.S.; Bessho, Y.; Yokoyama, S.; Ohno, S.; Nishikawa, K.; Yokogawa, T.; et al. Aquifex aeolicus tRNA $\left(N^{2}, N^{2}\right.$-guanine)-dimethyltransferase (Trm1) catalyzes transfer of methyl groups not only to guanine 26 but also to guanine 27 in tRNA. J. Biol. Chem. 2009, 284, 20467-20478. [CrossRef] [PubMed]

25. Kilpatrick, M.W.; Walker, R.T. The nucleotide sequence of the $\mathrm{tRNA}_{\mathrm{M}}{ }^{\mathrm{Met}}$ from the archaebacterium Thermoplasma acidophilum. Nucleic Acids Res. 1981, 9, 4387-4390. [CrossRef] [PubMed]

26. Caldeira de Araujo, A.; Favre, A. Induction of size reduction in Escherichia coli by near-ultraviolet light. Eur. J. Biochem. 1985, 146, 605-610. [CrossRef] [PubMed] 
27. Kramer, G.F.; Baker, J.C.; Ames, B.N. Near-UV stress in Salmonella typhimurium: 4-thiouridine in tRNA, ppGpp, and ApppGpp as components of an adaptive response. J. Bacteriol. 1988, 170, 2344-2351. [CrossRef] [PubMed]

28. Mueller, E.G.; Buck, C.J.; Palenchar, P.M.; Barnhart, L.E.; Paulson, J.L. Identification of a gene involved in the generation of 4-thiouridine in tRNA. Nucleic Acids Res. 1998, 26, 2060-2610. [CrossRef]

29. Kambampati, R.; Lauhon, C.T. IscS is a sulfurtransferase for the in vitro biosynthesis of 4-thiouridine in Escherichia coli tRNA. Biochemistry 1999, 38, 16561-16568. [CrossRef] [PubMed]

30. Hori, H.; Saneyoshi, M.; Kumagai, I.; Miura, K.; Watanabe, K. Effects of modification of 4-thiouridine in E. coli RRNA $_{\mathrm{f}}^{\mathrm{Met}}$ on its methyl acceptor activity by thermostable Gm-methylases. J. Biochem. 1989, 106, 798-802. [CrossRef] [PubMed]

31. Naumann, P.T.; Lauhon, C.T.; Ficner, R. Purification, crystallization and preliminary crystallographic analysis of a 4-thiouridine synthetase-RNA complex. Acta Crystallogr. Sect. F Struct. Biol. Cryst. Commun. 2013, 69, 421-424. [CrossRef] [PubMed]

32. Neumann, P.; Lakomek, K.; Naumann, P.T.; Erwin, W.M.; Lauhon, C.T.; Ficner, R. Crystal structure of a 4-thiouridine synthetase-RNA complex reveals specificity of tRNA U8 modification. Nucleic Acids Res. 2014, 42, 6673-6685. [CrossRef] [PubMed]

33. Nomura, Y.; Ohno, S.; Nishikawa, K.; Yokogawa, T. Correlation between the stability of tRNA tertiary structure and the catalytic efficiency of a tRNA-modifying enzyme, archaeal tRNA-guanine transglycosylase. Genes Cells 2016, 21, 41-52. [CrossRef] [PubMed]

34. Liu, Y.; Vinyard, D.J.; Reesbeck, M.E.; Suzuki, T.; Manakongtreecheep, K.; Holland, P.L.; Brudvig, G.W.; Söll, D. A [3Fe-4S] cluster is required for tRNA thiolation in archaea and eukaryotes. Proc. Natl. Acad. Sci. USA 2016, 113, 12703-12708. [CrossRef] [PubMed]

35. Čavužić, M.; Liu, Y. Biosynthesis of sulfur-containing tRNA modifications: A comparison of bacterial, archaeal, and eukaryotic pathways. Biomolecules 2017, 7, 27. [CrossRef] [PubMed]

36. Tomikawa, C.; Ohira, T.; Inoue, Y.; Kawamura, T.; Yamagishi, A.; Suzuki, T.; Hori, H. Distinct tRNA modifications in the thermo-acidophilic archaeon, Thermoplasma acidophilum. FEBS Lett. 2013, 587, 3537-3580. [CrossRef] [PubMed]

37. Kempenaers, M.; Roovers, M.; Oudjama, Y.; Tkaczuk, K.L.; Bujnicki, J.M.; Droogmans, L. New archaeal methyltransferases forming 1-methyladenosine or 1-methyladenosine and 1-methylguanosine at position 9 of tRNA. Nucleic Acids Res. 2010, 38, 6533-6543. [CrossRef] [PubMed]

38. Van Laer, B.; Roovers, M.; Wauters, L.; Kasprzak, J.M.; Dyzma, M.; Deyaert, E.; Kumar Singh, R.; Feller, A.; Bujnicki, J.M.; Droogmans, L.; et al. Structural and functional insights into tRNA binding and adenosine $N^{1}$-methylation by an archaeal Trm10 homologue. Nucleic Acids Res. 2016, 44, 940-953. [CrossRef] [PubMed]

39. Singh, R.K.; Feller, A.; Roovers, M.; Van Elder, D.; Wauters, L.; Droogmans, L.; Versées, W. Structural and biochemical analysis of the dual-specificity Trm10 enzyme from Thermococcus kodakaraensis prompts reconsideration of its catalytic mechanism. RNA 2018, 24, 1080-1092. [CrossRef] [PubMed]

40. Armengaud, J.; Urbonavicius, J.; Fernandez, B.; Chaussinand, G.; Bujnicki, J.M.; Grosjean, H. N²-methylation of guanosine at position 10 in tRNA is catalyzed by a THUMP domain-containing, S-adenosylmethioninedependent methyltransferase, conserved in Archaea and Eukaryota. J. Biol. Chem. 2004, 279, 37142-37152. [CrossRef] [PubMed]

41. Gabant, G.; Auxilien, S.; Tuszynska, I.; Locard, M.; Gajda, M.J.; Chaussinand, G.; Fernandez, B.; Dedieu, A.; Grosjean, H.; Golinelli-Pimpaneau, B.; et al. THUMP from archaeal tRNA:m ${ }_{2} \mathrm{G} 10$ methyltransferase, a genuine autonomously folding domain. Nucleic Acids Res. 2006, 34, 2483-2494. [CrossRef] [PubMed]

42. Urbonavicius, J.; Armengaud, J.; Grosjean, H. Identity elements required for enzymatic formation of $\mathrm{N}^{2}, \mathrm{~N}^{2}$-dimethylguanosine from $\mathrm{N}^{2}$-monomethylated derivative and its possible role in avoiding alternative conformations in archaeal tRNA. J. Mol. Biol. 2006, 357, 387-399. [CrossRef] [PubMed]

43. Hirata, A.; Nishiyama, S.; Tamura, T.; Yamauchi, A.; Hori, H. Structural and functional analyses of the archaeal tRNA ${ }^{2} \mathrm{G} / \mathrm{m}^{2}{ }_{2} \mathrm{G} 10$ methyltransferase aTrm11 provide mechanistic insights into site specificity of a tRNA methyltransferase that contains common RNA-binding modules. Nucleic Acids Res. 2016, 44, 6377-6390. [CrossRef] [PubMed]

44. Kuchino, Y.; Ihara, M.; Yabusaki, Y.; Nishimura, S. Initiator tRNAs from archaebacteria show common unique sequence characteristics. Nature 1982, 298, 684-685. [CrossRef] [PubMed] 
45. Kaya, Y.; Ofengand, J. A novel unanticipated type of pseudouridine synthase with homologs in bacteria, archaea, and eukarya. RNA 2003, 9, 711-721. [CrossRef] [PubMed]

46. Muller, S.; Urban, A.; Hecker, A.; Leclerc, F.; Branlant, C.; Motorin, Y. Deficiency of the tRNATyr: Psi 35-synthase aPus7 in Archaea of the Sulfolobales order might be rescued by the H/ACA sRNA-guided machinery. Nucleic Acids Res. 2009, 37, 1308-1322. [CrossRef] [PubMed]

47. Kawamura, T.; Hirata, A.; Ohno, S.; Nomura, Y.; Nagano, T.; Nameki, N.; Yokogawa, T.; Hori, H. Multisite-specific archaeosine tRNA-guanine transglycosylase (ArcTGT) from Thermoplasma acidophilum, a thermo-acidophilic archaeon. Nucleic Acids Res. 2016, 44, 1894-1908. [CrossRef] [PubMed]

48. Gupta, R. Halobacterium volcanii tRNAs. Identification of 41 tRNAs covering all amino acids, and the sequences of 33 class I tRNAs. J. Biol. Chem. 1984, 259, 9461-9471. [PubMed]

49. Gregson, J.M.; Crain, P.F.; Edmonds, C.G.; Gupta, R.; Hashizume, T.; Phillipson, D.W.; McCloskey, J.A. Structure of the archaeal transfer RNA nucleoside G*-15 (2-amino-4,7-dihydro-4-oxo-7-beta-D-ribofuranosyl1H-pyrrolo[2,3-d]pyrimidine-5-carboximi dam ide (archaeosine)). J. Biol. Chem. 1993, 268, 10076-10086. [PubMed]

50. Watanabe, M.; Matsuo, M.; Tanaka, S.; Akimoto, H.; Asahi, S.; Nishimura, S.; Katze, J.R.; Hashizume, T.; Crain, P.F.; McCloskey, J.A.; et al. Biosynthesis of archaeosine, a novel derivative of 7-deazaguanosine specific to archaeal tRNA, proceeds via a pathway involving base replacement on the tRNA polynucleotide chain. J. Biol. Chem. 1997, 272, 20146-20151. [CrossRef] [PubMed]

51. Bai, Y.; Fox, D.T.; Lacy, J.A.; Van Lanen, S.G.; Iwata-Reuyl, D. Hypermodification of tRNA in Thermophilic archaea. Cloning, overexpression, and characterization of tRNA-guanine transglycosylase from Methanococcus jannaschii. J. Biol. Chem. 2000, 275, 28731-28738. [CrossRef] [PubMed]

52. Watanabe, M.; Nameki, N.; Matsuo-Takasaki, M.; Nishimura, S.; Okada, N. tRNA recognition of tRNA-guanine transglycosylase from a hyperthermophilic archaeon, Pyrococcus horikoshii. J. Biol. Chem. 2001, 276, 2387-2394. [CrossRef] [PubMed]

53. Ishitani, R.; Nureki, O.; Kijimoto, T.; Watanabe, M.; Kondo, H.; Nameki, N.; Okada, N.; Nishimura, S.; Yokoyama, S. Crystallization and preliminary X-ray analysis of the archaeosine tRNA-guanine transglycosylase from Pyrococcus horikoshii. Acta Crystallogr. D Biol. Crystallogr. 2001, 57, 1659-1662. [CrossRef] [PubMed]

54. Ishitani, R.; Nureki, O.; Fukai, S.; Kijimoto, T.; Nameki, N.; Watanabe, M.; Kondo, H.; Sekine, M.; Okada, N.; Nishimura, S.; et al. Crystal structure of archaeosine tRNA-guanine transglycosylase. J. Mol. Biol. 2002, 318, 665-677. [CrossRef]

55. Ishitani, R.; Nureki, O.; Fukai, S.; Kijimoto, T.; Nameki, N.; Watanabe, M.; Kondo, H.; Sekine, M.; Okada, N.; Nishimura, S.; et al. Alternative tertiary structure of tRNA for recognition by a posttranscriptional modification enzyme. Cell 2003, 113, 383-394. [CrossRef]

56. Noon, K.R.; Guymon, R.; Crain, P.F.; McCloskey, J.A.; Thomm, M.; Lim, J.; Cavicchioli, R. Influence of temperature on tRNA modification in archaea: Methanococcoides burtonii (optimum growth temperature [Topt], 23 degrees C) and Stetteria hydrogenophila (Topt, 95 degrees C). J. Bacteriol. 2003, 185, 5483-5490. [CrossRef] [PubMed]

57. Sabina, J.; Söll, D. The RNA-binding PUA domain of archaeal tRNA-guanine transglycosylase is not required for archaeosine formation. J. Biol. Chem. 2006, 281, 6993-7001. [CrossRef] [PubMed]

58. Oliva, R.; Tramontano, A.; Cavallo, L. $\mathrm{Mg}^{2+}$ binding and archaeosine modification stabilize the G15 C48 Levitt base pair in tRNAs. RNA 2007, 13, 1427-1436. [CrossRef] [PubMed]

59. Phillips, G.; Chikwana, V.M.; Maxwell, A.; El-Yacoubi, B.; Swairjo, M.A.; Iwata-Reuyl, D.; de Crécy-Lagard, V. Discovery and characterization of an amidinotransferase involved in the modification of archaeal tRNA. J. Biol. Chem. 2010, 285, 12706-12713. [CrossRef] [PubMed]

60. Phillips, G.; Swairjo, M.A.; Gaston, K.W.; Bailly, M.; Limbach, P.A.; Iwata-Reuyl, D.; de Crécy-Lagard, V. Diversity of archaeosine synthesis in crenarchaeota. ACS Chem. Biol. 2012, 7, 300-305. [CrossRef] [PubMed]

61. Nomura, Y.; Onda, Y.; Ohno, S.; Taniguchi, H.; Ando, K.; Oka, N.; Nishikawa, K.; Yokogawa, T. Purification and comparison of native and recombinant tRNA-guanine transglycosylases from Methanosarcina acetivorans. Protein Expr. Purif. 2013, 88, 13-19. [CrossRef] [PubMed]

62. Mei, X.; Alvarez, J.; Bon Ramos, A.; Samanta, U.; Iwata-Reuyl, D.; Swairjo, M.A. Crystal structure of the archaeosine synthase QueF-like-Insights into amidino transfer and tRNA recognition by the tunnel fold. Proteins 2017, 85, 103-116. [CrossRef] [PubMed] 
63. Bon Ramos, A.; Bao, L.; Turner, B.; de Crécy-Lagard, V.; Iwata-Reuyl, D. QueF-Like, a Non-homologous archaeosine synthase from the crenarchaeota. Biomolecules 2017, 7, 36. [CrossRef] [PubMed]

64. Takada-Guerrier, C.; Grosjean, H.; Dirheimer, G.; Keith, G. The primary structure of $\mathrm{tRNA}_{2}{ }^{\mathrm{Val}}$ from Bacillus stearothermophilus. FEBS Lett. 1976, 62, 1-3. [CrossRef]

65. Bishop, A.C.; Xu, J.; Johnson, R.C.; Schimmel, P.; de Crécy-Lagard, V. Identification of the tRNA-dihydrouridine synthase family. J. Biol. Chem. 2002, 277, 25090-25095. [CrossRef] [PubMed]

66. Bou-Nader, C.; Montémont, H.; Guérineau, V.; Jean-Jean, O.; Brégeon, D.; Hamdane, D. Unveiling structural and functional divergences of bacterial tRNA dihydrouridine synthases: Perspectives on the evolution scenario. Nucleic Acids Res. 2018, 46, 1386-1394. [CrossRef] [PubMed]

67. Horie, N.; Hara-Yokoyama, M.; Yokoyama, S.; Watanabe, K.; Kuchino, Y.; Nishimura, S.; Miyazawa, T. Two tRNA ${ }^{\text {Ile }} 1$ species from an extreme thermophile, Thermus thermophilus HB8: Effect of 2-thiolation of ribothymidine on the thermostability of tRNA. Biochemistry 1985, 24, 5711-5715. [CrossRef] [PubMed]

68. Persson, B.C.; Jäger, G.; Gustafsson, C. The spoU gene of Escherichia coli, the fourth gene of the spoT operon, is essential for tRNA (Gm18) 2'-O-methyltransferase activity. Nucleic Acids Res. 1997, 25, 4093-4097. [CrossRef] [PubMed]

69. Kumagai, I.; Watanabe, K.; Oshima, T. A thermostable tRNA (guanosine-2')-methyltransferase from Thermus. thermophilus HB27 and the effect of ribose methylation on the conformational stability of tRNA. J. Biol. Chem. 1982, 257, 7388-7395. [PubMed]

70. Matsumoto, T.; Ohta, T.; Kumagai, I.; Oshima, T.; Murao, K.; Hasegawa, T.; Ishikura, H.; Watanabe, K. A thermostable Gm-methylase recognizes the tertiary structure of tRNA. J. Biochem. 1987, 101, 1191-1198. [CrossRef] [PubMed]

71. Matsumoto, T.; Nishikawa, K.; Hori, H.; Ohta, T.; Miura, K.; Watanabe, K. Recognition sites of tRNA by a thermostable tRNA(guanosine-2'-)-methyltransferase from Thermus thermophilus HB27. J. Biochem. 1990, 107, 331-338. [CrossRef] [PubMed]

72. Hori, H.; Yamazaki, N.; Matsumoto, T.; Watanabe, Y.; Ueda, T.; Nishikawa, K.; Kumagai, I.; Watanabe, K. Substrate recognition of tRNA (Guanosine-2'-)-methyltransferase from Thermus thermophilus HB27. J. Biol. Chem. 1998, 273, 25721-25727. [CrossRef] [PubMed]

73. Hori, H.; Suzuki, T.; Sugawara, K.; Inoue, Y.; Shibata, T.; Kuramitsu, S.; Yokoyama, S.; Oshima, T.; Watanabe, K. Identification and characterization of tRNA (Gm18) methyltransferase from Thermus thermophilus HB8: Domain structure and conserved amino acid sequence motifs. Genes Cells 2002, 7, 259-272. [CrossRef] [PubMed]

74. Hori, H.; Kubota, S.; Watanabe, K.; Kim, J.M.; Ogasawara, T.; Sawasaki, T.; Endo, Y. Aquifex aeolicus tRNA (Gm18) methyltransferase has unique substrate specificity: tRNA recognition mechanism of the enzyme. J. Biol. Chem. 2003, 278, 25081-25090. [CrossRef] [PubMed]

75. Nureki, O.; Watanabe, K.; Fukai, S.; Ishii, R.; Endo, Y.; Hori, H.; Yokoyama, S. Deep knot structure for construction of active site and cofactor binding site of tRNA modification enzyme. Structure 2004, 12, 593-604. [CrossRef] [PubMed]

76. Watanabe, K.; Nureki, O.; Fukai, S.; Ishii, R.; Okamoto, H.; Yokoyama, S.; Endo, Y.; Hori, H. Roles of conserved amino acid sequence motifs in the SpoU (TrmH) RNA methyltransferase family. J. Biol. Chem. 2005, 280, 10368-10377. [CrossRef] [PubMed]

77. Pleshe, E.; Truesdell, J.; Batey, R.T. Structure of a class II TrmH tRNA-modifying enzyme from Aquifex aeolicus. Acta Crystallogr. Sect. F Struct. Biol. Cryst. Commun. 2005, 61, 722-728. [CrossRef] [PubMed]

78. Watanabe, K.; Nureki, O.; Fukai, S.; Endo, Y.; Hori, H. Functional categorization of the conserved basic amino acid residues in TrmH (tRNA (Gm18) methyltransferase) enzymes. J. Biol. Chem. 2006, 281, 34630-34639. [CrossRef] [PubMed]

79. Ochi, A.; Makabe, K.; Kuwajima, K.; Hori, H. Flexible recognition of the tRNA G18 methylation target site by TrmH methyltransferase through first binding and induced fit processes. J. Biol. Chem. 2010, 285, 9018-9029. [CrossRef] [PubMed]

80. Ochi, A.; Makabe, K.; Yamagami, R.; Hirata, A.; Sakaguchi, R.; Hou, Y.M.; Watanabe, K.; Nureki, O.; Kuwajima, K.; Hori, H. The catalytic domain of topological knot tRNA methyltransferase (TrmH) discriminates between substrate tRNA and nonsubstrate tRNA via an induced-fit process. J. Biol. Chem. 2013, 288, 25562-25574. [CrossRef] [PubMed] 
81. Hori, H.; Terui, Y.; Nakamoto, C.; Iwashita, C.; Ochi, A.; Watanabe, K.; Oshima, T. Effects of polyamines from Thermus thermophilus, an extreme-thermophilic eubacterium, on tRNA methylation by tRNA (Gm18) methyltransferase (TrmH). J. Biochem. 2016, 159, 509-517. [CrossRef] [PubMed]

82. Savage, D.F.; de Crécy-Lagard, V.; Bishop, A.C. Molecular determinants of dihydrouridine synthase activity. FEBS Lett. 2006, 580, 5198-5202. [CrossRef] [PubMed]

83. Yu, F.; Tanaka, Y.; Yamamoto, S.; Nakamura, A.; Kita, S.; Hirano, N.; Tanaka, I.; Yao, M. Crystallization and preliminary X-ray crystallographic analysis of dihydrouridine synthase from Thermus thermophilus and its complex with tRNA. Acta Crystallogr. Sect. F Struct. Biol. Cryst. Commun. 2011, 67, 685-688. [CrossRef] [PubMed]

84. Yu, F.; Tanaka, Y.; Yamashita, K.; Suzuki, T.; Nakamura, A.; Hirano, N.; Suzuki, T.; Yao, M.; Tanaka, I. Molecular basis of dihydrouridine formation on tRNA. Proc. Natl. Acad. Sci. USA 2011, 108, 19593-19598. [CrossRef] [PubMed]

85. Kusuba, H.; Yoshida, T.; Iwasaki, E.; Awai, T.; Kazayama, A.; Hirata, A.; Tomikawa, C.; Yamagami, R.; Hori, H. In vitro dihydrouridine formation by tRNA dihydrouridine synthase from Thermus thermophilus, an extreme-thermophilic eubacterium. J. Biochem. 2015, 158, 513-521. [PubMed]

86. Roovers, M.; Kaminska, K.H.; Tkaczuk, K.L.; Gigot, D.; Droogmans, L.; Bujnicki, J.M. The YqfN protein of Bacillus subtilis is the tRNA: $\mathrm{M}^{1} \mathrm{~A} 22$ methyltransferase (TrmK). Nucleic Acids Res. 2008, 36, 3252-3262. [CrossRef] [PubMed]

87. Blaby, I.K.; Majumder, M.; Chatterjee, K.; Jana, S.; Grosjean, H.; de Crécy-Lagard, V.; Gupta, R. Pseudouridine formation in archaeal RNAs: The case of Haloferax volcanii. RNA 2011, 17, 1367-1380. [CrossRef] [PubMed]

88. Lorenz, C.; Lünse, C.E.; Mörl, M. tRNA modifications: Impact on structure and thermal adaptation. Biomolecules 2017, 7, 35. [CrossRef] [PubMed]

89. Kawamura, T.; Anraku, R.; Hasegawa, T.; Tomikawa, C.; Hori, H. Transfer RNA methyltransferases from Thermoplasma acidophilum, a thermoacidophilic archaeon. Int. J. Mol. Sci. 2014, 16, 91-113. [CrossRef] [PubMed]

90. Phillips, J.H.; Kjellin-Straby, K. Studies on microbial ribonucleic acid. IV. Two mutants of Saccharomyces cerevisiae lacking N-2-dimethylguanine in soluble ribonucleic acid. J. Mol. Biol. 1967, 26, 509-518. [CrossRef]

91. Constantinesco, F.; Benachenhou, N.; Motorin, Y.; Grosjean, H. The tRNA(guanine-26, $\mathrm{N}^{2}-\mathrm{N}^{2}$ ) methyltransferase (Trm1) from the hyperthermophilic archaeon Pyrococcus furiosus: Cloning, sequencing of the gene and its expression in Escherichia coli. Nucleic Acids Res. 1998, 26, 3753-3761. [CrossRef] [PubMed]

92. Constantinesco, F.; Motorin, Y.; Grosjean, H. Characterisation and enzymatic properties of tRNA (guanine 26, N (2), N (2))-dimethyltransferase (Trm1p) from Pyrococcus furiosus. J. Mol. Biol. 1999, 291, 375-392. [CrossRef] [PubMed]

93. Ihsanawati; Nishimoto, M.; Higashijima, K.; Shirouzu, M.; Grosjean, H.; Bessho, Y.; Yokoyama, S. Crystal structure of tRNA N ${ }^{2}, \mathrm{~N}^{2}$-guanosine dimethyltransferase Trm1 from Pyrococcus horikoshii. J. Mol. Biol. 2008, 383, 871-884. [CrossRef] [PubMed]

94. Vakiloroayaei, A.; Shah, N.S.; Oeffinger, M.; Bayfield, M.A. The RNA chaperone La promotes pre-tRNA maturation via indiscriminate binding of both native and misfolded targets. Nucleic Acids Res. 2017, 45, 11341-11355. [CrossRef] [PubMed]

95. Awai, T.; Ochi, A.; Ihsanawati; Sengoku, T.; Hirata, A.; Bessho, Y.; Yokoyama, S.; Hori, H. Substrate tRNA recognition mechanism of a multisite-specific tRNA methyltransferase, Aquifex aeolicus Trm1, based on the X-ray crystal structure. J. Biol. Chem. 2011, 286, 35236-35246. [CrossRef] [PubMed]

96. Somme, J.; Van Laer, B.; Roovers, M.; Steyaert, J.; Versées, W.; Droogmans, L. Characterization of two homologous 2'-O-methyltransferases showing different specificities for their tRNA substrates. RNA 2014, 20, 1257-1271. [CrossRef] [PubMed]

97. Edmonds, C.G.; Crain, P.F.; Gupta, R.; Hashizume, T.; Hocart, C.H.; Kowalak, J.A.; Pomerantz, S.C.; Stetter, K.O.; McCloskey, J.A. Posttranscriptional modification of tRNA in Thermophilic archaea (Archaebacteria). J. Bacteriol. 1991, 173, 3138-3148. [CrossRef] [PubMed]

98. Kowalak, J.A.; Dalluge, J.J.; McCloskey, J.A.; Stetter, K.O. The role of posttranscriptional modification in stabilization of transfer RNA from Hyperthermophiles. Biochemistry 1994, 33, 7869-7876. [CrossRef] [PubMed] 
99. McCloskey, J.A.; Graham, D.E.; Zou, S.; Crain, P.F.; Ibba, M.; Konisky, J.; Soll, D.; Olsen, G.J. Post-transcriptional modification in archaeal tRNAs: Identities and phylogenetic relations of nucleotides from mesophilic and hyperthermophilic Methanococcales. Nucleic Acids Res. 2001, 29, 4299-4706. [CrossRef]

100. Sauerwald, A.; Sitaramaiah, D.; McCloskey, J.A.; Söll, D.; Crain, P.F. $N^{6}$-Acetyladenosine: A new modified nucleoside from Methanopyrus kandleri tRNA. FEBS Lett. 2005, 579, 2807-2810. [CrossRef] [PubMed]

101. Purta, E.; van Vliet, F.; Tkaczuk, K.L.; Dunin-Horkawicz, S.; Mori, H.; Droogmans, L.; Bujnicki, J.M. The $y f h Q$ gene of Escherichia coli encodes a tRNA: Cm32/Um32 methyltransferase. BMC Mol. Biol. 2006, 7, 23. [CrossRef] [PubMed]

102. Jaroensuk, J.; Atichartpongkul, S.; Chionh, Y.H.; Wong, Y.H.; Liew, C.W.; McBee, M.E.; Thongdee, N.; Prestwich, E.G.; DeMott, M.S.; Mongkolsuk, S.; et al. Methylation at position 32 of tRNA catalyzed by TrmJ alters oxidative stress response in Pseudomonas aeruginosa. Nucleic Acids Res. 2016, 44, 10834-10848. [CrossRef] [PubMed]

103. Wolf, J.; Gerber, A.P.; Keller, W. tadA, an essential tRNA-specific adenosine deaminase from Escherichia coli. EMBO J. 2002, 21, 3841-3851. [CrossRef] [PubMed]

104. Elias, Y.; Huang, R.H. Biochemical and structural studies of A-to-I editing by tRNA: A34 deaminases at the wobble position of transfer RNA. Biochemistry 2005, 44, 12057-12065. [CrossRef] [PubMed]

105. Kuratani, M.; Ishii, R.; Bessho, Y.; Fukunaga, R.; Sengoku, T.; Shirouzu, M.; Sekine, S.; Yokoyama, S. Crystal structure of tRNA adenosine deaminase (TadA) from Aquifex aeolicus. J. Biol. Chem. 2005, 280, 16002-16008. [CrossRef] [PubMed]

106. Yokobori, S.; Kitamura, A.; Grosjean, H.; Bessho, Y. Life without tRNAArg-adenosine deaminase TadA: Evolutionary consequences of decoding the four CGN codons as arginine in Mycoplasmas and other Mollicutes. Nucleic Acids Res. 2013, 41, 6531-6543. [CrossRef] [PubMed]

107. Torres, A.G.; Piñeyro, D.; Filonava, L.; Stracker, T.H.; Batlle, E.; Ribas de Pouplana, L. A-to-I editing on tRNAs: Biochemical, biological and evolutionary implications. FEBS Lett. 2014, 588, 4279-4286. [CrossRef] [PubMed]

108. Muramatsu, T.; Yokoyama, S.; Horie, N.; Matsuda, A.; Ueda, T.; Yamaizumi, Z.; Kuchino, Y.; Nishimura, S.; Miyazawa, T. A novel lysine-substituted nucleoside in the first position of the anticodon of minor isoleucine tRNA from Escherichia coli. J. Biol. Chem. 1988, 263, 9261-9267. [PubMed]

109. Muramatsu, T.; Nishikawa, K.; Nemoto, F.; Kuchino, Y.; Nishimura, S.; Miyazawa, T.; Muramatsu, T.; Nishikawa, K.; Nemoto, F.; Kuchino, Y.; et al. Codon and amino-acid specificities of a transfer RNA are both converted by a single post-transcriptional modification. Nature 1988, 336, 179-181. [CrossRef] [PubMed]

110. Soma, A.; Ikeuchi, Y.; Kanemasa, S.; Kobayashi, K.; Ogasawara, N.; Ote, T.; Kato, J.; Watanabe, K.; Sekine, Y.; Suzuki, T. An RNA-modifying enzyme that governs both the codon and amino acid specificities of isoleucine tRNA. Mol. Cell 2003, 12, 689-698. [CrossRef]

111. Nakanishi, K.; Fukai, S.; Ikeuchi, Y.; Soma, A.; Sekine, Y.; Suzuki, T.; Nureki, O. Structural basis for lysidine formation by ATP pyrophosphatase accompanied by a lysine-specific loop and a tRNA-recognition domain. Proc. Natl. Acad. Sci. USA 2005, 102, 7487-7492. [CrossRef] [PubMed]

112. Kuratani, M.; Yoshikawa, Y.; Bessho, Y.; Higashijima, K.; Ishii, T.; Shibata, R.; Takahashi, S.; Yutani, K.; Yokoyama, S. Structural basis of the initial binding of tRNA(Ile) lysidine synthetase TilS with ATP and L-lysine. Structure 2007, 15, 1642-1653. [CrossRef] [PubMed]

113. Nakanishi, K.; Bonnefond, L.; Kimura, S.; Suzuki, T.; Ishitani, R.; Nureki, O. Structural basis for translational fidelity ensured by transfer RNA lysidine synthetase. Nature 2009, 461, 1144-1148. [CrossRef] [PubMed]

114. Suzuki, T.; Numata, T. Convergent evolution of AUA decoding in bacteria and archaea. RNA Biol. 2014, 11, 1586-1596. [CrossRef] [PubMed]

115. Numata, T. Mechanisms of the tRNA wobble cytidine modification essential for AUA codon decoding in prokaryotes. Biosci. Biotechnol. Biochem. 2015, 79, 347-353. [CrossRef] [PubMed]

116. Ikeuchi, Y.; Kimura, S.; Numata, T.; Nakamura, D.; Yokogawa, T.; Ogata, T.; Wada, T.; Suzuki, T.; Suzuki, T. Agmatine-conjugated cytidine in a tRNA anticodon is essential for AUA decoding in archaea. Nat. Chem. Biol. 2010, 6, 277-282. [CrossRef] [PubMed]

117. Mandal, D.; Köhrer, C.; Su, D.; Russell, S.P.; Krivos, K.; Castleberry, C.M.; Blum, P.; Limbach, P.A.; Söll, D.; RajBhandary, U.L. Agmatidine, a modified cytidine in the anticodon of archaeal tRNA(Ile), base pairs with adenosine but not with guanosine. Proc. Natl. Acad. Sci. USA 2010, 107, 2872-2877. [CrossRef] [PubMed] 
118. Terasaka, N.; Kimura, S.; Osawa, T.; Numata, T.; Suzuki, T. Biogenesis of 2-agmatinylcytidine catalyzed by the dual protein and RNA kinase TiaS. Nat. Struct. Mol. Biol. 2011, 18, 1268-1274. [CrossRef] [PubMed]

119. Osawa, T.; Kimura, S.; Terasaka, N.; Inanaga, H.; Suzuki, T.; Numata, T. Structural basis of tRNA agmatinylation essential for AUA codon decoding. Nat. Struct. Mol. Biol. 2011, 18, 1275-1280. [CrossRef] [PubMed]

120. Voorhees, R.M.; Mandal, D.; Neubauer, C.; Köhrer, C.; RajBhandary, U.L.; Ramakrishnan, V. The structural basis for specific decoding of AUA by isoleucine tRNA on the ribosome. Nat. Struct. Mol. Biol. 2013, 20, 641-643. [CrossRef] [PubMed]

121. Yamanaka, K.; Hwang, J.; Inouye, M. Characterization of GTPase activity of TrmE, a member of a novel GTPase superfamily, from Thermotoga maritima. J. Bacteriol. 2000, 182, 7078-7082. [CrossRef] [PubMed]

122. Urbonavicius, J.; Qian, Q.; Durand, J.M.; Hagervall, T.G.; Björk, G.R. Improvement of reading frame maintenance is a common function for several tRNA modifications. EMBO J. 2001, 20, 4863-4873. [CrossRef] [PubMed]

123. Urbonavicius, J.; Stahl, G.; Durand, J.M.; Ben Salem, S.N.; Qian, Q.; Farabaugh, P.J.; Björk, G.R. Transfer RNA modifications that alter +1 frameshifting in general fail to affect -1 frameshifting. RNA 2003, 9, 760-768. [CrossRef] [PubMed]

124. Takai, K.; Yokoyama, S. Roles of 5-substituents of tRNA wobble uridines in the recognition of purine-ending codons. Nucleic Acids Res. 2003, 31, 6383-6391. [CrossRef] [PubMed]

125. Bujnicki, J.M.; Oudjama, Y.; Roovers, M.; Owczarek, S.; Caillet, J.; Droogmans, L. Identification of a bifunctional enzyme MnmC involved in the biosynthesis of a hypermodified uridine in the wobble position of tRNA. RNA 2004, 18, 1236-1242. [CrossRef] [PubMed]

126. Armengod, M.E.; Moukadiri, I.; Prado, S.; Ruiz-Partida, R.; Benítez-Páez, A.; Villarroya, M.; Lomas, R.; Garzón, M.J.; Martínez-Zamora, A.; Meseguer, S.; Navarro-González, C. Enzymology of tRNA modification in the bacterial MnmEG pathway. Biochimie 2012, 94, 1510-1520. [CrossRef] [PubMed]

127. Moukadiri, I.; Garzón, M.J.; Björk, G.R.; Armengod, M.E. The output of the tRNA modification pathways controlled by the Escherichia coli MnmEG and MnmC enzymes depends on the growth conditions and the tRNA species. Nucleic Acids Res. 2014, 42, 2602-2623. [CrossRef] [PubMed]

128. Armengod, M.E.; Meseguer, S.; Villarroya, M.; Prado, S.; Moukadiri, I.; Ruiz-Partida, R.; Garzón, M.J.; Navarro-González, C.; Martínez-Zamora, A. Modification of the wobble uridine in bacterial and mitochondrial tRNAs reading NNA/NNG triplets of 2-codon boxes. RNA Biol. 2014, 11, 1495-1507. [CrossRef] [PubMed]

129. Kalhor, H.R.; Clarke, S. Novel methyltransferase for modified uridine residues at the wobble position of tRNA. Mol. Cell Biol. 2003, 23, 9283-9292. [CrossRef] [PubMed]

130. Huang, B.; Johansson, M.J.; Byström, A.S. An early step in wobble uridine tRNA modification requires the Elongator complex. RNA 2005, 11, 424-436. [CrossRef] [PubMed]

131. Begley, U.; Dyavaiah, M.; Patil, A.; Rooney, J.P.; DiRenzo, D.; Young, C.M.; Conklin, D.S.; Zitomer, R.S.; Begley, T.J. Trm9-catalyzed tRNA modifications link translation to the DNA damage response. Mol. Cell 2007, 28, 860-870. [CrossRef] [PubMed]

132. Mazauric, M.H.; Dirick, L.; Purushothaman, S.K.; Björk, G.R.; Lapeyre, B. Trm112p is a 15-kDa zinc finger protein essential for the activity of two tRNA and one protein methyltransferases in yeast. J. Biol. Chem. 2010, 285, 18505-18515. [CrossRef] [PubMed]

133. Chavarria, N.E.; Hwang, S.; Cao, S.; Fu, X.; Holman, M.; Elbanna, D.; Rodriguez, S.; Arrington, D.; Englert, M.; Uthandi, S.; et al. Archaeal Tuc1/Ncs6 homolog required for wobble uridine tRNA thiolation is associated with ubiquitin-proteasome, translation, and RNA processing system homologs. PLoS ONE 2014, 9, e99104. [CrossRef] [PubMed]

134. Arragain, S.; Bimai, O.; Legrand, P.; Caillat, S.; Ravanat, J.L.; Touati, N.; Binet, L.; Atta, M.; Fontecave, M.; Golinelli-Pimpaneau, B. Nonredox thiolation in tRNA occurring via sulfur activation by a [4Fe-4S] cluster. Proc. Natl. Acad. Sci. USA 2017, 114, 7355-7360. [CrossRef] [PubMed]

135. Black, K.A.; Dos Satos, P.C. Abbreviated Pathway for Biosynthesis of 2-Thiouridine in Bacillus subtilis. J. Bacteriol. 2015, 197, 1952-1962. [CrossRef] [PubMed] 
136. Kitamura, A.; Nishimoto, M.; Sengoku, T.; Shibata, R.; Jäger, G.; Björk, G.R.; Grosjean, H.; Yokoyama, S.; Bessho, Y. Characterization and structure of the Aquifex aeolicus protein DUF752: A bacterial tRNA-methyltransferase (MnmC2) functioning without the usually fused oxidase domain (MnmC1). J. Biol. Chem. 2012, 287, 43950-43960. [CrossRef] [PubMed]

137. Mandal, D.; Köhrer, C.; Su, D.; Babu, I.R.; Chan, C.T.; Liu, Y.; Söll, D.; Blum, P.; Kuwahara, M.; Dedon, P.C.; Rajbhandary, U.L. Identification and codon reading properties of 5-cyanomethyl uridine, a new modified nucleoside found in the anticodon wobble position of mutant haloarchaeal isoleucine tRNAs. RNA 2014, 20, 177-188. [CrossRef] [PubMed]

138. Scrima, A.; Vetter, I.R.; Armengod, M.E.; Wittinghofer, A. The structure of the TrmE GTP-binding protein and its implications for tRNA modification. EMBO J. 2005, 24, 23-33. [CrossRef] [PubMed]

139. Scrima, A.; Wittinghofer, A. Dimerisation-dependent GTPase reaction of MnmE: How potassium acts as GTPase-activating element. EMBO J. 2006, 25, 2940-2951. [CrossRef] [PubMed]

140. Osawa, T.; Inanaga, H.; Numata, T. Crystallization and preliminary X-ray diffraction analysis of the tRNA-modification enzyme GidA from Aquifex aeolicus. Acta Crystallogr. Sect. F Struct. Biol. Cryst. Commun. 2009, 65, 508-511. [CrossRef] [PubMed]

141. Osawa, T.; Ito, K.; Inanaga, H.; Nureki, O.; Tomita, K.; Numata, T. Conserved cysteine residues of GidA are essential for biogenesis of 5-carboxymethylaminomethyluridine at tRNA anticodon. Structure 2009, 17, 713-724. [CrossRef] [PubMed]

142. Selcadurai, K.; Wang, P.; Seimetz, J.; Huang, R.H. Archaeal Elp3 catalyzes tRNA wobble uridine modification at C5 via a radical mechanism. Nat. Chem. Biol. 2014, 10, 810-812. [CrossRef] [PubMed]

143. Benítez-Páez, A.; Villarroya, M.; Douthwaite, S.; Gabaldón, T.; Armengod, M.E. YibK is the 2'-O-methyltransferase TrmL that modifies the wobble nucleotide in Escherichia coli tRNA(Leu) isoacceptors. RNA 2010, 16, 2131-2143. [CrossRef] [PubMed]

144. Pang, P.; Deng, X.; Wang, Z.; Xie, W. Structural and biochemical insights into the 2'-O-methylation of pyrimidines 34 in tRNA. FEBS J. 2017, 284, 2251-2263. [CrossRef] [PubMed]

145. Okada, N.; Noguchi, S.; Nishimura, S.; Ohgi, T.; Goto, T.; Crain, P.F.; McCloskey, J.A. Structure determination of a nucleoside $Q$ precursor isolated from E. coli tRNA: 7-(aminomethyl)-7-deazaguanosine. Nucleic Acids Res. 1978, 5, 2289-2296. [CrossRef] [PubMed]

146. Okada, N.; Noguchi, S.; Kasai, H.; Shindo-Okada, N.; Ohgi, T.; Goto, T.; Nishimura, S. Novel mechanism of post-transcriptional modification of tRNA. Insertion of bases of $Q$ precursors into tRNA by a specific tRNA transglycosylase reaction. J. Biol. Chem. 1979, 254, 3067-3073. [PubMed]

147. Nakanishi, S.; Ueda, T.; Hori, H.; Yamazaki, N.; Okada, N.; Watanabe, K. A UGU sequence in the anticodon loop is a minimum requirement for recognition by Escherichia coli tRNA-guanine transglycosylase. J. Biol. Chem. 1994, 269, 32221-32225. [PubMed]

148. Slany, R.K.; Bösl, M.; Kersten, H. Transfer and isomerization of the ribose moiety of AdoMet during the biosynthesis of queuosine tRNAs, a new unique reaction catalyzed by the QueA protein from Escherichia coli. Biochimie 1994, 76, 389-393. [CrossRef]

149. Van Lanen, S.G.; Kinzie, S.D.; Matthieu, S.; Link, T.; Culp, J.; Iwata-Reuyl, D. tRNA modification by S-adenosylmethionine: tRNA ribosyltransferase-isomerase. Assay development and characterization of the recombinant enzyme. J. Biol. Chem. 2003, 278, 10491-10499. [CrossRef] [PubMed]

150. Miles, Z.D.; Myers, W.K.; Kincannon, W.M.; Britt, R.D.; Bandarian, V. Biochemical and Spectroscopic Studies of Epoxyqueuosine Reductase: A Novel Iron-Sulfur Cluster- and Cobalamin-Containing Protein Involved in the Biosynthesis of Queuosine. Biochemistry 2015, 54, 4927-4935. [CrossRef] [PubMed]

151. Mathews, I.; Schwarzenbacher, R.; McMullan, D.; Abdubek, P.; Ambing, E.; Axelrod, H.; Biorac, T.; Canaves, J.M.; Chiu, H.J.; Deacon, A.M.; et al. Crystal structure of S-adenosylmethionine: tRNA ribosyltransferase-isomerase (QueA) from Thermotoga maritima at 2.0 A resolution reveals a new fold. Proteins 2005, 59, 869-974. [CrossRef] [PubMed]

152. Vinayak, M.; Pathak, C. Queuosine modification of tRNA: Its divergent role in cellular machinery. Biosci. Rep. 2009, 30, 135-148. [CrossRef] [PubMed]

153. Hutinet, G.; Swarjo, M.A.; de Crécy-Lagard, V. Deazaguanine derivatives, examples of crosstalk between RNA and DNA modification pathways. RNA Biol. 2017, 14, 1175-1184. [CrossRef] [PubMed] 
154. Clouet d'Orval, B.; Bortolin, M.L.; Gaspin, C.; Bachellerie, J.P. Box C/D RNA guides for the ribose methylation of archaeal tRNAs. The tRNA ${ }^{\operatorname{Tr}}$ intron guides the formation of two ribose-methylated nucleosides in the mature tRNA ${ }^{\text {Trp }}$. Nucleic Acids Res. 2001, 29, 4518-4529. [CrossRef] [PubMed]

155. Bortolin, M.L.; Bachellerie, J.P.; Clouet-d'Orval, B. In vitro RNP assembly and methylation guide activity of an unusual box C/D RNA, cis-acting archaeal pre-tRNA ${ }^{\operatorname{Tr}}$. Nucleic Acids Res. 2003, 31, 6524-6535. [CrossRef] [PubMed]

156. Byström, A.S.; Björk, G.R. Chromosomal location and cloning of the gene $(\mathrm{trmD})$ responsible for the synthesis of tRNA $\left(\mathrm{m}^{1} \mathrm{G}\right)$ methyltransferase in Escherichia coli K-12. Mol. Gen. Genet. 1982, 188, 440-446. [CrossRef] [PubMed]

157. Björk, G.R.; Wikstrom, P.M.; Byström, A.S. Prevention of translational frameshifting by the modified nucleoside 1-methylguanosine. Science 1989, 244, 986-989. [CrossRef] [PubMed]

158. Farabaugh, P.J.; Björk, G.R. How translational accuracy influences reading frame maintenance. EMBO J. 1999, 18, 1427-1434. [CrossRef] [PubMed]

159. Björk, G.R.; Jacobsson, K.; Nilsson, K.; Johansson, M.J.; Byström, A.S.; Persson, O.P. A primordial tRNA modification required for the evolution of life? EMBO J. 2001, 20, 231-239. [CrossRef] [PubMed]

160. Liu, J.; Wang, W.; Shin, D.H.; Yokota, H.; Kim, R.; Kim, S.H. Crystal structure of tRNA (m ${ }^{1}$ G37) methyltransferase from Aquifex aeolicus at 2.6 A resolution: A novel methyltransferase fold. Proteins 2003, 53, 326-328. [CrossRef] [PubMed]

161. Christian, T.; Evilia, C.; Williams, S.; Hou, Y.M. Distinct origins of $\operatorname{tRNA}\left(\mathrm{m}^{1} \mathrm{G} 37\right)$ methyltransferase. J. Mol. Biol. 2004, 339, 707-719. [CrossRef] [PubMed]

162. Takeda, H.; Toyooka, T.; Ikeuchi, Y.; Yokobori, S.; Okadome, K.; Takano, F.; Oshima, T.; Suzuki, T.; Endo, Y.; Hori, H. The substrate specificity of tRNA ( $\left.{ }^{1} \mathrm{G} 37\right)$ methyltransferase (TrmD) from Aquifex aeolicus. Genes Cells 2006, 11, 1353-1365. [CrossRef] [PubMed]

163. Christian, T.; Evilia, C.; Hou, Y.M. Catalysis by the second class of $\mathrm{tRNA}\left(\mathrm{m}^{1} \mathrm{G} 37\right)$ methyl transferase requires a conserved proline. Biochemistry 2006, 45, 7463-7473. [CrossRef] [PubMed]

164. Christian, T.; Hou, Y.M. Distinct determinants of tRNA recognition by the TrmD and Trm5 methyl transferases. J. Mol. Biol. 2007, 373, 623-632. [CrossRef] [PubMed]

165. Toyooka, T.; Awai, T.; Kanai, T.; Imanaka, T.; Hori, H. Stabilization of tRNA ( $\left.\mathrm{m}^{1} \mathrm{G} 37\right)$ methyltransferase [TrmD] from Aquifex aeolicus by an intersubunit disulfide bond formation. Genes Cells 2008, 13, 807-816. [CrossRef] [PubMed]

166. Goto-Ito, S.; Ito, T.; Ishii, R.; Muto, Y.; Bessho, Y.; Yokoyama, S. Crystal structure of archaeal tRNA(m(1)G37)methyltransferase aTrm5. Proteins 2008, 72, 1274-1289. [CrossRef] [PubMed]

167. Goto-Ito, S.; Ito, T.; Kuratani, M.; Bessho, Y.; Yokoyama, S. Tertiary structure checkpoint at anticodon loop modification in tRNA functional maturation. Nat. Struct. Mol. Biol. 2009, 16, 1109-1115. [CrossRef] [PubMed]

168. Lahoud, G.; Goto-Ito, S.; Yoshida, K.; Ito, T.; Yokoyama, S.; Hou, Y.M. Differentiating analogous tRNA methyltransferases by fragments of the methyl donor. RNA 2011, 17, 1236-1246. [CrossRef] [PubMed]

169. Sakaguchi, R.; Giessing, A.; Dai, Q.; Lahoud, G.; Liutkeviciute, Z.; Klimasauskas, S.; Piccirilli, J.; Kirpekar, F.; Hou, Y.M. Recognition of guanosine by dissimilar tRNA methyltransferases. RNA 2012, 18, 1687-1701. [CrossRef] [PubMed]

170. Christian, T.; Gamper, H.; Hou, Y.M. Conservation of structure and mechanism by Trm5 enzymes. RNA 2013, 19, 1192-1199. [CrossRef] [PubMed]

171. Ito, T.; Masuda, I.; Yoshida, K.; Goto-Ito, S.; Sekine, S.; Suh, S.W.; Hou, Y.M.; Yokoyama, S. Structural basis for methyl-donor-dependent and sequence-specific binding to tRNA substrates by knotted methyltransferase TrmD. Proc. Natl. Acad. Sci. USA 2015, 112, E4197-4205. [CrossRef] [PubMed]

172. Goto-Ito, S.; Ishii, R.; Ito, T.; Shibata, R.; Fusatomi, E.; Sekine, S.I.; Bessho, Y.; Yokoyama, S. Structure of an archaeal TYW1, the enzyme catalyzing the second step of wye-base biosynthesis. Acta Crystallogr. D Biol. Crystallogr. 2007, 63, 1059-1068. [CrossRef] [PubMed]

173. Suzuki, Y.; Noma, A.; Suzuki, T.; Senda, M.; Senda, T.; Ishitani, R.; Nureki, O. Crystal structure of the radical SAM enzyme catalyzing tricyclic modified base formation in tRNA. J. Mol. Biol. 2007, 372, 1204-1214. [CrossRef] [PubMed] 
174. Umitsu, M.; Nishimasu, H.; Noma, A.; Suzuki, T.; Ishitani, R.; Nureki, O. Structural basis of AdoMet-dependent aminocarboxypropyl transfer reaction catalyzed by tRNA-wybutosine synthesizing enzyme, TYW2. Proc. Natl. Acad. Sci. USA 2009, 106, 15616-15621. [CrossRef] [PubMed]

175. Perche-Letuvée, P.; Kathirvelu, V.; Berggren, G.; Clemancey, M.; Latour, J.M.; Maurel, V.; Douki, T.; Armengaud, J.; Mulliez, E.; Fontecave, M.; et al. 4-Demethylwyosine synthase from Pyrococcus abyssi is a radical-S-adenosyl-L-methionine enzyme with an additional $[4 \mathrm{Fe}-4 \mathrm{~S}](+2)$ cluster that interacts with the pyruvate co-substrate. J. Biol. Chem. 2012, 287, 41174-41185. [CrossRef] [PubMed]

176. Urbonavičius, J.; Rutkienè, R.; Lopato, A.; Tauraitè, D.; Stankevičiūtè, J.; Aučynaitèm, A.; Kaliniene, L.;

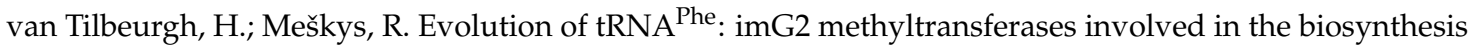
of wyosine derivatives in Archaea. RNA 2016, 22, 1871-1883.

177. Wang, C.; Jia, Q.; Chen, R.; Wei, Y.; Li, J.; Ma, J.; Xie, W. Crystal structures of the bifunctional tRNA methyltransferase Trm5a. Sci. Rep. 2016, 6, 33553. [CrossRef] [PubMed]

178. Currie, M.A.; Brown, G.; Wong, A.; Ohira, T.; Sugiyama, K.; Suzuki, T.; Yakunin, A.F.; Jia, Z. Structural and functional characterization of the TYW3/Taw3 class of SAM-dependent methyltransferases. RNA 2017, 23, 346-354. [CrossRef] [PubMed]

179. Wang, C.; Jia, Q.; Zeng, J.; Chen, R.; Xie, W. Structural insight into the methyltransfer mechanism of the bifunctional Trm5. Sci. Adv. 2017, 3, e1700195. [CrossRef] [PubMed]

180. Wu, J.; Jia, Q.; Wu, S.; Zeng, H.; Sun, Y.; Wang, C.; Ge, R.; Xie, W. The crystal structure of the Pyrococcus abyssi mono-functional methyltransferase PaTrm5b. Biochem. Biophys. Res. Commun. 2017, 493, 240-245. [CrossRef] [PubMed]

181. de Crécy-Lagard, V.; Brochier-Armanet, C.; Urbonavicius, J.; Fernandez, B.; Phillips, G.; Lyons, B.; Noma, A.; Alvarez, S.; Droogmans, L.; Armengaud, J.; et al. Biosynthesis of wyosine derivatives in tRNA: An ancient and highly diverse pathway in Archaea. Mol. Biol. Evol. 2010, 27, 2062-2077. [CrossRef] [PubMed]

182. Urbonavičius, J.; Meškys, R.; Grosjean, H. Biosynthesis of wyosine derivatives in tRNA(Phe) of Archaea: Role of a remarkable bifunctional tRNA(Phe):m1G/imG2 methyltransferase. RNA 2014, 20, 747-753. [CrossRef] [PubMed]

183. Perche-Letuvée, P.; Molle, T.; Forouhar, F.; Mulliez, E.; Atta, M. Wybutosine biosynthesis: Structural and mechanistic overview. RNA Biol. 2014, 11, 1508-1518. [CrossRef] [PubMed]

184. Mao, D.Y.; Neculai, D.; Downey, M.; Orlicky, S.; Haffani, Y.Z.; Ceccarelli, D.F.; Ho, J.S.; Szilard, R.K.; Zhang, W.; Ho, C.S.; et al. Atomic structure of the KEOPS complex: An ancient protein kinase-containing molecular machine. Mol. Cell 2008, 32, 259-275. [CrossRef] [PubMed]

185. Hecker, A.; Lopreiato, R.; Graille, M.; Collinet, B.; Forterre, P.; Libri, D.; van Tilbeurgh, H. Structure of the archaeal Kae1/Bud32 fusion protein MJ1130: A model for the eukaryotic EKC/KEOPS subcomplex. EMBO J. 2008, 27, 2340-2351. [CrossRef] [PubMed]

186. Hecker, A.; Graille, M.; Madec, E.; Gadelle, D.; Le Cam, E.; van Tilbergh, H.; Forterre, P. The universal Kae1 protein and the associated Bud32 kinase (PRPK), a mysterious protein couple probably essential for genome maintenance in Archaea and Eukarya. Biochem. Soc. Trans. 2009, 37, 29-35. [CrossRef] [PubMed]

187. Perrochia, L.; Crozat, E.; Hecker, A.; Zhang, W.; Bareille, J.; Collinet, B.; van Tilbeurgh, H.; Forterre, P.; Basta, T. In vitro biosynthesis of a universal $\mathrm{t}^{6} \mathrm{~A}$ tRNA modification in Archaea and Eukarya. Nucleic Acids Res. 2013, 41, 1953-1964. [CrossRef] [PubMed]

188. Wan, L.C.; Pillon, M.C.; Thevakumaran, N.; Sun, Y.; Chakrabartty, A.; Guarné, A.; Kurinov, I.; Durocher, D.; Sicheri, F. Structural and functional characterization of KEOPS dimerization by Pcc1 and its role in $\mathrm{t}^{6} \mathrm{~A}$ biosynthesis. Nucleic Acids Res. 2016, 44, 6971-6980. [CrossRef] [PubMed]

189. Pichard-Kostuch, A.; Zhang, W.; Liger, D.; Daugeron, M.C.; Letoquart, J.; Li de la Sierra-Gallay, I.; Forterre, P.; Collinet, B.; van Tilbeurgh, H.; Basta, T. Structure-function analysis of Sua5 protein reveals novel functional motifs required for the biosynthesis of the universal $t^{6} \mathrm{~A}$ tRNA modification. RNA 2018, 24, 926-938. [CrossRef] [PubMed]

190. Luthra, A.; Swinehart, W.; Bayooz, S.; Phan, P.; Stec, B.; Iwata-Reuyl, D.; Swairjo, M.A. Structure and mechanism of a bacterial $t^{6} \mathrm{~A}$ biosynthesis system. Nucleic Acids Res. 2018, 46, 1395-1411. [CrossRef] [PubMed]

191. Thiaville, P.C.; Iwata-Reuyl, D.; de Crécy-Lagard, V. Diversity of the biosynthesis pathway for threonylcarbamoyladenosine $\left(\mathrm{t}^{6} \mathrm{~A}\right)$, a universal modification of tRNA. RNA Biol. 2014, 11, 1529-1539. [CrossRef] [PubMed] 
192. Caillet, J.; Droogmans, L. Molecular cloning of the Escherichia coli miaA gene involved in the formation of delta 2-isopentenyl adenosine in tRNA. J. Bacteriol. 1988, 170, 4147-4152. [CrossRef] [PubMed]

193. Esberg, B.; Leung, H.C.; Tsui, H.C.; Björk, G.R.; Winkler, M.E. Identification of the miaB gene, involved in methylthiolation of isopentenylated A37 derivatives in the tRNA of Salmonella typhimurium and Escherichia coli. J. Bacteriol. 1999, 181, 7256-7265. [PubMed]

194. Pierrel, F.; Hernandez, H.L.; Johnson, M.K.; Fontecave, M.; Atta, M. MiaB protein from Thermotoga maritima. Characterization of an extremely thermophilic tRNA-methylthiotransferase. J. Biol. Chem. 2003, 278, 29515-29524. [CrossRef] [PubMed]

195. Pierrel, F.; Douki, T.; Fontecave, M.; Atta, M. MiaB protein is a bifunctional radical-S-adenosylmethionine enzyme involved in thiolation and methylation of tRNA. J. Biol. Chem. 2004, 279, 47555-47563. [CrossRef] [PubMed]

196. Hernández, H.L.; Pierrel, F.; Elleingand, E.; García-Serres, R.; Huynh, B.H.; Johnson, M.K.; Fontecave, M.; Atta, M. MiaB, a bifunctional radical-S-adenosylmethionine enzyme involved in the thiolation and methylation of tRNA, contains two essential [4Fe-4S] clusters. Biochemistry 2007, 46, 5140-5147. [CrossRef] [PubMed]

197. Schweizer, U.; Bohleber, S.; Fradejas-Villar, N. The modified base isopentenyladenosine and its derivatives in tRNA. RNA Biol. 2017, 14, 1197-1208. [CrossRef] [PubMed]

198. Golovina, A.Y.; Sergiev, P.V.; Golovin, A.V.; Serebryakova, M.V.; Demina, I.; Govorun, V.M.; Dontsova, O.A. The $y$ fiC gene of $E$. coli encodes an adenine- $N^{6}$ methyltransferase that specifically modifies A37 of $\left.\mathrm{tRNA}_{1} \mathrm{Val} \mathrm{cmo}^{5} \mathrm{UAC}\right)$. RNA 2009, 15, 1134-1141. [CrossRef] [PubMed]

199. Allaudeen, H.S.; Yang, S.K.; Söll, D. Leucine tRNA(1) from HisT mutant of Salmonella typhimurium lacks two pseudouridines. FEBS Lett. 1972, 28, 205-208. [CrossRef]

200. Kammen, H.O.; Marvel, C.C.; Hardy, L.; Penhoet, E.E. Purification, structure, and properties of Escherichia coli tRNA pseudouridine synthase I. J. Biol. Chem. 1988, 263, 2255-2263. [PubMed]

201. Lecointe, F.; Simos, G.; Sauer, A.; Hurt, E.C.; Motorin, Y.; Grosjean, H. Characterization of yeast protein Deg1 as pseudouridine synthase (Pus3) catalyzing the formation of psi 38 and psi 39 in tRNA anticodon loop. J. Biol. Chem. 1998, 273, 1316-1323. [CrossRef] [PubMed]

202. Dong, X.; Bessho, Y.; Shibata, R.; Nishimoto, M.; Shirouzu, M.; Kuramitsu, S.; Yokoyama, S. Crystal structure of tRNA pseudouridine synthase TruA from Thermus thermophilus HB8. RNA Biol. 2006, 3, 115-122. [CrossRef] [PubMed]

203. Spenkuch, F.; Motorin, Y.; Helm, M. Pseudouridine: Still mysterious, but never a fake (uridine)! RNA Biol. 2014, 11, 1540-1554. [CrossRef] [PubMed]

204. Morozov, I.A.; Gambaryan, A.S.; Lvova, T.N.; Nedospasov, A.A.; Venkstern, T.V. Purification and characterization of tRNA (adenine-1-)-methyltransferase from Thermus flavus strain 71. Eur. J. Biochem. 1982, 129, 429-436. [CrossRef] [PubMed]

205. De Bie, L.G.; Roovers, M.; Oudjama, Y.; Wattiez, R.; Tricot, C.; Stalon, V.; Droogmans, L.; Bujnicki, J.M. The yggH gene of Escherichia coli encodes a tRNA ( $\left.\mathrm{m}^{7} \mathrm{G} 46\right)$ methyltransferase. J. Bacteriol. 2003, 185, 3238-3243. [CrossRef] [PubMed]

206. Okamoto, H.; Watanabe, K.; Ikeuchi, Y.; Suzuki, T.; Endo, Y.; Hori, H. Substrate tRNA recognition mechanism of tRNA ( $\left.\mathrm{m}^{7} \mathrm{G} 46\right)$ methyltransferase from Aquifex aeolicus. J. Biol. Chem. 2004, 279, 49151-49159. [CrossRef] [PubMed]

207. Tomikawa, C.; Ochi, A.; Hori, H. The C-terminal region of thermophilic tRNA ( $\left.\mathrm{m}^{7} \mathrm{G} 46\right)$ methyltransferase (TrmB) stabilizes the dimer structure and enhances fidelity of methylation. Proteins 2008, 71, 1400-1408. [CrossRef] [PubMed]

208. Tomikawa, C.; Takai, K.; Hori, H. Kinetic characterization of substrate-binding sites of thermostable tRNA methyltransferase (TrmB). J. Biochem. 2018, 163, 133-142. [CrossRef] [PubMed]

209. Auxilien, S.; El Khadali, F.; Rasmussen, A.; Douthwaite, S.; Grosjean, H. Archease from Pyrococcus abyssi improves substrate specificity and solubility of a tRNA $\mathrm{m}^{5} \mathrm{C}$ methyltransferase. J. Biol. Chem. 2007, 282, 18711-18721. [CrossRef] [PubMed]

210. Kuratani, M.; Hirano, M.; Goto-Ito, S.; Itoh, Y.; Hikida, Y.; Nishimoto, M.; Sekine, S.; Bessho, Y.; Ito, T.; Grosjean, H.; et al. Crystal structure of Methanocaldococcus jannaschii Trm4 complexed with sinefungin. J. Mol. Biol. 2010, 401, 323-333. [CrossRef] [PubMed] 
211. Roovers, M.; Hale, C.; Tricot, C.; Terns, M.P.; Terns, R.M.; Grosjean, H.; Droogmans, L. Formation of the conserved pseudouridine at position 55 in archaeal tRNA. Nucleic Acids Res. 2006, 34, 4293-4301. [CrossRef] [PubMed]

212. Gurha, P.; Gupta, R. Archaeal Pus10 proteins can produce both pseudouridine 54 and 55 in tRNA. RNA 2008, 14, 2521-2527. [CrossRef] [PubMed]

213. Joardar, A.; Jana, S.; Fitzek, E.; Gurha, P.; Majumder, M.; Chatterjee, K.; Geisler, M.; Gupta, R. Role of forefinger and thumb loops in production of $\Psi 54$ and $\Psi 55$ in tRNAs by archaeal Pus10. RNA 2013, 19, 1279-1294. [CrossRef] [PubMed]

214. Kamalampeta, R.; Keffer-Wilkes, L.C.; Kothe, U. tRNA binding, positioning, and modification by the pseudouridine synthase Pus10. J. Mol. Biol. 2013, 425, 3863-3874. [CrossRef] [PubMed]

215. Chen, H.Y.; Yuan, Y.A. Crystal structure of Mj1640/DUF358 protein reveals a putative SPOUT-class RNA methyltransferase. J. Mol. Cell. Biol. 2010, 2, 366-374. [CrossRef] [PubMed]

216. Wurm, J.P.; Griese, M.; Bahr, U.; Held, M.; Heckel, A.; Karas, M.; Soppa, J.; Wöhnert, J. Identification of the enzyme responsible for $N^{1}$-methylation of pseudouridine 54 in archaeal tRNAs. RNA 2012, 18, 412-420. [CrossRef] [PubMed]

217. Chatterjee, K.; Blaby, I.K.; Thiaville, P.C.; Majumder, M.; Grosjean, H.; Yuan, Y.A.; Gupta, R.; de Crécy-Lagard, V. The archaeal COG1901/DUF358 SPOUT-methyltransferase members, together with pseudouridine synthase Pus10, catalyze the formation of 1-methylpseudouridine at position 54 of tRNA. RNA 2012, 18, 421-433. [CrossRef] [PubMed]

218. Davanloo, P.; Sprinzl, M.; Watanabe, K.; Albani, M.; Kersten, H. Role of ribothymidine in the thermal stability of transfer RNA as monitored by proton magnetic resonance. Nucleic Acids Res. 1979, 6, 1571-1581. [CrossRef] [PubMed]

219. Watanabe, K.; Himeno, H.; Ohta, T. Selective utilization of 2-thioribothymidine- and ribothymidine-containing tRNAs by the protein synthetic systems of Thermus thermophilus HB 8 depending on the environmental temperature. J. Biochem. 1984, 96, 1625-1632. [CrossRef] [PubMed]

220. Yokoyama, S.; Watanabe, K.; Miyazawa, T. Dynamic structures and functions of transfer ribonucleic acids from extreme thermophiles. Adv. Biophys. 1987, 23, 115-147. [CrossRef]

221. Urbonavicius, J.; Skouloubris, S.; Myllykallio, H.; Grosjean, H. Identification of a novel gene encoding a flavin-dependent tRNA: $\mathrm{m}^{5} \mathrm{U}$ methyltransferase in bacteria-evolutionary implications. Nucleic Acids Res. 2005, 33, 3955-3964. [CrossRef] [PubMed]

222. Cicmil, N. Crystallization and preliminary X-ray crystallographic characterization of TrmFO, a folate-dependent tRNA methyltransferase from Thermotoga maritima. Acta Crystallogr. Sect. F Struct. Biol. Cryst. Commun. 2008, 64, 193-195. [CrossRef] [PubMed]

223. Nishimasu, H.; Ishitani, R.; Yamashita, K.; Iwashita, C.; Hirata, A.; Hori, H.; Nureki, O. Atomic structure of a folate/FAD-dependent tRNA T54 methyltransferase. Proc. Natl. Acad. Sci. USA 2009, 106, 8180-8185. [CrossRef] [PubMed]

224. Yamagami, R.; Yamashita, K.; Nishimasu, H.; Tomikawa, C.; Ochi, A.; Iwashita, C.; Hirata, A.; Ishitani, R.; Nureki, O.; Hori, H. The tRNA recognition mechanism of folate/FAD-dependent tRNA methyltransferase (TrmFO). J. Biol. Chem. 2012, 287, 42480-42494. [CrossRef] [PubMed]

225. Yamagami, R.; Tomikawa, C.; Shigi, N.; Kazayama, A.; Asai, S.; Takuma, H.; Hirata, A.; Fourmy, D.; Asahara, H.; Watanabe, K.; et al. The folate/FAD-dependent tRNA methyltransferase (TrmFO) from Thermus thermophilus regulates the other modifications in tRNA at low temperatures. Genes Cells 2016, 21, 740-754. [CrossRef] [PubMed]

226. Hamdane, D.; Grosjean, H.; Fontecave, M. Flavin-Dependent Methylation of RNAs: Complex Chemistry for a Simple Modification. J. Mol. Biol. 2016, 428, 4867-4881. [CrossRef] [PubMed]

227. Yamagami, R.; Miyake, R.; Fukumoto, A.; Nakashima, M.; Hori, H. Consumption of $N^{5}$, $\mathrm{N}^{10}$-methylenetetrahydrofolate in Thermus thermophilus under nutrient-poor condition. J. Biochem. 2018, 164, 141-152. [CrossRef] [PubMed]

228. Shigi, N.; Suzuki, T.; Tamakoshi, M.; Oshima, T.; Watanabe, K. Conserved bases in the TPsi C loop of tRNA are determinants for thermophile-specific 2-thiouridylation at position 54. J. Biol. Chem. 2002, 277, 39128-39135. [CrossRef] [PubMed] 
229. Shigi, N.; Suzuki, T.; Terada, T.; Shirouzu, M.; Yokoyama, S.; Watanabe, K. Temperature-dependent biosynthesis of 2-thioribothymidine of Thermus thermophilus tRNA. J. Biol. Chem. 2006, 281, 2104-2113. [CrossRef] [PubMed]

230. Shigi, N.; Sakaguchi, Y.; Suzuki, T.; Watanabe, K. Identification of two tRNA thiolation genes required for cell growth at extremely high temperatures. J. Biol. Chem. 2006, 281, 14296-14306. [CrossRef] [PubMed]

231. Shigi, N.; Sakaguchi, Y.; Asai, S.; Suzuki, T.; Watanabe, K. Common thiolation mechanism in the biosynthesis of tRNA thiouridine and sulphur-containing cofactors. EMBO J. 2008, 27, 3267-3278. [CrossRef] [PubMed]

232. Shigi, N. Posttranslational modification of cellular proteins by a ubiquitin-like protein in bacteria. J. Biol. Chem. 2012, 287, 17568-17577. [CrossRef] [PubMed]

233. Nakagawa, H.; Kuratani, M.; Goto-Ito, S.; Ito, T.; Katsura, K.; Terada, T.; Shirouzu, M.; Sekine, S.; Shigi, N.; Yokoyama, S. Crystallographic and mutational studies on the tRNA thiouridine synthetase TtuA. Proteins 2013, 81, 1232-1244. [CrossRef] [PubMed]

234. Chen, M.; Narai, S.; Omura, N.; Shigi, N.; Chimnaronk, S.; Tanaka, Y.; Yao, M. Crystallographic study of the 2-thioribothymidine-synthetic complex TtuA-TtuB from Thermus thermophilus. Acta Crystallogr. F Struct. Biol. Commun. 2016, 72, 777-781. [CrossRef] [PubMed]

235. Shigi, N.; Asai, S.-I.; Watanabe, K. Identification of a rhodanese-like protein involved in thiouridine biosynthesis in Thermus thermophilus tRNA. FEBS Lett. 2016, 590, 4628-4637. [CrossRef] [PubMed]

236. Chen, M.; Asai, S.-I.; Narai, S.; Nambu, S.; Omura, N.; Sakaguchi, Y.; Suzuki, T.; Ikeda-Saito, M.; Watanabe, K.; Yao, M.; et al. Biochemical and structural characterization of oxygen-sensitive 2-thiouridine synthesis catalyzed by an iron-sulfur protein TtuA. Proc. Natl. Acad. Sci. USA 2017, 114, 4954-4959. [CrossRef] [PubMed]

237. Urbonavicius, J.; Auxilien, S.; Walbott, H.; Trachana, K.; Golinelli-Pimpaneau, B.; Brochier-Armanet, C.; Grosjean, H. Acquisition of a bacterial RumA-type tRNA(uracil-54, C5)-methyltransferase by Archaea through an ancient horizontal gene transfer. Mol. Microbiol. 2008, 67, 323-335. [CrossRef] [PubMed]

238. Walbott, H.; Leulliot, N.; Grosjean, H.; Golinelli-Pimpaneau, B. The crystal structure of Pyrococcus abyssi tRNA (uracil-54, C5)-methyltransferase provides insights into its tRNA specificity. Nucleic Acids Res. 2008, 36, 4929-4940. [CrossRef] [PubMed]

239. Shigi, N. Biosynthesis and functions of sulfur modifications in tRNA. Front. Genet. 2014, 5, 67. [CrossRef] [PubMed]

240. Gurha, P.; Joardar, A.; Chaurasia, P.; Gupta, R. Differential roles of archaeal box H/ACA proteins in guide RNA-dependent and independent pseudouridine formation. RNA Biol. 2007, 4, 101-109. [CrossRef] [PubMed]

241. Muller, S.; Fourmann, J.B.; Loegler, C.; Charpentier, B.; Branlant, C. Identification of determinants in the protein partners aCBF5 and aNOP10 necessary for the tRNA: Psi55-synthase and RNA-guided RNA: Psi-synthase activities. Nucleic Acids Res. 2007, 35, 5610-5624. [CrossRef] [PubMed]

242. Kamalampeta, R.; Kothe, U. Archaeal proteins Nop10 and Gar1 increase the catalytic activity of Cbf5 in pseudouridylating tRNA. Sci. Rep. 2012, 2, 663. [CrossRef] [PubMed]

243. Nurse, K.; Wrzesinski, J.; Bakin, A.; Lane, B.G.; Ofengand, J. Purification, cloning, and properties of the tRNA psi 55 synthase from Escherichia coli. RNA 1995, 1, 102-112. [PubMed]

244. Pan, H.; Agarwalla, S.; Moustakas, D.T.; Finer-Moore, J.; Stroud, R.M. Structure of tRNA pseudouridine synthase TruB and its RNA complex: RNA recognition through a combination of rigid docking and induced fit. Proc. Natl. Acad. Sci. USA 2003, 100, 12648-12653. [CrossRef] [PubMed]

245. Wouters, J.; Tricot, C.; Durbecq, V.; Roovers, M.; Stalon, V.; Droogmans, L. Preliminary X-ray crystallographic analysis of tRNA pseudouridine 55 synthase from the thermophilic eubacterium Thermotoga maritima. Acta Crystallogr. D Biol. Crystallogr. 2003, 59, 152-154. [CrossRef] [PubMed]

246. Phannachet, K.; Huang, R.H. Conformational change of pseudouridine 55 synthase upon its association with RNA substrate. Nucleic Acids Res. 2004, 32, 1422-1429. [CrossRef] [PubMed]

247. Phannachet, K.; Elias, Y.; Huang, R.H. Dissecting the roles of a strictly conserved tyrosine in substrate recognition and catalysis by pseudouridine 55 synthase. Biochemistry 2005, 44, 15488-15494. [CrossRef] [PubMed] 
248. Ishida, K.; Kunibayashi, T.; Tomikawa, C.; Ochi, A.; Kanai, T.; Hirata, A.; Iwashita, C.; Hori, H. Pseudouridine at position 55 in tRNA controls the contents of other modified nucleotides for low-temperature adaptation in the extreme-thermophilic eubacterium Thermus thermophilus. Nucleic Acids Res. 2011, 39, 2304-2318. [CrossRef] [PubMed]

249. Renalier, M.H.; Joseph, N.; Gaspin, C.; Thebault, P.; Mougin, A. The Cm56 tRNA modification in archaea is catalyzed either by a specific 2'-O-methylase, or a C/D sRNP. RNA 2005, 11, 1051-1063. [CrossRef] [PubMed]

250. Tkaczuk, K.L.; Dunin-Horkawicz, S.; Purta, E.; Bujnicki, J.M. Structural and evolutionary bioinformatics of the SPOUT superfamily of methyltransferases. BMC Bioinfor. 2007, 8, 73. [CrossRef] [PubMed]

251. Kuratani, M.; Bessho, Y.; Nishimoto, M.; Grosjean, H.; Yokoyama, S. Crystal structure and mutational study of a unique SpoU family archaeal methylase that forms $2^{\prime}$-O-methylcytidine at position 56 of tRNA. J. Mol. Biol. 2008, 375, 1064-1075. [CrossRef] [PubMed]

252. Walker, R.T. Mycoplasma evolution: A review of the use of ribosomal and transfer RNA nucleotide sequences in the determination of phylogenetic relationships. Yale J. Biol. Med. 1983, 56, 367-372. [PubMed]

253. Yamaizumi, Z.; Ihara, M.; Kuchino, Y.; Gupta, R.; Woese, C.R.; Nishimura, S. Archaebacterial tRNA contains 1-methylinosine at residue 57 in T psi C-loop. Nucleic Acids Symp. Ser. 1982, 11, 209-213.

254. Grosjean, H.; Constantinesco, F.; Foiret, D.; Benachenhou, N. A novel enzymatic pathway leading to 1-methylinosine modification in Haloferax volcanii tRNA. Nucleic Acids Res. 1995, 23, 4312-4319. [CrossRef] [PubMed]

255. Roovers, M.; Wouters, J.; Bujnicki, J.M.; Tricot, C.; Stalon, V.; Grosjean, H.; Droogmans, L. A primordial RNA modification enzyme: The case of tRNA $\left(\mathrm{m}^{1} \mathrm{~A}\right)$ methyltransferase. Nucleic Acids Res. 2004, 32, 465-476. [CrossRef] [PubMed]

256. Guelorget, A.; Roovers, M.; Guérineau, V.; Barbey, C.; Li, X.; Golinelli-Pimpaneau, B. Insights into the hyperthermostability and unusual region-specificity of archaeal Pyrococcus abyssi tRNA m ${ }^{1}$ A57/58 methyltransferase. Nucleic Acids Res. 2010, 38, 6206-6218. [CrossRef] [PubMed]

257. Guelorget, A.; Barraud, P.; Tisné, C.; Golinelli-Pimpaneau, B. Structural comparison of tRNA m(1)A58 methyltransferases revealed different molecular strategies to maintain their oligomeric architecture under extreme conditions. BMC Struct. Biol. 2011, 11, 48. [CrossRef] [PubMed]

258. Hamdane, D.; Guelorget, A.; Guérineau, V.; Golinelli-Pimpaneau, B. Dynamics of RNA modification by a multi-site-specific tRNA methyltransferase. Nucleic Acids Res. 2014, 42, 11697-11706. [CrossRef] [PubMed]

259. Biou, V.; Yaremchuk, A.; Tukalo, M.; Cusack, S. The 2.9 A crystal structure of T. thermophilus seryl-tRNA synthetase complexed with tRNA(Ser). Science 1994, 263, 1404-1410. [CrossRef] [PubMed]

260. Droogmans, L.; Roovers, M.; Bujnicki, J.M.; Tricot, C.; Hartsch, T.; Stalon, V.; Grosjean, H. Cloning and characterization of tRNA ( $\mathrm{m}^{1} \mathrm{~A} 58$ ) methyltransferase (TrmI) from Thermus thermophilus HB27, a protein required for cell growth at extreme temperatures. Nucleic Acids Res. 2003, 31, 2148-2156. [CrossRef] [PubMed]

261. Barraud, P.; Golinelli-Pimpaneau, B.; Atmanene, C.; Sanglier, S.; Van Dorsselaer, A.; Droogmans, L.; Dardel, F.; Tisné, C. Crystal structure of Thermus thermophilus tRNA $\mathrm{m}^{1} \mathrm{~A} 58$ methyltransferase and biophysical characterization of its interaction with tRNA. J. Mol. Biol. 2008, 377, 535-550. [CrossRef] [PubMed]

262. Kuratani, M.; Yanagisawa, T.; Ishii, R.; Matsuno, M.; Si, S.Y.; Katsura, K.; Ushikoshi-Nakayama, R.; Shibata, R.; Shirouzu, M.; Bessho, Y.; et al. Crystal structure of tRNA m ${ }^{1}$ A58 methyltransferase TrmI from Aquifex aeolicus in complex with S-adenosyl-L-methionine. J. Struct. Funct. Genomics 2014, 15, 173-180. [CrossRef] [PubMed]

263. Takuma, H.; Ushio, N.; Minoji, M.; Kazayama, A.; Shigi, N.; Hirata, A.; Ochi, A.; Hori, H. Substrate tRNA recognition mechanism of eubacterial tRNA ( ${ }^{1}$ A58) methyltransferase (TrmI). J. Biol. Chem. 2015, 290, 5912-5925. [CrossRef] [PubMed]

264. Dégut, C.; Ponchon, L.; Folly-Klan, M.; Barraud, P.; Tisné, C. The $\mathrm{m}^{1} \mathrm{~A} 58$ modification in eubacterial tRNA: An overview of tRNA recognition and mechanism of catalysis by TrmI. Biophys. Chem. 2016, 210, $27-34$. [CrossRef] [PubMed]

265. Väre, V.Y.; Eruysal, E.R.; Narendran, A.; Sarachan, K.L.; Agris, P.F. Chemical and Conformational Diversity of Modified Nucleosides Affects tRNA Structure and Function. Biomolecules 2017, 7, 29. [CrossRef] [PubMed]

266. Motorin, Y.; Helm, M. tRNA stabilization by modified nucleotides. Biochemistry 2010, 49, 4934-4944. [CrossRef] [PubMed]

267. El Yacoubi, B.; Bailly, M.; de Crécy-Lagard, V. Biosynthesis and function of posttranscriptional modifications of transfer RNAs. Annu. Rev. Genet. 2012, 46, 69-95. [CrossRef] [PubMed] 
268. Manickam, N.; Joshi, K.; Bhatt, M.J.; Farabaugh, P.J. Effects of tRNA modification on translational accuracy depend on intrinsic codon-anticodon strength. Nucleic Acids Res. 2016, 44, 1871-1881. [CrossRef] [PubMed]

269. Grosjean, H.; Westhof, E. An integrated, structure- and energy-based view of the genetic code. Nucleic Acids Res. 2016, 44, 8020-8040. [CrossRef] [PubMed]

270. Agris, P.F.; Eruysal, E.R.; Narendran, A.; Väre, V.Y.P.; Vangaveti, S.; Ranganathan, S.V. Celebrating wobble decoding: Half a century and still much is new. RNA Biol. 2017, 16, 1-17. [CrossRef] [PubMed]

271. Perret, V.; Garcia, A.; Grosjean, H.; Ebel, J.P.; Florentz, C.; Giegé, R. Relaxation of a transfer RNA specificity by removal of modified nucleotides. Nature 1990, 344, 787-789. [CrossRef] [PubMed]

272. Aström, S.U.; Byström, A.S. Rit1, a tRNA backbone-modifying enzyme that mediates initiator and elongator tRNA discrimination. Cell 1994, 79, 535-546. [CrossRef]

273. Kaneko, T.; Suzuki, T.; Kapushoc, S.T.; Rubio, M.A.; Ghazvini, J.; Watanabe, K.; Simpson, L.; Suzuki, T. Wobble modification differences and subcellular localization of tRNAs in Leishmania tarentolae: Implication for tRNA sorting mechanism. EMBO J. 2003, 22, 657-667. [CrossRef] [PubMed]

274. Anderson, J.; Phan, L.; Cuesta, R.; Carison, B.A.; Pak, M.; Asano, K.; Björk, G.R.; Tamame, M.; Hinnebusch, A.G. The essential Gcd10p-Gcd14p nuclear complex is required for 1-methyladenosine modification and maturation of initiator methionyl-tRNA. Genes Dev. 1998, 12, 3650-3652. [CrossRef] [PubMed]

275. Anderson, J.; Phan, L.; Hinnebusch, A.G. The Gcd10p/Gcd14p complex is the essential two-subunit tRNA(1-methyladenosine) methyltransferase of Saccharomyces cerevisiae. Proc. Natl. Acad. Sci. USA 2000, 97, 5173-5178. [CrossRef] [PubMed]

276. Ohira, T.; Suzuki, T. Retrograde nuclear import of tRNA precursors is required for modified base biogenesis in yeast. Proc. Natl. Acad. Sci. USA 2011, 108, 10502-10507. [CrossRef] [PubMed]

277. Ohira, T.; Suzuki, T. Precursors of tRNAs are stabilized by methylguanosine cap structures. Nat. Chem. Biol. 2016, 12, 648-655. [CrossRef] [PubMed]

278. Chatterjee, K.; Nostramo, R.T.; Wan, Y.; Hopper, A.K. tRNA dynamics between the nucleus, cytoplasm and mitochondrial surface: Location, location, location. Biochim. Biophys. Acta 2018, 1861, 373-386. [CrossRef] [PubMed]

279. Kadaba, S.; Krueger, A.; Trice, T.; Krecic, A.M.; Hinnebusch, A.G.; Anderson, J. Nuclear surveillance and degradation of hypomodified initiator tRNA ${ }^{\text {Met }}$ in S. cerevisiae. Genes Dev. 2004, 18, 1227-1240. [CrossRef] [PubMed]

280. Alexandrov, A.; Chernyakov, I.; Gu, W.; Hiley, S.L.; Hughes, T.R.; Grayhack, E.J.; Phizicky, E.M. Rapid tRNA decay can result from lack of nonessential modifications. Mol. Cell 2006, 21, 87-96. [CrossRef] [PubMed]

281. Phizicky, E.M.; Hopper, A.K. tRNA biology charges to the front. Genes Dev. 2010, 24, 1832-1860. [CrossRef] [PubMed]

282. Durand, J.M.; Okada, N.; Tobe, T.; Watarai, M.; Fukuda, I.; Suzuki, T.; Nakata, N.; Komatsu, K.; Yoshikawa, M.; Sasakawa, C. vacC, a virulence-associated chromosomal locus of Shigella flexneri, is homologous to tgt, a gene encoding tRNA-guanine transglycosylase (Tgt) of Escherichia coli K-12. J. Bacteriol. 1994, 176, 4627-4634. [CrossRef] [PubMed]

283. Saga, A.E.; Vasil, A.I.; Vasil, M.L. Molecular characterization of mutants affected in the osmoprotectantdependent induction of phspholipase C in Pseudomonas aeruginosa PAO1. Mol. Microbiol. 1997, 23, 43-56. [CrossRef]

284. Takano, Y.; Takayanagi, N.; Hori, H.; Ikeuchi, Y.; Suzuki, T.; Kimura, A.; Okuno, T. A gene involved in modifying transfer RNA is required for fungal pathogenicity and stress tolerance of Colletotrichum lagenarium. Mol. Microbiol. 2006, 60, 81-92. [CrossRef] [PubMed]

285. Sleiman, D.; Goldschmidt, V.; Barraud, P.; Marquet, R.; Paillart, J.C.; Tisné, C. Initiation of HIV-1 reverse transcription and functional role of nucleocapsid-mediated tRNA/viral genome interactions. Virus Res. 2012, 169, 324-339. [CrossRef] [PubMed]

286. Saadatmand, J.; Kleiman, L. Aspects of HIV-1 assembly that promote primer tRNA (Lys3) annealing to viral RNA. Virus Res. 2012, 169, 340-348. [CrossRef] [PubMed]

287. Gehrig, S.; Eberle, M.-E.; Botschen, F.; Rimbach, K.; Eberle, F.; Eigenbrod, T.; Kaiser, S.; Holmes, W.M.; Erdmann, V.A.; Sprinzl, M.; et al. Identification of modifications in microbial, native tRNA that suppress immunostimulatory activity. J. Exp. Med. 2012, 209, 225-233. [CrossRef] [PubMed] 
288. Jöckel, S.; Nees, G.; Sommer, R.; Zhao, Y.; Cherkasov, D.; Hori, H.; Ehm, G.; Schnare, M.; Nain, M.; Kaufmann, A.; Bauer, S. The 2'-O-methylation status of a single guanosine controls transfer RNA-mediated Toll-like receptor 7 activation or inhibition. J. Exp. Med. 2012, 209, 235-241. [CrossRef] [PubMed]

289. Schmitt, F.C.F.; Freund, I.; Weigand, M.A.; Helm, M.; Dalpke, A.H.; Eigenbrod, T. Identification of an optimized 2'-O-methylated trinucleotide RNA motif inhibiting Toll-like receptors 7 and 8. RNA 2017, 23, 1344-1351. [CrossRef] [PubMed]

290. Keller, P.; Freund, I.; Marchand, V.; Bec, G.; Huang, R.; Motorin, Y.; Eigenbrod, T.; Dalpke, A.; Helm, M. Double methylation of tRNA-U54 to $2^{\prime}$-O-methylthymidine (Tm) synergistically decreases immune response by Toll-like receptor 7. Nucleic Acids Res. 2018. [CrossRef] [PubMed]

291. Gu, X.R.; Nicoghosian, K.; Cedergren, R.J.; Wong, J.T. Sequences of halobacterial tRNAs and the paucity of U in the first position of their anticodons. Nucleic Acids Res. 1983, 11, 5433-5442. [CrossRef] [PubMed]

292. Grosjean, H.; Gaspin, C.; Marck, C.; Decatur, W.A.; de Crecy-Lagard, V. RNomics and Modomics in the halophilic archaea Haloferax volcanii: Identification of RNA modification genes. BMC Genom. 2008, 9, 470. [CrossRef] [PubMed]

293. Phillips, G.; de Crécy-Lagard, V. Biosynthesis and function of tRNA modifications in Archaea. Curr. Opin. Microbiol. 2011, 14, 335-341. [CrossRef] [PubMed]

294. Grosjean, H.; Gupta, R.; Maxwell, S. Modified nucleotides in arhcaeal RNAs. In Archaea: New Models for Prokaryotic Biology; Blum, P., Ed.; Caister Academic Press: Portland, OR, USA, 2008; pp. 171-196.

295. Rintala-Dempsey, A.C.; Kothe, U. Eukaryotic stand-alone pseudouridine synthases-RNA modifying enzymes and emerging regulators of gene expression? RNA Biol. 2017, 14, 1185-1196. [CrossRef] [PubMed]

296. Hori, H. Methylated nucleosides in tRNA and tRNA methyltransferases. Front. Genet. 2014, 5, 144. [CrossRef] [PubMed]

297. Grosjean, H.; Oshima, T. How nucleic acids cope with high temperature. In Physiology and Biochemistry of Extremophiles; Gerday, C., Glansdorff, N., Eds.; ASM Press: Washington, DC, USA, 2007; pp. 39-56.

298. Kumazawa, Y.; Yokogawa, T.; Tsurui, H.; Miura, K.; Watanabe, K. Effect of the higher-order structure of tRNAs on the stability of hybrids with oligodeoxyribonucleotides: Separation of tRNA by an efficient solution hybridization. Nucleic Acids Res. 1992, 20, 2223-2232. [CrossRef] [PubMed]

299. Tsurui, H.; Kumazawa, Y.; Sanokawa, R.; Watanabe, Y.; Kuroda, T.; Wada, A.; Watanabe, K.; Shirai, T. Batchwise purification of specific tRNAs by a solid-phase DNA probe. Anal. Biochem. 1994, 221, 166-172. [CrossRef] [PubMed]

300. Suzuki, T.; Ueda, T.; Watanabe, K. A new method for identifying the amino acid attached to a particular RNA in the cell. FEBS Lett. 1996, 381, 195-198. [CrossRef]

301. Yokogawa, T.; Kitamura, Y.; Nakamura, D.; Ohno, S.; Nishikawa, K. Optimization of the hybridization-based method for purification of thermostable tRNAs in the presence of tetraalkylammonium salts. Nucleic Acids Res. 2010, 38, e89. [CrossRef] [PubMed]

302. Kazayama, A.; Yamagami, R.; Yokogawa, T.; Hori, H. Improved solid-phase DNA probe method for tRNA purification: Large-scale preparation and alteration of DNA fixation. J. Biochem. 2015, 157, 411-418. [CrossRef] [PubMed]

303. Stanley, J.; Vassilenko, S. A different approach to RNA sequencing. Nature 1978, 274, 87-89. [CrossRef] [PubMed]

304. Kuchino, Y.; Kato, M.; Sugisaki, H.; Nishimura, S. Nucleotide sequence of starfish initiator tRNA. Nucleic Acids Res. 1979, 6, 3459-3469. [CrossRef] [PubMed]

305. Suzuki, T.; Ikeuchi, Y.; Noma, A.; Suzuki, T.; Sakaguchi, Y. Mass spectrometric identification and characterization of RNA-modifying enzymes. Methods Enzymol. 2007, 425, 211-229. [PubMed]

306. Suzuki, T.; Suzuki, T. A complete landscape of post-transcriptional modifications in mammalian mitochondrial tRNAs. Nucleic Acids Res. 2014, 42, 7346-7357. [CrossRef] [PubMed]

307. Mengel-Jorgensen, J.; Kirpekar, F. Detection of pseudouridine and other modifications in tRNA by cyanoethylation and MALDI mass spectrometry. Nucleic Acids Res 2002, 30, e135. [CrossRef] [PubMed]

308. Chen, C.; Huang, B.; Anderson, J.T.; Byström, A.S. Unexpected accumulation of ncm(5)U and ncm(5)S(2) (U) in a trm 9 mutant suggests an additional step in the synthesis of $\mathrm{mcm}(5) \mathrm{U}$ and $\mathrm{mcm}(5) \mathrm{S}(2) \mathrm{U}$. PLoS ONE 2011, 6, e20783.

309. Agris, P.F.; Koh, H.; Söll, D. The effect of growth temperatures on the in vivo ribose methylation of Bacillus stearothermophilus transfer RNA. Arch Biochem Biophys. 1973, 154, 277-282. [CrossRef] 
310. Andachi, Y.; Yamao, F.; Muto, A.; Osawa, S. Codon recognition patterns as deduced from sequences of the complete set of transfer RNA species in Mycoplasma capricolum. Resemblance to mitochondria. J. Mol. Biol. 1989, 209, 37-54. [CrossRef]

311. Matsugi, J.; Jia, H.T.; Murao, K.; Ishikura, H. Nucleotide sequences of serine tRNAs from Bacillus subtilis. Biochem. Biophys. Acta 1992, 1130, 333-335. [CrossRef]

312. Hori, H. Transfer RNA methyltransferases with a SpoU-TrmD (SPOUT) fold and their modified nucleosides in tRNA. Biomolecules 2017, 7, 23. [CrossRef] [PubMed]

313. Reddy, D.M.; Crain, P.F.; Edmonds, C.G.; Gupta, R.; Hashizume, T.; Stetter, K.O.; Widdel, F.; McCloskey, J.A. Structure determination of two new amino acid-containing derivatives of adenosine from tRNA of thermophilic bacteria and archaea. Nucleic Acids Res. 1992, 20, 5607-5615. [CrossRef] [PubMed]

314. Cusack, S.; Yaremchuk, A.; Krikliviy, I.; Tukalo, M. tRNA ${ }^{\text {Pro }}$ anticodon recognition by Thermus thermophilus prolyl-tRNA synthetase. Structure 1998, 6, 101-108. [CrossRef]

315. Li, F.; Dong, J.; Hu, X.; Gong, W.; Li, J.; Shen, J.; Tian, H.; Wang, J. A covalent approach for site-specific RNA labeling in Mammalian cells. Angew. Chem. Int. Ed. Engl. 2015, 54, 4597-4602. [CrossRef] [PubMed]

316. Singh, S.K.; Gurha, P.; Tran, E.J.; Maxwell, E.S.; Gupta, R. Sequential 2'-O-methylation of archaeal pre-tRNA ${ }^{\text {Trp }}$ nucleotides is guided by the intron-encoded but trans-acting box C/D ribonucleoprotein of pre-tRNA. J. Biol. Chem. 2004, 279, 47661-47671. [CrossRef] [PubMed]

317. Haas, E.S.; Daniels, C.J.; Reeve, J.N. Genes encoding 5 S rRNA and tRNAs in the extremely thermophilic archaebacterium Methanothermus fervidus. Gene 1989, 77, 253-263. [CrossRef]

318. Randau, L.; Münch, R.; Hohn, M.J.; Jahn, D.; Söll, D. Nanoarchaeum equitans creates functional tRNAs from separate genes for their $5^{\prime}$ - and $3^{\prime}$-halves. Nature 2005, 433, 537-541. [CrossRef] [PubMed]

319. Randau, L.; Pearson, M.; Söll, D. The complete set of tRNA species in Nanoarchaeum equitans. FEBS Lett. 2005, 579, 2945-2947. [CrossRef] [PubMed]

320. Richter, H.; Mohr, S.; Randau, L. C/D box sRNA, CRISPR RNA and tRNA processing in an archaeon with a minimal fragmented genome. Biochem. Soc. Trans. 2013, 41, 411-415. [CrossRef] [PubMed]

321. Hardin, J.W.; Reyes, F.E.; Batey, R.T. Analysis of a critical interaction within the archaeal box C/D small ribonucleoprotein complex. J. Biol. Chem. 2009, 284, 15317-15324. [CrossRef] [PubMed]

322. McCloskey, J.A.; Crain, P.F.; Edmonds, C.G.; Gupta, R.; Hashizume, T.; Phillipson, D.W.; Stetter, K.O. Structure determination of a new fluorescent tricyclic nucleoside from archaebacterial tRNA. Nucleic Acids Res. 1987, 15, 683-693. [CrossRef] [PubMed]

323. Ushida, C.; Muramatsu, T.; Mizushima, H.; Ueda, T.; Watanabe, K.; Stetter, K.O.; Crain, P.F.; McCloskey, J.A.; Kuchino, Y. Structural feature of the initiator tRNA gene from Pyrodictium occultum and the thermal stability of its gene product, tRNA(imet). Biochimie 1996, 79, 847-855. [CrossRef]

324. McCloskey, J.A.; Liu, X.H.; Crain, P.F.; Bruenger, E.; Guymon, R.; Hashizume, T.; Stetter, K.O. Posttranscriptional modification of transfer RNA in the submarine hyperthermophile Pyrolobus fumarii. Nucleic Acids Symp. Ser. 2000, 44, 267-268. [CrossRef]

325. Zhou, S.; Sitaramaiah, D.; Noon, K.R.; Guymon, R.; Hashizume, T.; McCloskey, J.A. Structures of two new "minimalist" modified nucleosides from archaeal tRNA. Bioorg. Chem. 2004, 32, 82-91. [CrossRef] [PubMed]

326. Yang, Z.; Lin, J.; Ye, K. Box C/D guide RNAs recognize a maximum of $10 \mathrm{nt}$ of substrates. Proc. Natl. Acad. Sci. USA 2016, 27, 10878-10883. [CrossRef] [PubMed]

327. Agari, Y.; Sato, S.; Wakamatsu, T.; Bessho, Y.; Ebihara, A.; Yokoyama, S.; Kuramitsu, S.; Shinkai, A. X-ray crystal structure of a hypothetical Sua5 protein from Sulfolobus tokodaii strain 7. Proteins 2008, 70, 1108-1111. [CrossRef] [PubMed]

328. Kuratani, M.; Kasai, T.; Akasaka, R.; Higashijima, K.; Terada, T.; Kigawa, T.; Shinkai, A.; Bessho, Y.; Yokoyama, S. Crystal structure of Sulfolobus tokodaii Sua5 complexed with L-threonine and AMPPNP. Proteins 2011, 79, 2065-2075. [CrossRef] [PubMed]

329. Parthier, C.; Goerlich, S.; Jaenecke, F.; Breithaupt, C.; Brauer, U.; Fandrich, U.; Clausnitzer, D.; Wehmeier, U.F.; Bottcher, C.; Scheel, D.; et al. The O-carbamoyltransferase TobZ catalyzes an ancient enzymatic reaction. Angew. Chem. Int. Ed. Engl. 2012, 51, 4046-4052. [CrossRef] [PubMed]

330. Klenk, H.P.; Schwass, V.; Zillig, W. Nucleotide sequence of the genes encoding proline tRNA(UGG) and threonine tRNA(GGU) and consensus promoter model of Thermococcus celer. Biochim. Biophys. Acta 1993, 1172, 236-238. [CrossRef] 
331. Watanabe, K.; Oshima, T.; Saneyoshi, M.; Nishimura, S. Replacement of ribothymidine by 5-methyl-2-thiouridine in sequence GT psi C in tRNA of an extreme thermophile. FEBS Lett. 1974, 43, 59-63. [CrossRef]

332. Dalluge, J.J.; Hashizume, T.; Sopchik, A.E.; McCloskey, J.A.; Davis, D.R. Conformational flexibility in RNA: The role of dihydrouridine. Nucleic Acids Res. 1996, 24, 1073-1079. [CrossRef] [PubMed]

333. Sokołowski, M.; Klassen, R.; Bruch, A.; Schaffrath, R.; Glatt, S. Cooperativity between different tRNA modifications and their modification pathways. Biochem. Biophys. Acta 2018, 1861, 409-418. [CrossRef] [PubMed]

334. Liu, R.J.; Zhou, M.; Fang, Z.P.; Wang, M.; Zhou, X.L.; Wang, E.D. The tRNA recognition mechanism of the minimalist SPOUT methyltransferase, TrmL. Nucleic Acids Res. 2013, 41, 7828-7842. [CrossRef] [PubMed]

335. Morales, A.J.; Swairjo, M.A.; Schimmel, P. Structure-specific tRNA-binding protein from the extreme thermophile Aquifex aeolicus. EMBO J. 1999, 18, 3475-3483. [CrossRef] [PubMed]

336. Swairjo, M.A.; Morales, A.J.; Wang, C.C.; Ortiz, A.R.; Schimmel, P. Crystal structure of trbp111: A structure-specific tRNA-binding protein. EMBO J. 2000, 19, 6278-6298. [CrossRef] [PubMed]

337. Kushiro, T.; Schimmel, P. Trbp111 selectively binds a noncovalently assembled tRNA-like structure. Proc. Natl. Acad. Sci. USA 2002, 99, 16631-16635. [CrossRef] [PubMed]

338. Desai, K.K.; Cheng, C.L.; Bingman, C.A.; Phillips, G.N., Jr.; Raines, R.T. A tRNA splicing operon: Archease endows RtcB with dual GTP/ATP cofactor specificity and accelerates RNA ligation. Nucleic Acids Res. 2014, 42, 3931-3942. [CrossRef] [PubMed]

339. Popow, J.; Jurkin, J.; Schleiffer, A.; Martinez, J. Analysis of orthologous groups reveals archease and DDX1 as tRNA splicing factors. Nature 2014, 511, 104-107. [CrossRef] [PubMed]

340. Maraia, R.J.; Arimbasseri, A.G. Factors That Shape Eukaryotic tRNAomes: Processing, Modification and Anticodon-Codon Use. Biomolecules 2017, 7, 26. [CrossRef] [PubMed]

341. Blewett, N.H.; Maraia, R.J. La involvement in tRNA and other RNA processing events including differences among yeast and other eukaryotes. Biochim. Biophys. Acta 2018, 1861, 361-372. [CrossRef] [PubMed]

342. Gutgsell, N.; Englund, N.; Niu, L.; Kaya, Y.; Lane, B.G.; Ofengand, J. Deletion of the Escherichia coli pseudouridine synthase gene truB blocks formation of pseudouridine 55 in tRNA in vivo, does not affect exponential growth, but confers a strong selective disadvantage in competition with wild-type cells. RNA 2000, 6, 1870-1881. [CrossRef] [PubMed]

343. Keffer-Wilkes, L.C.; Veerareddygari, G.R.; Kothe, U. RNA modification enzyme TruB is a tRNA chaperone. Proc. Natl. Acad. Sci. USA 2016, 113, 14306-14311. [CrossRef] [PubMed]

344. Quigley, G.J.; Teeter, M.M.; Rich, A. Structural analysis of spermine and magnesium ion binding to yeast phenylalanine transfer RNA. Proc. Natl. Acad. Sci. USA 1978, 75, 64-68. [CrossRef] [PubMed]

345. Frydman, B.; de los Santos, C.; Frydman, R.B. A ${ }^{13} \mathrm{C}$ NMR study of $\left[5,8-{ }^{13} \mathrm{C}_{2}\right]$ spermidine binding to tRNA and to Escherichia coli macromolecules. J. Biol. Chem. 1990, 265, 20874-20878. [PubMed]

346. Terui, Y.; Ohnuma, M.; Hiraga, K.; Kawashima, E.; Oshima, T. Stabilization of nucleic acids by unusual polyamines produced by an extreme thermophile, Thermus thermophilus. Biochem. J. 2005, 388, 427-433. [CrossRef] [PubMed]

347. Ouameur, A.A.; Bourassa, P.; Tajmir-Riahi, H.A. Probing tRNA interaction with biogenic polyamines. $R N A$ 2010, 16, 1968-1979. [CrossRef] [PubMed]

348. Oshima, T. Unique polyamines produced by an extreme thermophiles, Thermus thermophilus. Amino Acids 2007, 33, 367-372. [CrossRef] [PubMed]

349. Oshima, T.; Moriya, T.; Terui, Y. Identification, chemical synthesis, and biological functions of unusual polyamines produced by extreme thermophiles. Methods Mol. Biol. 2011, 720, 81-111. [PubMed]

350. Hamana, K.; Niitsu, M.; Samejima, K.; Matsuzaki, S. Polyamine distributions in thermophilic eubacteria belonging to Thermus and Acidothermus. J. Biochem. 1991, 109, 444-449. [CrossRef] [PubMed]

351. Hamana, K.; Tanaka, T.; Hosoya, R.; Niitsu, M.; Itoh, T. Cellular polyamines of the acidophilic, thermophilic and thermoacidophilic archaebacteria, Acidilobus, Ferroplasma, Pyrobaculum, Pyrococcus, Staphylothermus, Thermococcus, Thermodiscus and Vulcanisaeta. J. Gen. Appl. Microbiol. 2003, 49, 287-293. [CrossRef] [PubMed]

352. Hayrapetyan, A.; Grosjean, H.; Helm, M. Effect of a quaternary pentamine on RNA stabilization and enzymatic methylation. Biol. Chem. 2009, 390, 851-861. [CrossRef] [PubMed]

353. Nakashima, M.; Yamagami, R.; Tomikawa, C.; Ochi, Y.; Moriya, T.; Asahara, H.; Fourmy, D.; Yoshizawa, S.; Oshima, T.; Hori, H. Long and branched polyamines are required for maintenance of the ribosome, $\mathrm{tRNA}^{\text {His }}$ and tRNA ${ }^{\text {Tyr }}$ in Thermus thermophilus cells at high temperatures. Genes Cells 2017, 22, 628-645. [CrossRef] [PubMed] 
354. Yue, D.; Kintanar, A.; Horowitz, J. Nucleoside modifications stabilize $\mathrm{Mg}^{2+}$ binding in Escherichia coli tRNA(Val): An imino proton NMR investigation. Biochemistry 1994, 33, 8905-8911. [CrossRef] [PubMed]

355. Agris, P.F. The importance of being modified: Roles of modified nucleosides and $\mathrm{Mg}^{2+}$ in RNA structure and function. Prog. Nucleic Acid Res. Mol. Biol. 1996, 53, 79-129. [PubMed]

356. Nobles, K.N.; Yarian, C.S.; Liu, G.; Guenther, R.H.; Agris, P.F. Highly conserved modified nucleosides influence $\mathrm{Mg}^{2+}$-dependent tRNA folding. Nucleic Acids Res. 2002, 30, 4751-4760. [CrossRef] [PubMed]

357. Hensel, R.; Konig, H. Thermoadaptation of metanogenic bacteria by interacellular ion concentration. FEMS Microbiol. Lett. 1988, 49, 75-79. [CrossRef]

358. Nawrot, B.; Sochacka, E.; Duchler, M. tRNA structural and functional changes induced by oxidative stress. Cell Mol. Life Sci. 2011, 68, 4023-4032. [CrossRef] [PubMed]

359. Preston, M.A.; D'Silva, S.; Kon, Y.; Phizicky, E.M. tRNA ${ }^{\text {His }} 5$-methylcytidine levels increase in response to several growth arrest conditions in Saccharomyces cerevisiae. RNA 2013, 19, 243-256. [CrossRef] [PubMed]

360. Endres, L.; Dedon, P.C.; Begley, T.J. Codon-biased translation can be regulated by wobble-base tRNA modification systems during cellular stress responses. RNA Biol. 2015, 12, 603-614. [CrossRef] [PubMed]

361. Chan, C.T.; Deng, W.; Li, F.; DeMott, M.S.; Babu, I.R.; Begley, T.J.; Dedon, P.C. Highly Predictive Reprogramming of tRNA Modifications Is Linked to Selective Expression of Codon-Biased Genes. Chem. Res. Toxicol. 2015, 28, 978-988. [CrossRef] [PubMed]

362. Polikarpov, I.; Prade, R.; Caldana, C.; Paes Leme, A.F.; Mercadante, A.Z.; Riaño-Pachón, D.M.; Squina, F.M. Thermal adaptation strategies of the extremophile bacterium Thermus filiformis based on multi-omics analysis. Extremophiles 2017, 21, 775-788.

363. Kimura, S.; Suzuki, T. Iron-sulfur proteins responsible for RNA modifications. Biochim. Biophys. Acta 2015, 1853, 1272-1283. [CrossRef] [PubMed]

364. Ramamurthy, V.; Swann, S.L.; Spedaliere, C.J.; Mueller, E.G. Role of cysteine residues in pseudouridine synthases of different families. Biochemistry 1999, 38, 13106-13111. [CrossRef] [PubMed]

365. Urbonavicius, J.; Jäger, G.; Björk, G.R. Amino acid residues of the Escherichia coli tRNA(m $\left.{ }^{5} \mathrm{U} 54\right)$ methyltransferase (TrmA) critical for stability, covalent binding of tRNA and enzymatic activity. Nucleic Acids Res. 2007, 35, 3297-3305. [CrossRef] [PubMed]

366. Alian, A.; Lee, T.T.; Griner, S.L.; Stroud, R.M.; Finer-Moore, J. Structure of a TrmA-RNA complex: A consensus RNA fold contributes to substrate selectivity and catalysis in $\mathrm{m}^{5} \mathrm{U}$ methyltransferases. Proc. Natl. Acad. Sci. USA 2008, 105, 6876-6881. [CrossRef] [PubMed]

367. Byrne, R.T.; Jenkins, H.T.; Peters, D.T.; Whelan, F.; Stowell, J.; Aziz, N.; Kasatsky, P.; Rodnina, M.V.; Koonin, E.V.; Konevega, A.L.; et al. Major reorientation of tRNA substrates defines specificity of dihydrouridine synthases. Proc. Natl. Acad. Sci. USA 2015, 112, 6033-6037. [CrossRef] [PubMed]

368. Ryals, J.; Hsu, R.Y.; Lipsett, M.N.; Bremer, H. Isolation of single-site Escherichia coli mutants deficient in thiamine and 4-thiouridine syntheses: Identification of a nuvC mutant. J. Bacteriol. 1982, 151, 899-904. [PubMed]

369. Liu, Y.; Zhu, X.; Nakamura, A.; Orlando, R.; Söll, D.; Whitman, W.B. Biosynthesis of 4-thiouridine in tRNA in the methanogenic archaeon Methanococcus maripaludis. J. Biol. Chem. 2012, 287, 36683-36692. [CrossRef] [PubMed]

(C) 2018 by the authors. Licensee MDPI, Basel, Switzerland. This article is an open access article distributed under the terms and conditions of the Creative Commons Attribution (CC BY) license (http://creativecommons.org/licenses/by/4.0/). 